Florida International University FIU Digital Commons

FIU Electronic Theses and Dissertations

University Graduate School

9-5-2013

\title{
Acclimatization of the Tropical Reef Coral Acropora millepora to Hyperthermal Stress
}

Anthony John Bellantuono

anthjbell@gmail.com

DOI: $10.25148 /$ etd.FI13120905

Follow this and additional works at: https://digitalcommons.fiu.edu/etd

Part of the Biology Commons, Cellular and Molecular Physiology Commons, Environmental Microbiology and Microbial Ecology Commons, Marine Biology Commons, Molecular Genetics Commons, and the Other Genetics and Genomics Commons

\section{Recommended Citation}

Bellantuono, Anthony John, "Acclimatization of the Tropical Reef Coral Acropora millepora to Hyperthermal Stress" (2013). FIU Electronic Theses and Dissertations. 1005.

https://digitalcommons.fiu.edu/etd/1005

This work is brought to you for free and open access by the University Graduate School at FIU Digital Commons. It has been accepted for inclusion in FIU Electronic Theses and Dissertations by an authorized administrator of FIU Digital Commons. For more information, please contact dcc@fiu.edu. 


\section{FLORIDA INTERNATIONAL UNIVERSITY}

Miami, Florida

ACCLIMATIZATION OF THE TROPICAL REEF CORAL ACROPORA MILLEPORA TO HYPERTHERMAL STRESS

A dissertation submitted in partial fulfillment of the

requirements for the degree of

DOCTOR OF PHILOSOPHY

in

BIOLOGY

by

Anthony John Bellantuono

2013 
To: Dean Kenneth Furton

College of Arts and Sciences

This dissertation, written by Anthony John Bellantuono, and entitled Acclimatization of the Tropical Reef Coral Acropora millepora to Hyperthermal Stress, having been approved in respect to style and intellectual content, is referred to you for judgment.

We have read this dissertation and recommend that it be approved.

Deron E. Burkepile

Eric J. von Wettberg

Mehmet T. Dorak

Ove Hoegh-Guldberg

Mauricio Rodriguez-Lanetty, Major Professor

Date of Defense: September 5, 2013

The dissertation of Anthony John Bellantuono is approved.

$\begin{array}{r}\begin{array}{r}\text { Dean Kenneth Furton } \\ \text { College of Arts and Sciences }\end{array} \\ \hline \begin{array}{r}\text { Dean Lakshmi N. Reddi } \\ \text { University Graduate School }\end{array}\end{array}$

Florida International University, 2013 


\section{ACKNOWLEDGMENTS}

I wish to thank all current and former members of Rodriguez-Lanetty Lab. It is the support of this community that has made this work possible. I would specifically like to thank my advisor Dr. Mauricio Rodriguez-Lanetty for his continuous support over the past half decade, fostering my growth as a scientist. My committee members, Dr. Eric von Wettberg, Dr. Deron Burkepile, Dr. Mehmet Dorak, and Dr. Ove Hoegh-Guldberg, have been instrumental in the completion of my dissertation. I would like to extend my thanks to my former committee members, Dr. Glen Watson, Dr. Caryl Chlan, and Dr. David Miller, for their essential insights and support during the first four years of my PhD work. I would like to thank the Louisiana Board of Regents for awarding me a B.O.R. Fellowship which allowed me the freedom to undertake the body of work presented here. I am grateful for the teaching assistantship provided by Florida International University, and for the critical assistance of Dr. Steven Oberbauer and Dr. Lidia Kos. Furthermore, I would like to thank my former mentors Dr. Richard Wahle, Dr. Lynn Riddiford, Dr. James Truman, and Dr. Daniel Martinez, who have all inspired me throughout my graduate career. Finally, I would like to gratefully acknowledge the Proceedings of the Royal Society of London B for allowing me to reprint a publication which originally appeared in volume 279, issue 1731 as Chapter 2 of this dissertation, as well as the Public Library of Science for allowing the reprint of a publication originally appearing in PLoS ONE, volume 7, issue 11 as Chapter 3. 


\section{DEDICATION}

I dedicate this dissertation to my grandfather and namesake, Anthony S. DeNigris, whose life is a constant source of inspiration, and to my parents, for their unconditional love, support, and understanding. 


\title{
ABSTRACT OF THE DISSERTATION \\ ACCLIMATIZATION OF THE TROPICAL REEF CORAL ACROPORA MILLEPORA TO HYPERTHERMAL STRESS
}

\author{
by \\ Anthony John Bellantuono \\ Florida International University, 2013 \\ Miami, Florida \\ Professor Mauricio Rodriguez-Lanetty, Major Professor
}

The demise of reef-building corals potentially lies on the horizon, given ongoing climate change amid other anthropogenic environmental stressors. If corals cannot acclimatize or adapt to changing conditions, dramatic declines in the extent and health of the living reefs are expected within the next half century.

The primary and proximal global threat to corals is climate change. Reef-building corals are dependent upon a nutritional symbiosis with photosynthetic dinoflagellates belonging to the group Symbiodinium. The symbiosis between the cnidarian host and algal partner is a stress-sensitive relationship; temperatures just $1^{\circ} \mathrm{C}$ above normal thermal maxima can result in the breakdown of the symbiosis, resulting in coral bleaching (the loss of Symbiodinium and/or associated photopigments) and ultimately, colony death. As ocean temperatures continue to rise, corals will either acclimatize or adapt to changing conditions, or will perish. By experimentally preconditioning the coral Acropora millepora via sublethal heat treatment, the coral acquired thermal tolerance, resisting bleaching during subsequent hyperthermal stress. The complex nature of the coral holobiont translates to multiple possible explanations for acclimatization: acquired 
thermal tolerance could potentially originate from the host itself, the Symbiodinium, or from the bacterial community associated with the coral. By examining the type of in hospite Symbiodinium and the bacterial community prior acclimation and after thermal challenge, it is shown that short-term acclimatization is not due to a distinct change in the dinoflagellate or prokaryote community. Though the microbial partnerships remain without considerable flux in preconditioned corals, the host transcriptome is dynamic. One dominant pattern was the apparent tuning of gene expression observed between preconditioned and non-preconditioned treatments, showing a modulated transcriptomic response to stress. Additionally several genes were upregulated in association with thermal tolerance, including antiapoptotic genes, lectins, and oxidative stress response genes. Upstream of two of these thermal tolerance genes, inhibitor of $N F \kappa B$ and mannose-binding lectin, DNA polymorphisms were identified which vary significantly between the northern and southern Great Barrier Reef. The impact of these mutations in putative promoter regions remains to be seen, but variation across thermally-disparate geography serves to generate hypotheses regarding the role of regulatory element evolution in a coral adaptation context. 


\section{TABLE OF CONTENTS}

CHAPTER

PAGE

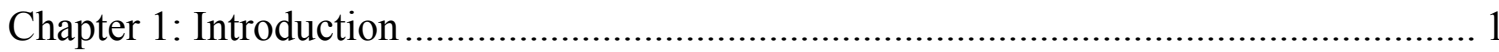

1.1 Climate change, the potential loss of the world's coral reefs, and the importance of understanding coral acclimatization and adaptation ..................................................... 1

1.2 Dissertation objectives, hypotheses, and organization ………............................... 4

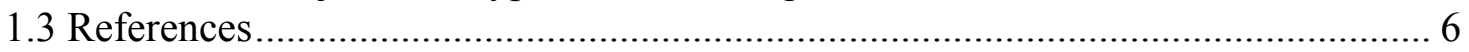

Chapter 2: Resistance to thermal stress in corals without changes in symbiont

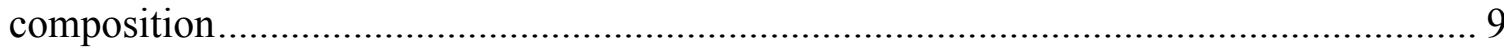

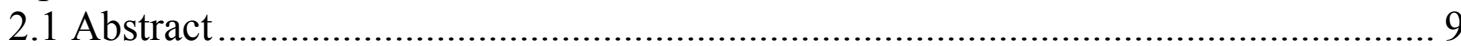

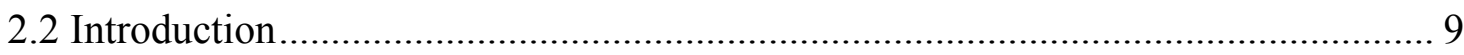

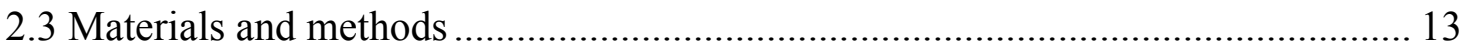

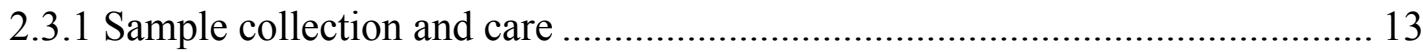

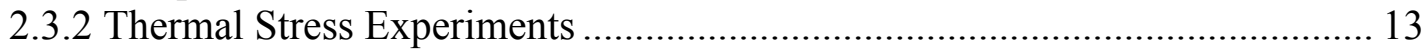

2.3.3 Symbiodinium density and genetic identification.......................................... 14

2.3.4 Bacterial community composition ............................................................... 16

2.3.5 Statistical analysis and multivarate analysis .................................................. 17

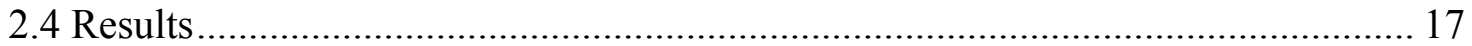

2.4.1 Thermal response by the bacterial community ............................................. 18

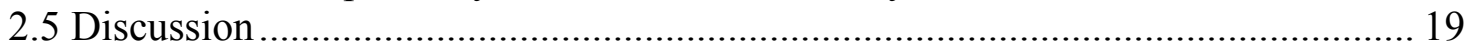

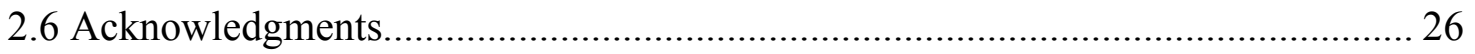

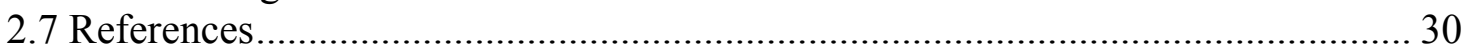

Chapter 3: Coral thermal tolerance: tuning gene expression to resist thermal stress ....... 36

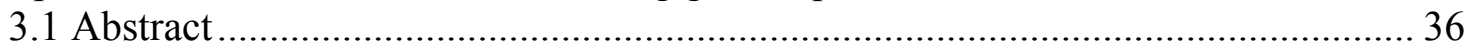

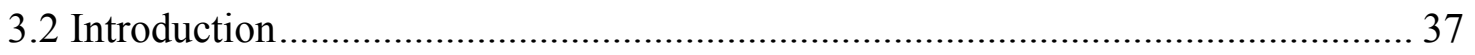

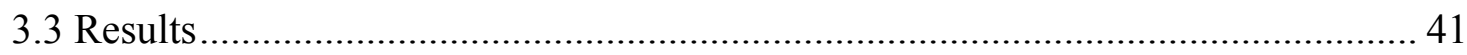

3.3.1 Symbiodinium density of corals with and without preconditioning................. 41

3.3.2 Comparison of gene expression levels ........................................................... 42

3.3.3 Spatial ordination of gene expression ................................................................ 43

3.3.4 Differentially expressed genes shared across treatments ................................... 44

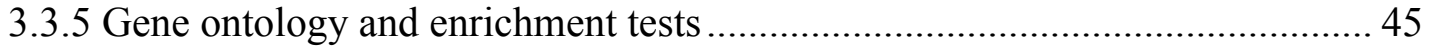

3.3.6 Genes involved in thermal injury.............................................................. 45

3.3.7 Gene expression co-occuring with thermal tolerance: Differential expression between preconditioned and non-preconditioned treatments .................................... 46 3.3.8 Gene expression co-occuring with thermal tolerance: Differential expression between preconditioned and control treatments …………..................................... 47

3.3.9 Genes differentially expressed across multiple days ....................................... 48

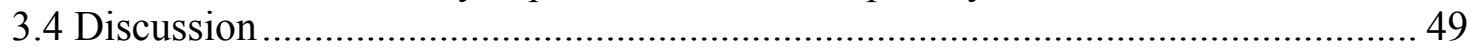

3.4.1 Lectins implicated in thermal tolerance ........................................................ 51

3.4.2 Heme-binding proteins, ferritin, and iron-induced oxidative injury................. 52

3.4.3 Transcription Factor AP-1, NF-kB inhibitor, and their role in apoptosis........ 53 
3.4.4 Thymosin as an antioxidant and the role of tyrosine kinase receptor in response

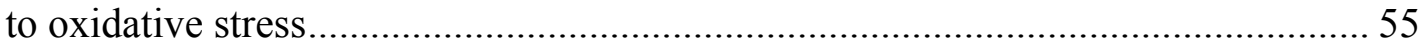

3.4.5 Calumenin and cnidarian/dinoflagellate symbiosis .......................................56

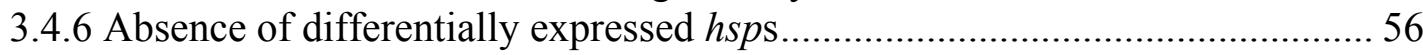

3.4.7 The Importance of understanding acclimatization............................................ 58

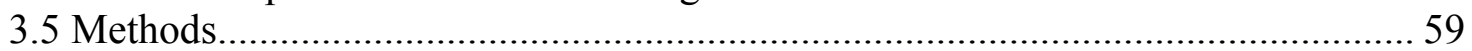

3.5.1 Coral collection, husbandry, and thermal stress treatments............................59

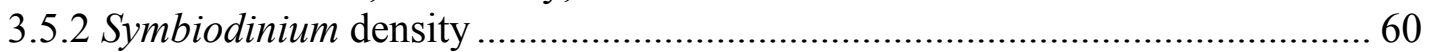

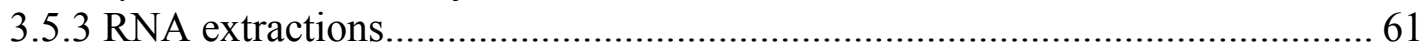

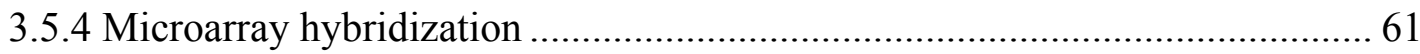

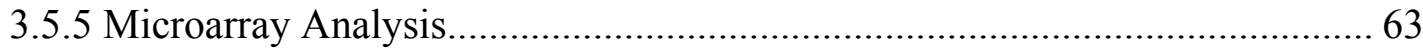

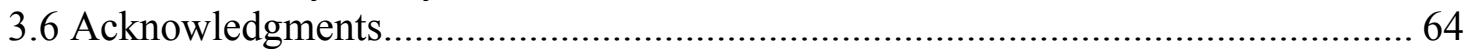

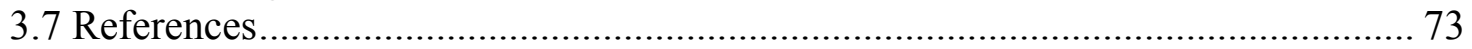

Chapter 4: Upstream of Acropora millepora thermal tolerance: a preliminary study of putative regulatory sequences of thermal tolerance genes across the Great Barrier Reef 82

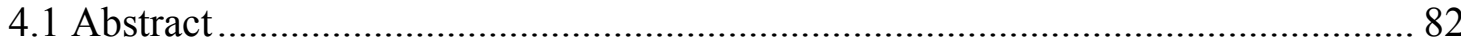

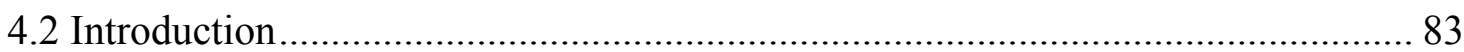

4.2.1 Background on epigenetics and stress response ............................................ 86

4.2.2 Cis-regulatory elements and adaptation: evo-devo and eco-evo-devo ............ 89

4.2.3 Evidence for the heritability of stress response in coral ................................ 90

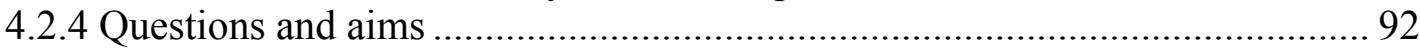

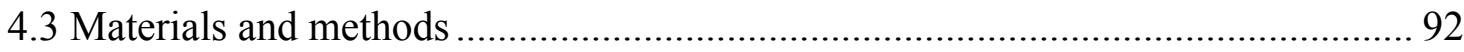

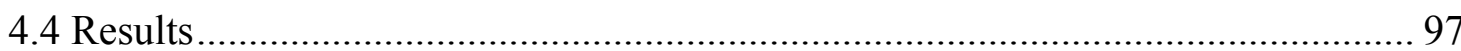

4.4.1 Identification of $\mathrm{CpG}$ islands and promoter-like elements .............................. 97

4.4.2 Bisulfite sequencing................................................................................... 97

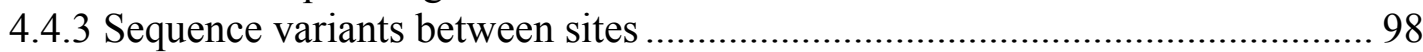

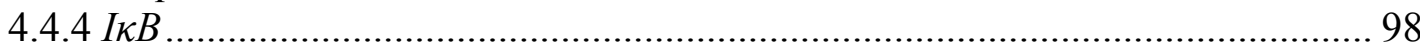

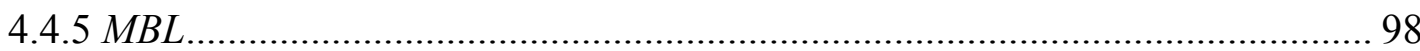

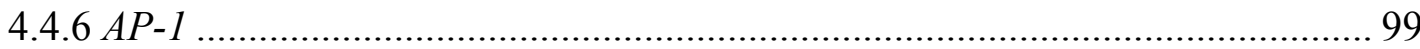

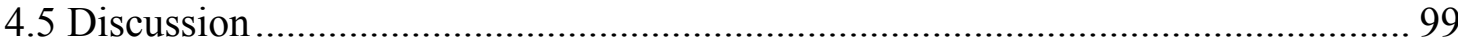

4.5.1 Polymorphic DNA upstream of thermal tolerance genes ............................... 100

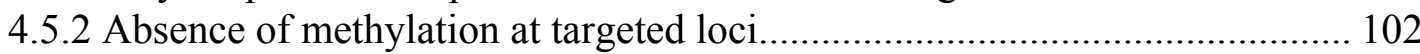

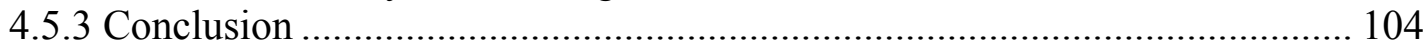

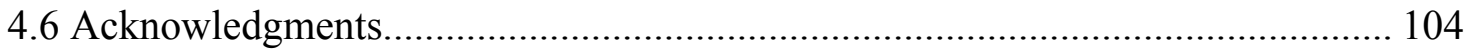

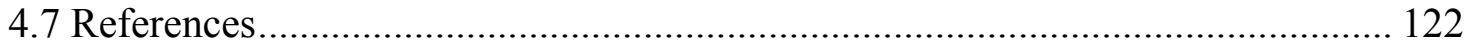

Chapter 5: Conclusions and future investigations ………........................................... 130

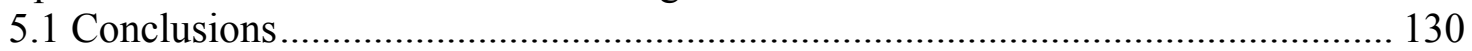

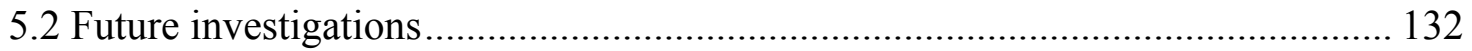

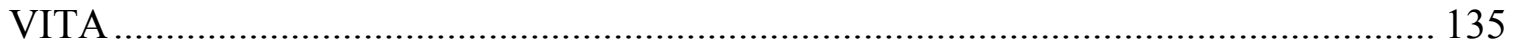




\section{LIST OF FIGURES}

CHAPTER-FIGURE

PAGE

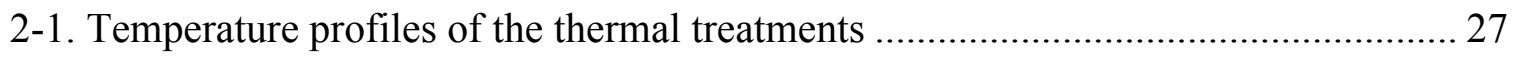

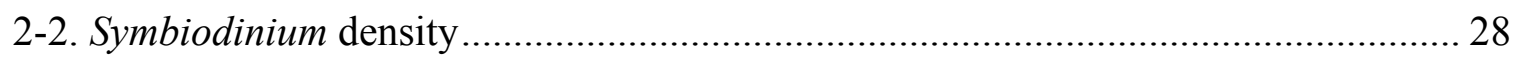

2-3. Correspondence analysis (CA) of reverse-transcribed bacterial 16S rRNA-DGGE

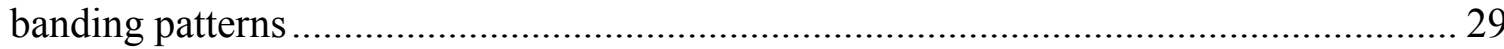

3-1. Temperature profiles of the thermal treatments to which Acropora millepora

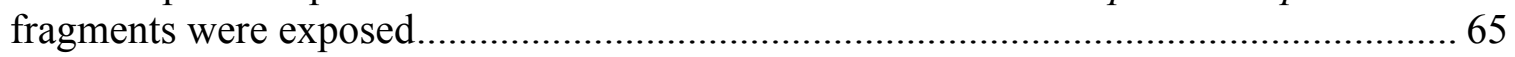

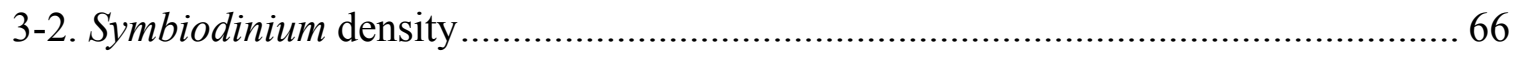

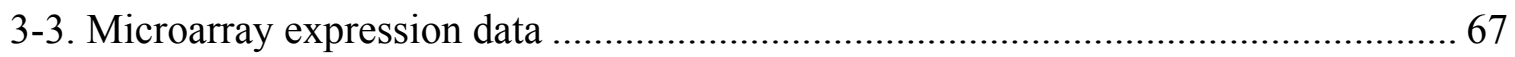

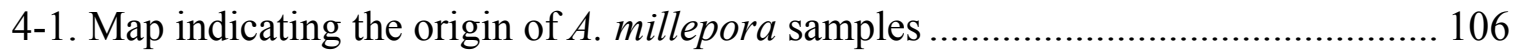

4-2. Mean sea surface temperature data from Prince Charlotte Bay and Heron Island.. 107

4-3. CpG locations and promoter-like elements ................................................ 108

4-4. Plot of promoter posterior probabilities of inhibitor of nuclear factor kappa beta

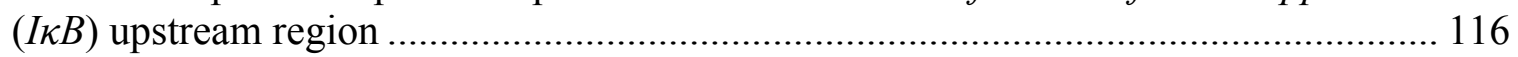

5-5. Plot of promoter posterior probabilities of activator protein $1(A P-1)$ upstream

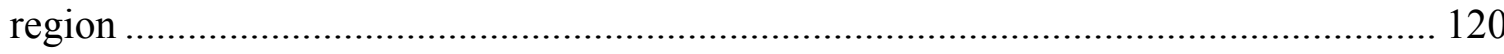




\section{LIST OF TABLES}

CHAPTER-TABLE

PAGE

3-1. Differentially expressed genes at two, four, and eight days of thermal challenge .... 72

4-1. Novel primers pairs used for the amplification and reamplification of bisulfite-

converted DNA and reamplification of PCR products for sequencing......................... 105

4-2. DNA polymorphisms present between the reference genome and targeted bisulfite sequencing of fragments upstream of $I \kappa B, A P-1$, and $M B L$

4-3. Sequences upstream of inhibitor of nuclear factor kappa beta, mannose-binding

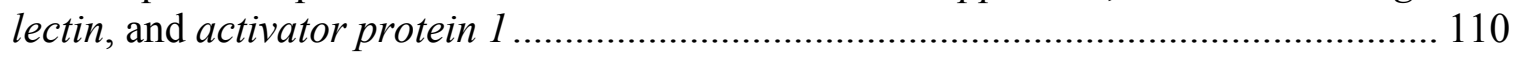

4-4. Bisulfite sequencing results from $I \kappa B$ upstream region................................... 111

4-5. Bisulfite sequencing results from $M B L$ upstream region .................................. 113

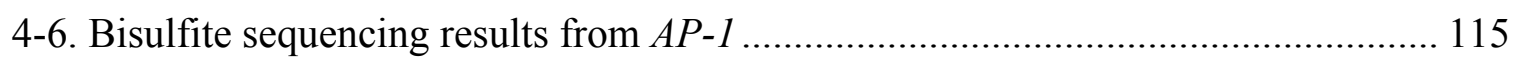

4-7. Promoter-like elements and positions identified in $I \kappa B$ upstream region ............... 117

4-8. Promoter-like elements and positions identified in $M B L$ upstream region ............ 118

4-9. Promoter-like elements and positions identified in $A P-1$ upstream region ............. 119

4-10. Promoter-like elements and positions identified in $A P-1$ upstream region ........... 121 


\section{Chapter 1: Introduction}

\subsection{Climate change, the potential loss of the world's coral reefs, and the importance of understanding coral acclimatization and adaptation}

Hermatypic corals have transformed tracts of tropical benthos into the most

diverse subtidal ecosystems the world over, the coral reef. As true ecosystem engineers of the sea, corals modify the environment that they occupy, creating a living reef superstructure that provide not just for the multitudinous reef inhabitants, but also for humans living near and far from the reef, across the globe. The benefits of reefs to society exceed an estimated annual value of $\$ 375$ billion, with services including storm protection, tourism, and an important source of food for half a billion people $[1,2]$.

Tropical coral reefs across exist in large part due to a critical mutualistic partnership. In a relationship that has spanned more than 200 million years, since the early beginnings of scleractinians as we know them, reef-building benefited from a nutritional symbiosis with the dinoflagellate Symbiodinium, which within gastrodermal cells of the scleractinian host $[3,4]$. It has long been known that calcification rates are significantly higher in symbiotic corals with photosynthetic endosymbionts, with the work of Kawaguti and Sakumoto dating to 1948 [5], and the concept of light-enhanced calcification introduced by Pearse and Muscatine in 1971 [6]. Approximately ninety percent of the carbon fixed by in hospite Symbiodinium is transferred from dinoflagellate to the host [7-9]; the symbiosis quite literally powers the living corals, and in turn is responsible for the growth and maintenance of the reef as we know it.

The crucial nutritional symbiosis between the cnidarian host and its algal endosymbiont is a fragile relationship with climate shifts already seen, and is in peril 
given the high-confidence forecasts for warming oceans in the coming decades and beyond [10-13]. Anthropogenic climate change has become a significant concern for many ecosystems the world over, with coral reefs being among the most vulnerable [10, $12,14,15]$. Field and laboratory evidence demonstrate that that ocean temperatures just $1{ }^{\circ} \mathrm{C}$ warmer than the typical summer maxima can cause coral bleaching $[10,12,14,15]$, a potentially lethal breakdown of the symbiotic relationship between the coral animal host and Symbiodinium, photosynthetic dinoflagellates which provide a nutritional symbiosis via their intracellular existence within the coral. The symptom of physiological distress, bleaching, is so termed because of the apparent loss of coral coloration, which is the result of the loss of Symbiodinium and/or their associated photopigments, and may ultimately end in the death of the coral colony [16].

The precise stepwise mechanism of the breakdown of symbiosis, resulting in bleaching, has, as of yet, not been elucidated completely and remains an important line of research. Our current understanding of bleaching holds that the phenonema is an interaction of heat- and light stress upon photosystem II of Symbiodinium, proceeding to a point where damage to the photosynthetic apparatus outpaces repair, resulting in the generation of reactive oxygen species [17]. These reactive oxygen species are responsible for cellular damage to the coral host, with downstream processes resulting in the loss of symbionts [17]. Though there are numerous proposed cellular processes for the loss of symbionts, there is strong evidence for host-mediated apoptosis of the symbiontcontaining cell [17-20].

If corals cannot acclimatize or adapt to the changing climes, we expect the reefs to fundamentally change in diversity, geographic expanse, potentially, even the existence 
of reefs as we know them; under current tolerance regimes, half of the world's coral reefs could disappear in the next twenty to forty years [14]. We are already witnessing dramatic overall decline on Australia's Great Barrier Reef, with the work of De'ath and collaborators [21] showing a decline from $28 \%$ coverage in 1985 to $13.8 \%$ coverage in 2012, more than half of coral cover. The state of affairs of coral is even worse in the Caribbean, with coverage dropping from 55\% in 1977 to a present-day level of just $10 \%$ $[22,23]$.

A future with coral reefs depends on a number of factors, including the international curtailing of carbon emissions $[12,15]$ management of non-thermal, local sources of coral stress [21], and coral acclimatization and adaptation [14]. Earlier work on modeling reef forecasts by Donner et al. [14] suggested that coral bleaching will become a regular event within the next half century if corals do not increase their heat tolerance by 0.2 to $1.0^{\circ} \mathrm{C}$ per decade. More recent forecast efforts [10] indicate that warming solely from the greenhouse gases already released into the atmosphere will result in detrimentally frequent high temperature stress events for half of the reefs of the world by the year 2080. The aforementioned scenario does not consider the time required for an international shift to a lower carbon emission commitment. Even if there is a marked global reduction in anthropogenic carbon emissions from our current business-asusual regime, reducing output to allow for a $550 \mathrm{ppm}$ carbon dioxide stabilization path, frequent mass bleaching is expected by 2030 [10]. A positive outcome for corals depends on both action to reduce carbon emissions and an increase in coral thermal tolerance. According to Donner [10], an increase of $1.5^{\circ} \mathrm{C}$ in coral thermal tolerance would suspend the onset of high-frequency heat stress by fifty to eighty years. The recent work of Frieler 
et al. [11] accounts for some increase in coral resilience to heat stress, yet still find that even limiting climate warming to $2^{\circ} \mathrm{C}$ would likely result in the loss of most coral reefs. Clearly, an understanding of coral acclimatization and/or adaptation to increasing thermal stress is paramount to forecasting and managing reefs. As it stands, we know that climate change is a tangible and increasing threat, but we do not know whether corals will mount an adaptive or acclimative response sufficient to prolong the existence of the modern coral reef.

At this time, the mechanisms and extent of acquired thermal tolerance via phenotypic plasticity and/or the potential for adaptation to warming climes remain vastly underexplored, especially considering that the persistence and resilience of corals in the coming decades is largely dependent upon increased thermal tolerance. Prior work has identified acquired stress tolerance in reef-building corals [24], apparent memory of prior stress and acquired thermal tolerance [25-28], and the transcriptomic differences between naturally-occurring heat-tolerant and heat-sensitive corals [29]. Clearly, there are numerous gaps in knowledge on acquired coral thermal tolerance and potential for acclimatization. As coral resilience in the coming century relies primary upon acquired thermal tolerance via phenotypic plasticity and/or genetic adaptation, there is a clear need a need for the understanding of the full scope of acclimative and adaptive potential of corals.

\subsection{Dissertation objectives, hypotheses, and organization}

The overarching purpose of this dissertation is to identify mechanisms by which corals may acclimatize or adapt to hyperthermal stress. Chapter Two is a reprint of an article previously published in a peer-reviewed journal; it tests the hypothesis that 
thermal preconditioning confers thermal tolerance to corals, and asks whether this change is the result of shifts in the composition of the microbial community. The work experimentally demonstrates acquired thermal tolerance (thermal bleaching resistance) via short-term sublethal preconditioning in the reef-building coral Acropora millepora and subsequently shows that the acquired bleaching resistance is not a result of a change in symbiotic symbiotic partners of the coral. Chapter Three, which has also been published in a peer-reviewed journal, tested the hypothesis was that coral host molecular changes are associated with acquired thermal tolerance. To address this hypothesis, the coral host transcriptome was queried in controlled experiment, comparing preconditioned thermal-tolerant corals with heat-sensitive and control corals; through this experiment, a host molecular response associated with acquired thermal tolerance was identified. In Chapter Four, two hypotheses are addressed: firstly, that an epigenetic mark is placed upstream of thermal tolerance genes, and secondly, that promoters of thermal tolerance genes have location-specific polymorphisms, associated with differential thermal history between populations. To examine these hypotheses, Chapter Four interrogates potential cis-regulatory elements upstream of genes involved in coral thermal tolerance, examining questions of methylation and epigenetics, and identifying the first known polymorphisms in putative coral promoters, providing variation for coral thermal adaptation. Chapter Five interprets the significance of these findings within the scope coral acclimatization, adaptation, and resilience in a changing climate. 


\subsection{References}

1. Brander L.M., Van Beukering P., Cesar H.S.J. 2007 The recreational value of coral reefs: a meta-analysis. Ecol Econ 63(1), 209-218.

2. Costanza R., dArge R., deGroot R., Farber S., Grasso M., Hannon B., Limburg K., Naeem S., Oneill R.V., Paruelo J., et al. 1997 The value of the world's ecosystem services and natural capital. Nature 387(6630), 253-260. (doi:10.1038/387253a0).

3. Stanley G.D. 2006 Photosymbiosis and the evolution of modern coral reefs. Science 312(5775), 857-858. (doi:10.1126/science.1123701).

4. Stanley G.D., Fautin D.G. 2001 The origins of modern corals. Science 291(5510), 1913-1914. (doi:10.1126/science.1056632).

5. Kawaguti S., Sakumoto D. 1948 The effect of light on the calcium deposition of corals. Bull Oceanogr Inst Taiwan 4, 65-70.

6. Pearse V.B., Muscatine L. 1971 Role of symbiotic algae (zooxanthellae) in coral calcification. The Biological Bulletin 141(2), 350-363.

7. Davies P.S. 1984 The role of zooxanthellae in the nutritional energy-requirements of Pocillopora eydouxi. Coral Reefs 2(4), 181-186.

8. Davy S.K., Lucas I.A.N., Turner J.R. 1996 Carbon budgets in temperate anthozoan-dinoflagellate symbioses. Mar Biol 126(4), 773-783.

(doi:10.1007/bf00351344).

9. $\quad$ Muscatine L., Falkowski P.G., Porter J.W., Dubinsky Z. 1984 Fate of photosynthetic fixed carbon in light-adapted and shade-adapted colonies of the symbiotic coral Stylophora pistillata. Proceedings of the Royal Society Series B-Biological Sciences 222(1227), 181-202. (doi:10.1098/rspb.1984.0058).

10. Donner S.D. 2009 Coping with Commitment: Projected Thermal Stress on Coral Reefs under Different Future Scenarios. PLoS ONE 4(6). (doi:e5712 10.1371/journal.pone.0005712).

11. Frieler K., Meinshausen M., Golly A., Mengel M., Lebek K., Donner S.D., Hoegh-Guldberg O. 2013 Limiting global warming to 2 degrees $\mathrm{C}$ is unlikely to save most coral reefs. Nature Climate Change 3(2), 165-170. (doi:10.1038/nclimate1674).

12. Hoegh-Guldberg O., Mumby P.J., Hooten A.J., Steneck R.S., Greenfield P., Gomez E., Harvell C.D., Sale P.F., Edwards A.J., Caldeira K., et al. 2007 Coral reefs under rapid climate change and ocean acidification. Science 318(5857), 1737-1742. (doi:10.1126/science.1152509). 
13. IPCC_2007. Climate change 2007: synthesis report. Contribution of Working Groups 1, 11 and 111 to the Fourth Assessment Report of the Intergovernmental Panel on Climate Change. IPCC, Geneva, Switzerland.

14. Donner S.D., Skirving W.J., Little C.M., Oppenheimer M., Hoegh-Guldberg O. 2005 Global assessment of coral bleaching and required rates of adaptation under climate change. Global Change Biol 11(12), 2251-2265.

15. Hoegh-Guldberg O. 1999 Climate change, coral bleaching and the future of the world's coral reefs. Mar Freshw Res 50(8), 839-866. (doi:10.1071/mf99078).

16. Fitt W.K., Brown B.E., Warner M.E., Dunne R.P. 2001 Coral bleaching: interpretation of thermal tolerance limits and thermal thresholds in tropical corals. Coral Reefs 20(1), 51-65. (doi:10.1007/s003380100146).

17. Weis V.M. 2008 Cellular mechanisms of Cnidarian bleaching: stress causes the collapse of symbiosis. J Exp Biol 211(19), 3059-3066. (doi:10.1242/jeb.009597).

18. Dunn S.R., Schnitzler C.E., Weis V.M. 2007 Apoptosis and autophagy as mechanisms of dinoflagellate symbiont release during cnidarian bleaching: every which way you lose. Proc R Soc Lond, Ser B: Biol Sci 274(1629), 3079-3085. (doi:10.1098/rspb.2007.0711).

19. Dunn S.R., Thomason J.C., Le Tissier M.D.A., Bythell J.C. 2004 Heat stress induces different forms of cell death in sea anemones and their endosymbiotic algae depending on temperature and duration. Cell Death Differ 11(11), 1213-1222. (doi:10.1038/sj.cdd.4401484).

20. Smith D.J., Suggett D.J., Baker N.R. 2005 Is photoinhibition of zooxanthellae photosynthesis the primary cause of thermal bleaching in corals? Global Change Biol 11(1), 1-11.

21. De'ath G., Fabricius K.E., Sweatman H., Puotinen M. 2012 The 27-year decline of coral cover on the Great Barrier Reef and its causes. Proc Natl Acad Sci U S A 109(44), 17995-17999. (doi:10.1073/pnas.1208909109).

22. Cote I.M., Gill J.A., Gardner T.A., Watkinson A.R. 2005 Measuring coral reef decline through meta-analyses. Philosophical Transactions of the Royal Society BBiological Sciences 360(1454), 385-395. (doi:10.1098/rstb.2004.1591).

23. Gardner T.A., Cote I.M., Gill J.A., Grant A., Watkinson A.R. 2003 Long-term region-wide declines in Caribbean corals. Science 301(5635), 958-960. (doi:10.1126/science.1086050).

24. Middlebrook R., Hoegh-Guldberg O., Leggat W. 2008 The effect of thermal history on the susceptibility of reef-building corals to thermal stress. $J$ Exp Biol 211(7), 1050-1056. (doi:10.1242/jeb.013284). 
25. Brown B.E., Downs C.A., Dunne R.P., Gibb S.W. 2002 Exploring the basis of thermotolerance in the reef coral Goniastrea aspera. Mar Ecol Prog Ser 242, 119-129. (doi:10.3354/meps242119).

26. Brown B.E., Dunne R.P., Goodson M.S., Douglas A.E. 2002 Experience shapes the susceptibility of a reef coral to bleaching. Coral Reefs 21(2), 119-126. (doi:10.1007/s00338-002-0215-z).

27. Brown B.E., Dunne R.P., Warner M.E., Ambarsari I., Fitt W.K., Gibb S.W., Cummings D.G. 2000 Damage and recovery of Photosystem II during a manipulative field experiment on solar bleaching in the coral Goniastrea aspera. Mar Ecol Prog Ser 195, $117-124$.

28. Maynard J.A., Anthony K.R.N., Marshall P.A., Masiri I. 2008 Major bleaching events can lead to increased thermal tolerance in corals. Mar Biol 155(2), 173-182. (doi:10.1007/s00227-008-1015-y).

29. Barshis D.J., Ladner J.T., Oliver T.A., Seneca F.O., Traylor-Knowles N., Palumbi S.R. 2012 Genomic basis for coral resilience to climate change. Proc Natl Acad Sci U S A 110(4), 1387-1392. (doi:10.1073/pnas.1210224110). 


\section{Chapter 2: Resistance to thermal stress in corals without changes in symbiont composition}

\subsection{Abstract}

Discovering how corals can adjust their thermal sensitivity in the context of global climate change is important in understanding long-term persistence of coral reefs. In the present study we show that short-term preconditioning to higher temperatures, $3^{\circ} \mathrm{C}$ below the experimentally determined bleaching threshold, for a period of seven days provides thermal tolerance for the symbiosis stability between the scleractinian coral, Acropora millepora and Symbiodinium. On the basis of our genotypic analysis, the results indicate that the acclimatization of this coral species to thermal stress does not come down to simple shifts in Symbiodinium and/or the bacterial communities that associate with reefbuilding corals. The results suggests that the physiological plasticity of the host and/or symbiotic components appears to play an important role in responding to ocean warming. The further study of host and symbiont physiology, both of Symbiodinium and prokaryotes, is of paramount importance in the context of global climate change, as mechanisms for rapid holobiont acclimatization will become increasingly important to the long-standing persistence of coral reefs.

\subsection{Introduction}

Coral reefs are among the most biologically diverse and economically important ecosystems on the planet, providing ecological services that are vital to human society and industries through fisheries, coastal protection, pharmaceutical compounds, and tourism [30]. The high productivity and structural complexity of coral reefs is derived and powered by the mutualistic association between corals and their symbiotic single- 
celled dinoflagellate algae (Symbiodinium Freudenthal 1962) [31]. Coral reefs worldwide, however, are among the most vulnerable ecosystems to global environmental change [15, 32]. Both field and laboratory evidence reveal that corals are highly sensitive to thermal stress, with $+1{ }^{\circ} \mathrm{C}$ above long-term summer maxima driving mass coral bleaching (i.e., the loss of symbiotic dinoflagellates and/or their photosynthetic pigments) and consequently coral mortality $[12,14,15]$. If the thermal sensitivity of corals does not change, coral reefs face serious problems in scenarios where tropical seas may be as much as $2-4^{\circ} \mathrm{C}$ warmer by the end of this century [14]. The capacity of corals for acclimatization to heat stress is a critical component of their long-term survival. Understanding the thermal tolerance of corals and their dinoflagellate and prokaryotic symbionts, which altogether represents the holobiont [33], is therefore important to any predictions of how the future may unfold for coral reefs.

At fine scales, thermal history, both in the long- and short-term, has been shown to be a determinant in the response of corals to hyperthermal stress and bleaching $[24,28$, 34]. By comparing the widespread thermal bleaching events that occurred on the Great Barrier Reef in the Coral Sea in 1998 and 2002, Maynard et al. [28] detected a lower incidence of bleaching for three major coral genera (Acropora, Pocillopora and Porites) in 2002 compared to 1998 on the same reefs despite the higher solar irradiance observed during the 2002 thermal event. Since colony mortality was not high enough during the bleaching episode in 1998 for selection to explain the increased thermal tolerance observed during the 2002 thermal event, acclimatization was suggested as the potential cause of bleaching resistance [28]. Potentially, a long-term acclimatization response could have a basis in epigenetics, conferring a transcriptional response conducive to 
bleaching resistance. Though the role of epigenetics in coral stress response is currently unknown, there is evidence for the regulation of stress responses of plants via epigenetic mechanisms [35], and even transmission of epigenetic effects to subsequent generations [36]. Other evidence for the natural acclimatization of coral to thermal stress come from studies conducted in the surroundings of the nuclear power plant near Nanwan Bay, Taiwan [37]. In 1988, the year the power plant began full operation, Acropora grandis samples taken near the hot water outlet of the nuclear power plant were completely bleached within two days of exposure to $33^{\circ} \mathrm{C}$. Two years later, however, corals from the same area required six days of exposure to $33^{\circ} \mathrm{C}$ water for the onset of signs of bleaching. The protective effect of thermal preconditioning has also been shown experimentally, in the reef coral Acropora aspera, where corals exposed to brief heat stress insufficient to cause bleaching later resisted bleaching temperatures, maintaining symbiont densities, photopigments, and quantum yield [24].

Attempts to understand the differences in the response of reef building corals to warming oceans has focused almost entirely on genetic variation within the dinoflagellate symbiont, Symbiodinium [38-40]. There are two proposed mechanisms by which the composition of the Symbiodinium population hosted by a coral can potentially change: switching, in which existing symbionts are expulsed and novel symbionts are acquired from the environment, or shuffling (also referred as to shifting), in which existing types already in hospite change in relative abundance [41]. Shuffling from less tolerant to heatresistant algal symbionts has been proposed as a means of adjusting to accelerating increases in seawater temperature [38-40, 42]. However, the higher proportions of hosts harboring heat-resistant algal symbionts after bleaching [39] could also be a result of 
differential survival of hosts containing the stress-resistant symbiont as opposed to changes of symbionts [43]. Sampayo et al. [44] monitored tagged colonies of Stylophora pistillata with sampling times spanning a bleaching event. Their results support differential mortality of corals hosting heat-sensitive symbionts as an explanation of an increase in the frequency of thermal-tolerant symbionts post-bleaching, not the beneficial shuffling of dinoflagellate symbionts[44]. Other work shows that bleached Porites divaricata challenged with heterologous Symbiodinium may transiently acquire symbionts from the water, but these novel symbioses are not maintained [45]. In contrast, the work of Jones et al. [46] supports acclimative shifts in Symbiodinium, finding that in tagged A. millepora colonies examined prior to and following a bleaching event, $71 \%$ of surviving colonies which initially harbored a majority of heat-sensitive symbionts shifted to predominantly heat-tolerant symbionts after bleaching. Clearly, a general model for the role of symbiont shuffling and/or switching has yet to be established.

Another possibility is an advantageous change in the coral-associated bacterial community, resulting in the rapid generation of a more heat-resistant holobiont. This alternate hypothesis is derived from the coral probiotic hypothesis [47], which states that corals form a symbiotic relationship with a diverse metabolically active microbial population living on their surface and in their tissues [33, 48-51], such that when environmental conditions are altered, the microbial biota undergoes changes that aid the coral holobiont fitness [47]. However, unambiguous switching to entirely novel symbioses as a beneficial response to thermal stress has yet to be demonstrated. It is still unknown if the thermal tolerance observed in rapid acclimatization responses is also associated with a shift to heat-resistant symbionts in coral holobionts. 
In the current study we asked whether short-term preconditioning of corals to thermal stress shifted their dinoflagellate and bacterial communities to new configurations, thereby resulting in greater thermal tolerance for the host and symbionts.

\subsection{Materials and methods}

\subsubsection{Sample collection and care}

Acropora millepora nubbins (small colony fragments) were collected from colonies on the reef flat in the vicinity of Heron Island (GBR), Queensland, Australia $\left(23^{\circ} 33^{\prime} \mathrm{S}, 151^{\circ} 54^{\prime} \mathrm{E}\right)$ in June 2009 . Branches $6-8 \mathrm{~cm}$ long were cut and embedded in marine epoxy in cut-off $15 \mathrm{ml}$ centrifuge tubes; a total of 72 coral fragments were allowed to recover for 20 days prior to the beginning of experimental manipulations.

\subsubsection{Thermal Stress Experiments}

We tested the response of $A$. millepora to thermal preconditioning by exposing coral nubbins to $28^{\circ} \mathrm{C}\left(3^{\circ} \mathrm{C}\right.$ below bleaching threshold) for ten days, prior to challenging them with water temperatures of $31^{\circ} \mathrm{C}$ for eight days (Figure 1). In another treatment (non-preconditioned), corals were exposed to $31^{\circ} \mathrm{C}$ without exposure to the $28^{\circ} \mathrm{C}$ treatment. These two treatments were compared to control coral fragments that were exposed only to ambient-temperature reef flat water $\left(21^{\circ} \mathrm{C}-22^{\circ} \mathrm{C}\right)$.

The experimental system was comprised of 151 transparent tanks plumbed into flowing seawater, with four replicate tanks for each treatment (a total of 12 tanks). All tanks were operated as open systems and received water from the adjacent reef flat at a

rate of 0.3 to $0.41 \mathrm{~min}^{-1}$, with additional flow provided by $2501 \mathrm{~h} \mathrm{~h}^{-1}$ submersible pumps. Control treatments received ambient water with no temperature manipulation. The temperatures in the experimental tanks were increased at rate of $2^{\circ} \mathrm{C}$ per day, with 
temperature changes taking place at $06: 30 \mathrm{~h}$. Water temperature of tanks were recorded throughout the experiment using HOBO Pro v2 Water Temperature Data Loggers (Onset, Pocasset, MA, USA). There were six nubbins per tank at the outset of the experiment (a total of 72 nubbins). One coral nubbin was collected for each experimental and control replicate tank at the following sampling times: 18 and 5 days prior to thermal stress (at which point the preconditioned treatment had been exposed to $28^{\circ} \mathrm{C}$ preconditioning for seven days), and after two, six, and eight days of $31^{\circ} \mathrm{C}$ thermal challenge. Sampling was done at 17:00 h on each sample date.

\subsubsection{Symbiodinium density and genetic identification}

For the determination of Symbiodinium cell densities per surface area, cell counts were performed using a Hirschman ${ }^{\circledR}$ Neubauer improved haemocytometer (Hirschmann Laborgeräte, Eberstadt, Germany), with coral area assessed by a wax coating method [52]. DNA extractions were performed using DNeasy Plant Mini Kit (QIAGEN, Valencia, CA, USA) from tissue collected 18 days prior to the start of thermal stress, as well as after eight days of thermal challenge. Symbiodinium 28S rDNA was amplified and directly sequenced using primers $28 \mathrm{~S}$-forward (5'CCCGCTGAATTTAAGCATATAAGTAAGCGG-3') and 28S-reverse (5'GTTAGACTCCTTGGTCCGTGTTTCAAGA-3') [53]. The PCR was performed in $25 \mu 1$ reaction volumes, using 10ng of DNA template, $10 \mu \mathrm{L}$ GoTaq Green Master Mix (Promega, Madison, Wisconsin, USA), and $0.25 \mu \mathrm{M}$ 28S-forward and 0.25 $\mu \mathrm{M}$ 28S-reverse primers. Thermocycling conditions consisted of a five-minute initial denaturation at $95^{\circ} \mathrm{C}$, followed by 35 cycles of $94^{\circ} \mathrm{C}$ ( 30 seconds), $65^{\circ} \mathrm{C}$ ( 40 seconds), and $72^{\circ} \mathrm{C}\left(60\right.$ seconds), and a 10 minute final extension at $72^{\circ} \mathrm{C}$. The PCR products were 
directly sequenced by the DNA Analysis Facility at Yale University (New Haven, CT, USA), using 28S-forward and 28S-reverse primers. Sequences were inspected and assembled using CodonCode Aligner v. 3.5.7 (CodonCode Corporation, Dedham, MA, USA). Sequences were identified by BLAST comparisons in NCBI Genbank.

The internal transcribed spacer region 2 (ITS2) rDNA was PCR-amplified using primers ITSintfor2 and ITS2CLAMP (5'GAATTGCAGAACTCCGTG-3' and 5’CGCCCGCCGCGCCCCGCGCCCGTCCCGCCGCCCCCGCCCGGGA TCCATATGCTTAAGTTCAGCGGGT-3') [54], in $20 \mu \mathrm{l}$ reactions consisting of $10 \mathrm{ng}$ of DNA template, $10 \mu \mathrm{L}$ GoTaq Green Master Mix (Promega, Madison, Wisconsin, USA) adjusted to $3.0 \mathrm{mM} \mathrm{MgCl}_{2}, 0.25 \mu \mathrm{M}$ ITSintfor2, and $0.75 \mu \mathrm{M}$ ITS2CLAMP. The touch-down PCR program consisted of a three-minute initial denaturation at $92^{\circ} \mathrm{C}$, 21 cycles of $92^{\circ} \mathrm{C}(30$ seconds $), 62^{\circ} \mathrm{C}\left(40\right.$ seconds), and $72^{\circ} \mathrm{C}(30$ seconds), decreasing by $0.5^{\circ} \mathrm{C}$ each cycle, followed by 15 cycles with a $52^{\circ} \mathrm{C}$ annealing step, and a 10 minute final extension at $72^{\circ} \mathrm{C}$. Denaturing gradient gel electrophoresis (DGGE) was used to separate PCR products on a 45-80\% gradient (8\% acrylimide) [54]. Gels were run for 14 hours at 100 volts at a constant temperature of $60^{\circ} \mathrm{C}$ [54].

Excised bands were incubated for 24 hours with shaking at room temperature in $30 \mu \mathrm{L}$ nuclease-free water. The liquid portion of this mixture was recovered, ethanolprecipiated, washed with $70 \%$ ethanol, and resuspended in $30 \mu \mathrm{L}$ nuclease-free water. One $\mu \mathrm{L}$ of each band isolate solution was subsequently re-amplified for direct sequencing in a $20 \mu \mathrm{L}$ reaction using $0.25 \mu \mathrm{M}$ ITSintfor2 [54] and ITSRev (5'GGATCCATATGCTTAAGTTCAGCGGGT-3') [55], $10 \mu \mathrm{L}$ GoTaq Green Master 
Mix (Promega, Madison, Wisconsin, USA) adjusted to $3.0 \mathrm{mM} \mathrm{MgCl}_{2}$, with a PCR program consisting of a three minute initial denaturation at $92^{\circ} \mathrm{C}, 35$ cycles of $92^{\circ} \mathrm{C}$ (30 seconds), $52{ }^{\circ} \mathrm{C}$ ( 40 seconds), $72^{\circ} \mathrm{C}(30$ seconds), and a 10 -minute final extension at $72^{\circ} \mathrm{C}$. Reamplification products were directly sequenced by the DNA Analysis Facility at Yale University (New Haven, Connecticut, USA) using primer ITSintfor2 [54]. Sequences were examined using CodonCode Aligner v. 3.5.7 (CodonCode Corporation, Dedham, Massachusetts, USA) and identified by BLAST comparisons in Genbank.

\subsubsection{Bacterial community composition}

The bacterial community was profiled using RNA to assess the active microbial assemblage; in a short-course experiment, a DNA profile may have provided results not reflective of the actual active bacteria at a given time. The RNA was extracted from snap frozen coral fragments sampled after six days at $31^{\circ} \mathrm{C}$. RNA isolations were performed using Trizol reagent (Invitrogen), followed by RNeasy Mini kit (QIAGEN, Valencia, California, USA). Total RNA (100 ng) was reverse-transcribed using a QuantiTect Reverse Transcription Kit (QIAGEN, Valencia, California, USA), with $1 \mu \mathrm{M}$ of modified primer 907R (CCTACGGGDGGCWGCAG)[56]. Subsequently, PCR was performed on cDNA samples using modified primers 341F-Clamp [57]

\section{(CGCCCGCCGCGCCCCGCGCCCGTCCCGCCGCCCCCGCCCGCCTACGGGDGGC}

WGCAG) and 907R to amplify the $16 \mathrm{~S}$ rRNA [56]. PCR was performed in $50 \mu \mathrm{l}$ reaction volumes, using GoTaq Green Master Mix (Promega, Madison, Wisconsin, USA) adjusted to $2.5 \mathrm{mM} \mathrm{MgCl}_{2}, 0.25 \mu \mathrm{M} 907 \mathrm{R}$, and $0.75 \mu \mathrm{M}$ 341F-Clamp. The PCR program consisted of a 5 minute initial denaturation at $95^{\circ} \mathrm{C}$, followed by 35 cycles of $95^{\circ} \mathrm{C}(30$ 
seconds), $51^{\circ} \mathrm{C}$ (60 seconds), and $72^{\circ} \mathrm{C}(60$ seconds), and a 7 minute final extension. The PCR products were run on DGGE using a 6\% acrylimide denaturing gradient gel (30$65 \%$ gradient) for 14 hours at 97 volts at a constant temperature of $60^{\circ} \mathrm{C}$.

Excised bands (processed as previously described) were subsequently reamplified for direct sequencing in a $25 \mu \mathrm{L}$ reaction using GoTaq Green Master Mix (Promega, Madison, Wisconsin, USA), $0.25 \mu \mathrm{M}$ 907R, and $0.25 \mu \mathrm{M}$ 341F. The PCR program consisted of a 5 minute initial denaturation at $95^{\circ} \mathrm{C}$, followed by 35 cycles of $95^{\circ} \mathrm{C}$ (30 seconds), $51^{\circ} \mathrm{C}$ (60 seconds), and $72^{\circ} \mathrm{C}$ (60 seconds), and a 7 minute final extension. The PCR products were directly sequenced by the DNA Analysis Facility at Yale University (New Haven, Connecticut, USA) using the 907R primer. Sequences were examined using CodonCode Aligner v. 3.5.7 (CodonCode Corporation, Dedham, Massachusetts, USA) and identified by BLAST comparisons in Genbank., and using the chimera-checked Greengenes database [58].

\subsubsection{Statistical analysis and multivarate analysis}

Symbiodinium density data were analyzed with one-way ANOVA with Tukey HSD, performed using the package Systat 13 (SYSTAT Inc, Evanston, IL, USA). The DGGE gel images of the bacterial 16S rDNA were scored using Gel2k [59]. Gel band intensity was normalized and assigned to categories prior to multivariate analysis. Correspondence analysis of the categorical data was performed using the $\mathrm{R}$ package Vegan $[60,61]$.

\subsection{Results}

Thermal response: Symbiodinium density and composition

Coral nubbins that were not exposed to the thermal pre-conditioning treatment suffered 
significant bleaching with exposure to $31^{\circ} \mathrm{C}$ water, as observed after six and eight days of thermal challenge at $31^{\circ} \mathrm{C}(\mathrm{p}<0.001$, one-way ANOVA with Tukey HSD, Figure 2.). Symbiodinium density decreased almost $80 \%$ after eight days of exposure to bleaching temperature. In contrast, preconditioned coral nubbins did not bleach with exposure to $31^{\circ} \mathrm{C}$, maintaining dinoflagellate symbiont densities consistent with those observed in control coral fragments during the eight days of thermal challenge ( $p>0.20$, one-way ANOVA with Tukey HSD; Figure 2).

To determine whether the response to thermal stress was associated with shifts in the composition of Symbiodinium strains, we directly sequenced the 28S rDNA and conducted DGGE analysis on the ITS2 of the resident Symbiodinium in the coral nubbins. The composition of Symbiodinium strains prior to thermal treatments and after eight days of thermal challenge was revealed to be the same across treatments, with all corals maintaining an association with clade C3 Symbiodinium (electronic supplementary material, Figure S1). With direct sequencing of 28S (GenBank accession number JF834208), no background sequences were detected.

\subsubsection{Thermal response by the bacterial community}

The DGGE analysis of PCR-amplified bacterial 16S rRNA fragments showed no differences in the composition of the bacterial community associated with preconditioned, non-preconditioned, and control coral nubbins, with the exception of one control coral containing an additional band (electronic supplementary material, Figure S2). Dominant banding patterns and bacterial types that were ubiquitous across treatments were sequenced, revealing that the majority of abundant sequences were Gammaproteobacteria of high identity (95-96\%) to Spongiobacter spp. sequences. However, differences 
occurred in the relative intensity of $16 \mathrm{~S}$ rRNA-DGGE bands, which were used as a rough proxy of the relative abundance. Analysis of gel banding-intensity patterns using correspondence analysis revealed an effect of temperature on both the nonpreconditioned and preconditioned corals after six days at $31{ }^{\circ} \mathrm{C}$, relative to controls (Figure 3). Nevertheless, this temperature effect was similar on both non-preconditioned (bleached) and preconditioned (thermal acclimatized) corals.

\subsection{Discussion}

The findings of our study revealed a surprising result that the acquired tolerance of preconditioned corals to thermal stress was not due to changes in the make-up of their symbionts. There were no changes detected in Symbiodinium strains associated with the thermal tolerance response described in this experiment. Even more, no change in the dominant members of the bacterial community was detected, and the community structures, on the basis of the relative abundance of bacteria, were largely similar across bleached non-preconditioned corals and non-bleaching preconditioned corals. Therefore, our results indicate that the rapid acclimatization of Acropora millepora corals to thermal stress did not come down to simple changes in Symbiodinium and/or the bacterial communities that associate with reef-building corals.

Changes in symbiont type via shuffling would seem unlikely, as the corals hosted a single Symbiodinium type, but the point of emphasis remains that even with one detectable symbiont type, preconditioned corals still exhibit evidence of acclimatization. It bears mentioning the DGGE implemented is capable of detecting broad changes in the symbiont community, but DGGE is unable to detect Symbiodinium present at less that 5 to $10 \%$ of the community $[62,63]$. In terms of switching, host-symbiont specificity 
would also seriously hinder the acquisition of novel symbiont types, both in terms of symbiont uptake and proliferation [64-66]. But even with a lack of specificity, the complete replacement of dominant symbionts by another type (switching) would take in excess of one month, according to a Symbiodinium population model for corals proposed by Jones and Yellowlees [67]. This month dictated by the population model stands in contrast to the thermal acclimation which occurred in only 10 days in this experiment, as well as in the work of Middlebrook et al. [24], with $48 \mathrm{~h}$ preconditioning regimes oneand two weeks prior to thermal challenge. The timescales are incompatible with a symbiont type switch. In accordance with this, our molecular genotyping of Symbiodinium revealed the same single symbiont type both at the outset and at the end of the experiment.

Likewise, it has been recently proposed that changes of the bacterial community in response to environmental stressors could also provide tolerance to changing environmental conditions much more rapidly than host evolution - this is referred as to 'the Coral Probiotic hypothesis' [47]. In A. millepora, shifts in resident bacteria have been shown during bleaching, with a change in the community shifting from a healthy community of bacteria dominated by Spongiobacter spp. to one dominated by Vibrio spp. during bleaching $[48,68]$. However, in the present experiment, a dramatic change in members of bacterial community was not found in either preconditioned or nonpreconditioned corals. While we indeed detected some changes in the apparent relative abundance of bacterial strains in response to an increase of temperature compared to controls, the changes were similar between pre-conditioned (acclimatized) and non- 
preconditioned (bleached) corals indicating no correlation between a change of the bacterial community and the thermal tolerance response.

One possibility that could explain the lack of a bacterial partner shift in this experiment is that the corals already possessed a community of bacteria able to cope with the fluctuating temperatures as a result of prior stress on the reef, as backreef environments usually experience greater temperature extremes and fluctuations than forereef environments [69]. Intriguingly, the effects of thermal acclimation on the bacterium Escherichia coli defy a single model, with acclimation competitively beneficial in some cases, but not in others, as shown experimentally [70]. Another consideration is that a mass bleaching event is one of an entire community, presumably with bacterial fauna present from the entire heat-stressed vicinity. However, in this experiment, the flowing seawater used originated from a reef flat that was not experiencing hyperthermal stress, eliminating a potential source of bacteria that may colonize corals during natural bleaching events. The absence of a larger bacterial community under conditions of thermal duress may explain why this experiment did not see a bacterial community flux as observed in other studies $[48,68]$. Similar to our results, Salerno et al. [71] found no systematic changes in the microbial community composition of Porites compressa as a result of a six day treatment of $1^{\circ} \mathrm{C}$ above ambient summer temperature.

Although symbionts are clearly of fundamental importance, the idea that the thermal tolerance of corals resides almost entirely within changes of symbiont types with different physiologies has been questioned $[34,72,73]$. Our findings instead suggest that the physiological plasticity of one or more members of the coral holobiont plays, in a 
timely and beneficial way, an important role in the acclimatization response to a rapid change of temperature. This study, to our knowledge, is the first that clearly shows the capacity of corals to tolerate thermal stress through a mechanism based on genotypeindependent phenotypic change.

In addition to the potential of Symbiodinium population shifts, the consideration of physiological acclimatization is important both in the host and the symbionts. Physiological acclimatization to heat stress has been previously documented in corals, and, alongside the role of the dinoflagellate symbiont, is held to be a significant part of the response to heat stress [74] In Montastraea franksi, exposure to elevated temperatures results in the up-regulation of HSP70 after six hours, with a return to control levels after continued exposure for 12 hours, and another increase in expression after 48 hours of heat stress [75]. Additionally, Gates and Edmunds [75] suggest a relationship between corals with high protein turnover and an increased capacity for thermal acclimatization. The relationship between protein turnover and acclimatization capacity is taken from evidence of Mytilus edulis, in which mussels with higher rates of protein turnover have been shown to acclimatize faster than those with lower rates of protein turnover [76, 77]. As shown with transcriptome analysis via cDNA microarrays, the aposymbiotic larvae of A. millepora exhibit a marked response in gene expression when heat stressed, including the rapid upregulation of three heat-shock proteins and a fluorescent protein [78]. Host physiology and the ability to induce stress response proteins has been suggested to play a role in resistance to heat stress in the case of Porites cylindrica, in addition to a heat resistant symbiont [79]. Pocillopora damicornis of a host genotype originating from a non-upwelling area showed greater thermal tolerance experimentally than another 
genotype, originating from an upwelling region of lower thermal stress, suggesting the possible importance of the host in thermal tolerance or the effects of long-term acclimatization to thermal stress [80].

Additionally, the prior experience of the host has been shown to be of great influence, even with differential exposure of stress within a colony. Brown et al. [27] found that the west faces of Goniastrea aspera colonies resisted bleaching during natural heat stress, while the east faces bleached. The west faces had been preconditioned via prior solar irradiance, conferring thermal tolerance without a change in dinoflagellate symbiont [27]. Though the source of acclimatization was reported to be that of solar irradiance, a resultant increase in thermal tolerance is mechanistically possible as stress responses are often unspecific [81]. Environmental stressors often coincide, and a general response has the advantage that a single stimulus mounts a response to potentially multiple simultaneous environmental conditions [81].

The contribution of the host to thermal tolerance is once again highlighted in a reciprocal transplant experiment with Porites lobata between genetically distinct populations of corals from back reef and forereef environments [73]. The host origin and associated genotype were the major determinants of ubiquitin-conjugated protein concentration, whereas Symbiodinium populating the corals were genetically indistinguishable [73]. Higher levels of ubiquitin-conjugated proteins were consistently found in colonies originating from the highly fluctuating back reef environment, both prior to and following transplantation, indicating a distinct physiological difference associated with colony genotype [73]. The differentiation in host populations between forereef and back reef sites calls into focus the potential for selection for physiological 
acclimatization to stress, given the disparate thermal regimens experienced by the two populations [73]. Thompson and van Woesik [82] add additional credence to an argument for host selection in response to thermal stress, but in the larger context of differential mortality and selection in response to thermal stress, as sites with historically high variability in temperature and solar irradiance resisted heat stress. This stands at odds with the conclusions drawn by Maynard et al. [28], finding that differential mortality did not explain thermal tolerance, but their sampling times may have not captured all postbleaching mortality [82].

Although a response of the cnidarian host to stress is one mechanism of acclimatization, there remain other possibilities, including that of physiological acclimatization of the dinoflagellate symbiont. In culture, Symbiodinium cells have been shown to decrease their cellular chlorophyll $a$ in response to supersaturating irradiance [83], a photoacclimation response common to many microalgae [84]. Warner et al. [69] found differences in photoacclimation between the symbionts of forereef and backreef coral species, with the Symbiodinium cells in the forereef Montastraea annularis less thermally tolerant than those in the back reef Siderastrea radians. While symbionts from both coral species induce non-photochemical quenching (NPQ) rapidly in response to elevated temperatures, the increase of NPQ is higher in the Symbiodinium of S. radians. Other work has identified non-photochemical quenching as a mechanism by which Symbiodinium can dissipate excess light energy in response to thermal stress that causes a loss in the functionality of PS II reaction centers [85]. Still, there remain many questions about the mechanisms and roles of acclimatization in Symbiodinium. 
Coral bleaching is a symptom of host/symbiont disequilibrium, and as such is potentially a consequence of multiple etiologies, with perhaps multiple modes of acclimatization under different circumstances and timeframes. Understanding how corals can adjust their thermal sensitivity in the context of global climate change continues to be important in understanding the long-term persistence of coral reefs under global change. 


\subsection{Acknowledgments}

We are grateful to Dr. Paulina Kaniewska, Alison Darling, Rachel Middlebrook, Camila Granados-Cifuentes, Robert Quinn, and the staff of the Heron Island Research Station for their assistance in the field and laboratory work on this project. This research was funded by a NSF-OCE grant (0851123) awarded to Mauricio Rodriguez-Lanetty. 


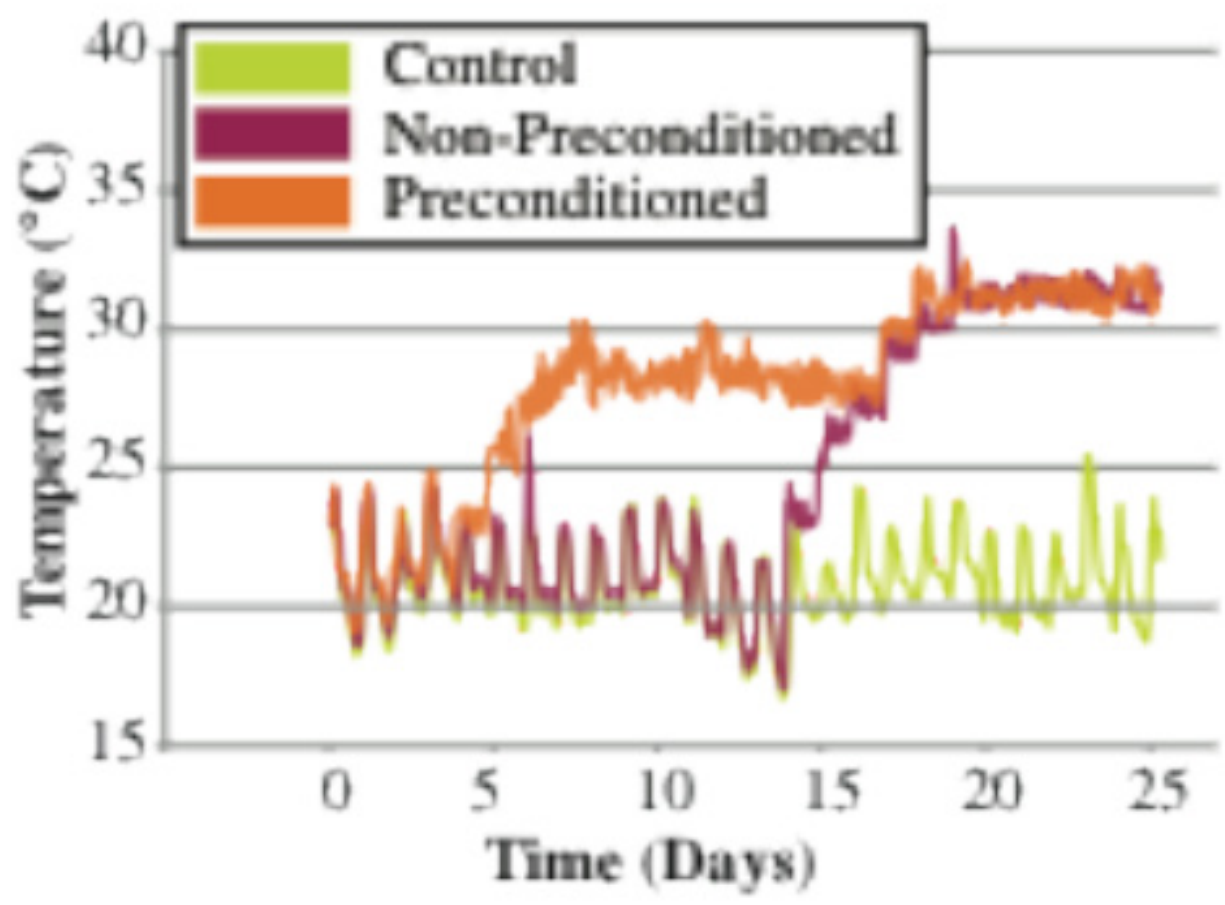

Figure 1. Temperature profiles of the thermal treatments with which Acropora millepora fragments were challenged. Preconditioned treatment comprised of a seven-day pre-stress at $28^{\circ} \mathrm{C}$ prior to exposure to $31^{\circ} \mathrm{C}$ (orange line). Non-preconditioned treatment with no pre-stress period prior to exposure to $31^{\circ} \mathrm{C}$ (red line), and control (green line) where coral fragments were not challenged to increase of temperature. Temperature was brought to $31^{\circ} \mathrm{C}$ at $2^{\circ} \mathrm{C}$ per day. Grey bars, ambient reef temperature; green bar, 7 days of $28^{\circ} \mathrm{C}$ preconditioning; dark green bars, 2 days at $31^{\circ} \mathrm{C}$; yellow bars, 6 days at $31^{\circ} \mathrm{C}$; pink bars, 8 days at $31^{\circ} \mathrm{C}$. 


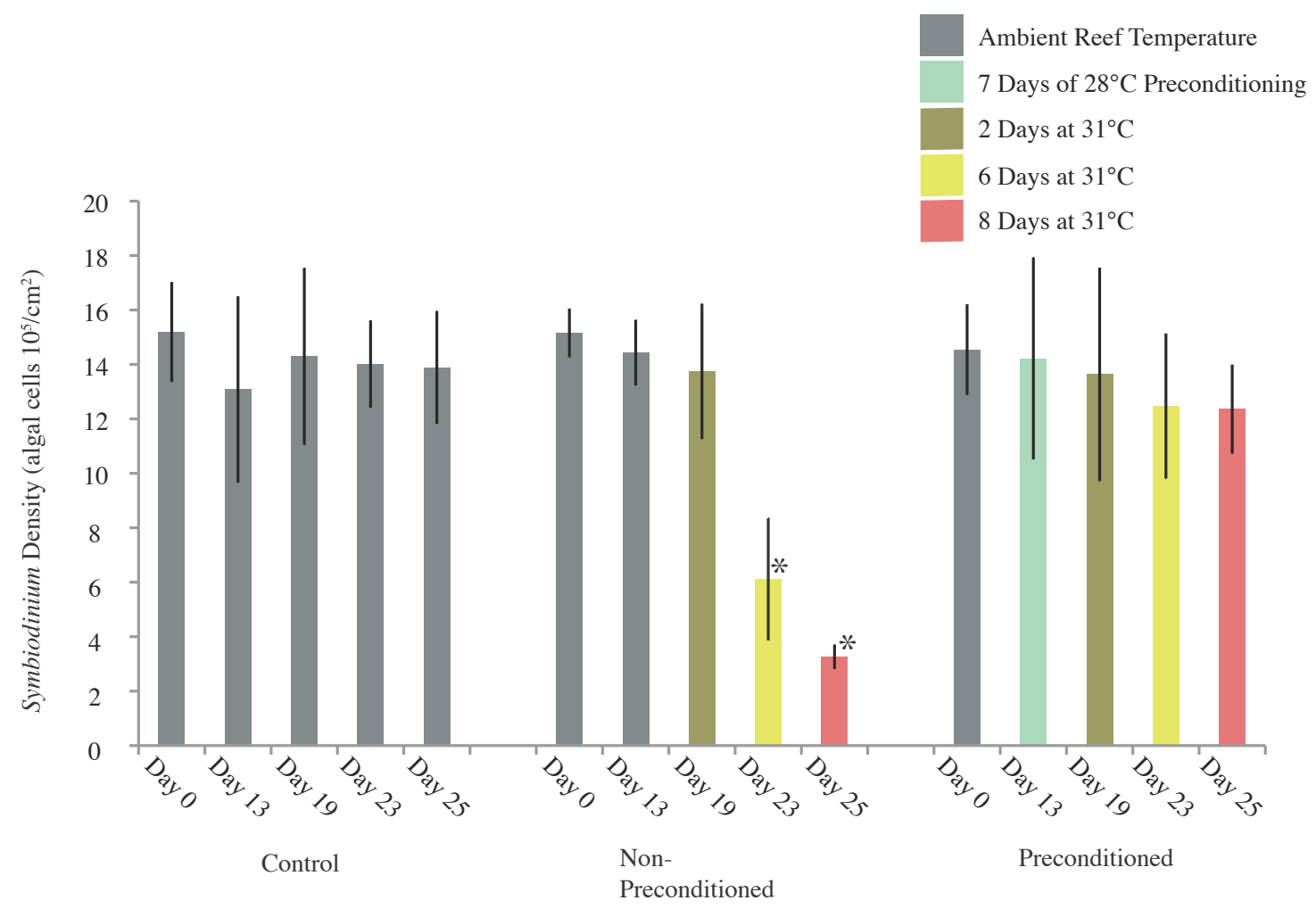

Figure 2. Symbiodinium density (algal cells $/ \mathrm{cm}^{2}$ ) at five different times: 18 and 5 days prior to exposure at $31^{\circ} \mathrm{C}$, and 2,6 , and 8 days during the exposure to $31^{\circ} \mathrm{C}$. Asterisks indicate group is significantly different from controls $(p<0.001$, one-way ANOVA with Tukey HSD, n=4). 


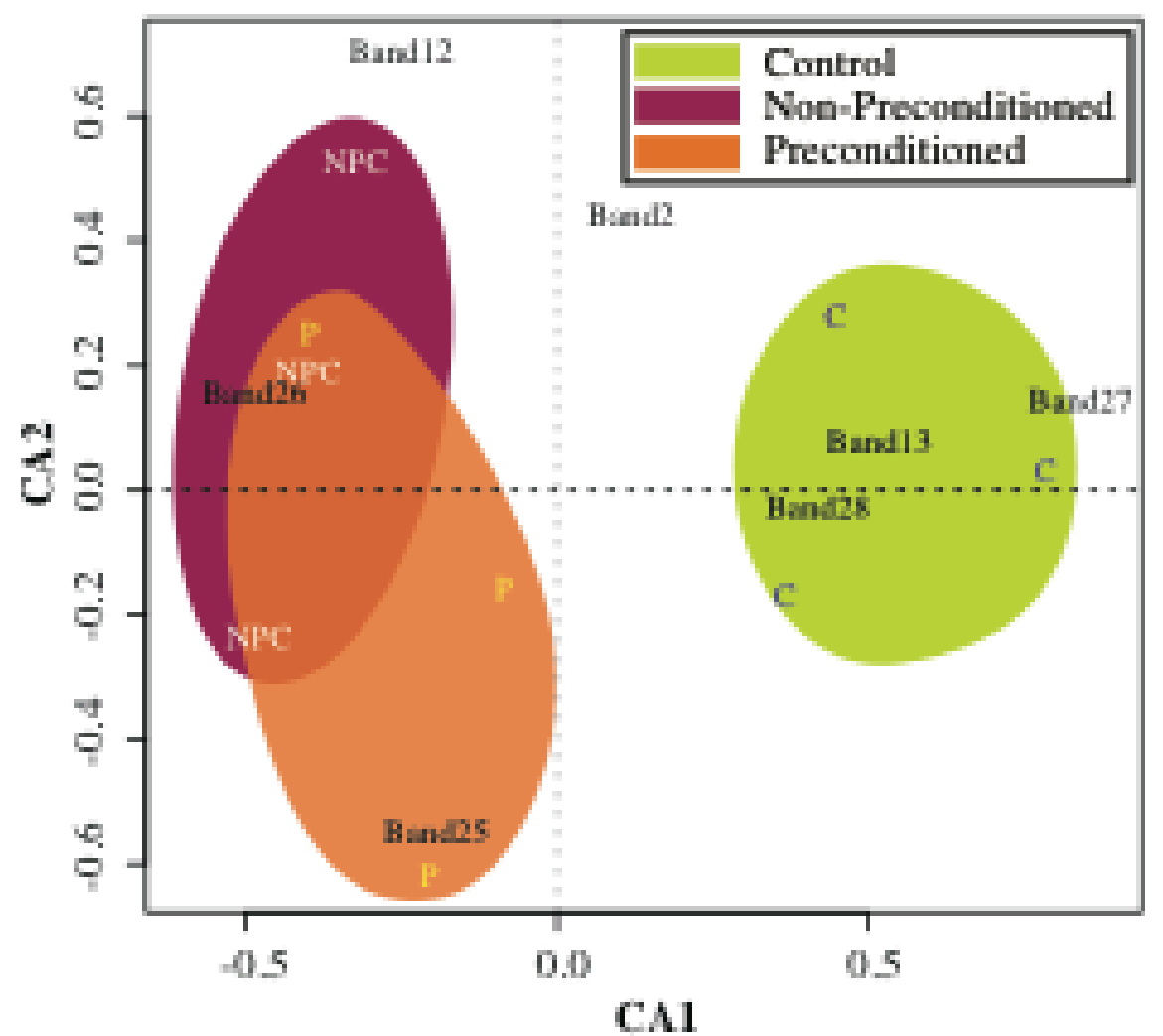

Figure 3. Correspondence analysis (CA) of reverse-transcribed bacterial 16S rRNADGGE banding patterns (treatment samples, as indicated in the insert legend, $n=3$ ). DGGE bands incorporated in the CA through relative abundance are shown. The bacterial community was profiled from RNA to assess the active microbial assemblage. CA1 explains $58.5 \%$ of variation; CA2 explains $19.3 \%$. NPC, non-preconditioned (red colour); $\mathrm{P}$, preconditioned (orange colour); $\mathrm{C}$, control (green colour). 


\subsection{References}

1. Moberg F., Folke C. 1999 Ecological goods and services of coral reef ecosystems. Ecol Econ 29(2), 215-233.

2. Freudenthal H.D. 1962 Symbiodinium gen. nov. and Symbiodinium microadriaticum sp. nov., a zooxanthella: taxonomy, life cycle, and morphology. $J$ Eukaryot Microbiol 9(1), 45-52. (doi:10.1111/j.1550-7408.1962.tb02579.x).

3. Hoegh-Guldberg O. 1999 Climate change, coral bleaching and the future of the world's coral reefs. Mar Freshw Res 50(8), 839-866.

4. Hughes T.P., Baird A.H., Bellwood D.R., Card M., Connolly S.R., Folke C., Grosberg R., Hoegh-Guldberg O., Jackson J.B.C., Kleypas J., et al. 2003 Climate change, human impacts, and the resilience of coral reefs. Science 301(5635), 929-933.

5. $\quad$ Donner S.D., Skirving W.J., Little C.M., Oppenheimer M., Hoegh-Guldberg O. 2005 Global assessment of coral bleaching and required rates of adaptation under climate change. Global Change Biol 11(12), 2251-2265.

6. Hoegh-Guldberg O., Mumby P.J., Hooten A.J., Steneck R.S., Greenfield P., Gomez E., Harvell C.D., Sale P.F., Edwards A.J., Caldeira K., et al. 2007 Coral reefs under rapid climate change and ocean acidification. Science 318(5857), 1737-1742. (doi:10.1126/science.1152509).

7. Rohwer F., Seguritan V., Azam F., Knowlton N. 2002 Diversity and distribution of coral-associated bacteria. Mar Ecol Prog Ser 243, 1-10.

8. Maynard J.A., Anthony K.R.N., Marshall P.A., Masiri I. 2008 Major bleaching events can lead to increased thermal tolerance in corals. Mar Biol 155(2), 173-182. (doi:10.1007/s00227-008-1015-y).

9. Middlebrook R., Hoegh-Guldberg O., Leggat W. 2008 The effect of thermal history on the susceptibility of reef-building corals to thermal stress. J Exp Biol 211(7), 1050-1056. (doi:10.1242/jeb.013284).

10. Oliver T.A., Palumbi S.R. 2011 Do fluctuating temperature environments elevate coral thermal tolerance? Coral Reefs 30(2), 429-440. (doi:10.1007/s00338-011-0721-y).

11. Chinnusamy V., Zhu J.K. 2009 Epigenetic regulation of stress responses in plants. Curr Opin Plant Biol 12(2), 133-139.

12. Molinier J., Ries G., Zipfel G., Hohn B. 2006 Transgeneration memory of stress in plants. Nature 442(7106), 1046. 
13. Fang L.S., Huang S.P., Lin K.L. 1997 High temperature induces the synthesis of heat-shock proteins and the elevation of intracellular calcium in the coral Acropora grandis. Coral Reefs 16(2), 127-131.

14. Baker A.C. 2001 Reef corals bleach to survive change. Nature 411(6839), 765766.

15. Baker A.C., Starger C.J., McClanahan T.R., Glynn P.W. 2004 Corals' adaptive response to climate change. Nature 430(7001), 741-741. (doi:10.1038/430741a).

16. Berkelmans R., van Oppen M.J.H. 2006 The role of zooxanthellae in the thermal tolerance of corals: a 'nugget of hope' for coral reefs in an era of climate change. Proc $R$ Soc Lond, Ser B: Biol Sci 273(1599), 2305-2312. (doi:10.1098/rspb.2006.3567).

17. Stat M., Carter D., Hoegh-Guldberg O. 2006 The evolutionary history of Symbiodinium and scleractinian hosts - symbiosis, diversity, and the effect of climate change. Perspect Plant Ecol Evol Syst 8(1), 23-43. (doi:10.1016/j.ppees.2006.04.001).

18. Buddemeier R.W., Fautin D.G. 1993 Coral bleaching as an adaptive mechanism: A testable hypothesis. Bioscience 43(5), 320-326.

19. Weis V.M. 2010 The susceptibility and resilience of corals to thermal stress: adaptation, acclimatization or both? Mol Ecol 19(8), 1515-1517. (doi:10.1111/j.1365294X.2010.04575.x).

20. Sampayo E., Ridgway T., Bongaerts P., Hoegh-Guldberg O. 2008 Bleaching susceptibility and mortality of corals are determined by fine-scale differences in symbiont type. Proc Natl Acad Sci U S A 105(30), 10444.

21. Coffroth M.A., Poland D.M., Petrou E.L., Brazeau D.A., Holmberg J.C. 2010 Environmental symbiont acquisition may not be the solution to warming seas for reefbuilding corals. PLoS ONE 5(10), e13258.

22. Jones A.M., Berkelmans R., van Oppen M.J.H., Mieog J.C., Sinclair W. 2008 A community change in the algal endosymbionts of a scleractinian coral following a natural bleaching event: field evidence of acclimatization. Proc R Soc Lond, Ser B: Biol Sci 275(1641), 1359.

23. Reshef L., Koren O., Loya Y., Zilber-Rosenberg I., Rosenberg E. 2006 The Coral Probiotic Hypothesis. Environ Microbiol 8(12), 2068-2073. (doi:10.1111/j.14622920.2006.01148.x).

24. Bourne D., Iida Y., Uthicke S., Smith-Keune C. 2008 Changes in coral-associated microbial communities during a bleaching event. ISME J 2(4), 350-363. (doi:10.1038/ismej.2007.112). 
25. Ritchie K.B. 2006 Regulation of microbial populations by coral surface mucus and mucus-associated bacteria. Mar Ecol Prog Ser 322, 1-14.

26. Rohwer F., Breitbart M., Jara J., Azam F., Knowlton N. 2001 Diversity of bacteria associated with the Caribbean coral Montastraea franksi. Coral Reefs 20(1), 8591.

27. Sweet M.J., Croquer A., Bythell J.C. 2011 Bacterial assemblages differ between compartments within the coral holobiont. Coral Reefs 30(1). (doi::10.1007/s00338-0100695-1).

28. Stimson J., Kinzie R.A. 1991 The temporal pattern and rate of release of zooxanthellae from the reef coral Pocillopora damicornis (Linnaeus) under nitrogenenrichment and control conditions. J Exp Mar Biol Ecol 153(1), 63-74.

29. Zardoya R., Costas E., Lopezrodas V., Garridopertierra A., Bautista J.M. 1995 Revised dinoflagellate phylogeny inferred from molecular analysis of large-subunit ribosomal RNA gene sequences. $J$ Mol Evol 41(5), 637-645.

30. LaJeunesse T.C., Trench R.K. 2000 Biogeography of two species of Symbiodinium (Freudenthal) inhabiting the intertidal sea anemone Anthopleura elegantissima (Brandt). Biol Bull (Woods Hole) 199(2), 126-134.

31. Coleman A.W., Suarez A., Goff L.J. 1994 Molecular delineation of species and syngens in Volvocacean green algae (Chlorophyta). J Phycol 30(1), 80-90.

32. Muyzer G., Brinkhoff T., Nübel U., Santegoeds C., Schäfer H., Wawer C. 1998 Denaturing gradient gel electrophoresis (DGGE) in microbial ecology

. In Molecular Microbial Ecology Manual (eds. Akkermans A.D.L., van Elsas J.D., de Bruijn F.J.), pp. 1-27. Dordrecht, the Netherlands, Kluwer Academic Publishers.

33. Muyzer G., Dewaal E.C., Uitterlinden A.G. 1993 Profiling of complex microbial populations by denaturing gradient gel electrophoresis analysis of polymerase chain reaction-amplified genes coding for 16S rRNA. Appl Environ Microbiol 59(3), 695-700.

34. DeSantis T.Z., Hugenholtz P., Larsen N., Rojas M., Brodie E.L., Keller K., Huber T., Dalevi D., Hu P., Andersen G.L. 2006 Greengenes, a chimera-checked 16S rRNA gene database and workbench compatible with ARB. Appl Environ Microbiol 72(7), 5069-5072. (doi:10.1128/aem.03006-05).

35. Norland S. 2004 GEL2k, v. 1.2.6. Bergen, Norway: University of Bergen. See http://folk.uib.no/ninsn/gel2k.

36. Oksanen J.F., Blanchet F.G., Kindt R., Legendre P., O'Hara R.B., Simpson G.L., Solymos M.P., Stevens H.H., Wagner H. 2011 Vegan: Community Ecology Package. (R package version 1.17-8 ed. 
37. R_Development_Core_Team. 2011 R: A language and environment for statistical computing. (Vienna, Austria, R Foundation for Statistical Computing.

38. Fabricius K.E., Mieog J.C., Colin P.L., Idip D., Van Oppen M.J.H. 2004 Identity and diversity of coral endosymbionts (zooxanthellae) from three Palauan reefs with contrasting bleaching, temperature and shading histories. Mol Ecol 13(8), 2445-2458. (doi:10.1111/j.1365-294X.2004.02230.x).

39. Thornhill D.J., LaJeunesse T.C., Kemp D.W., Fitt W.K., Schmidt G.W. 2006 Multi-year, seasonal genotypic surveys of coral-algal symbioses reveal prevalent stability or post-bleaching reversion. Mar Biol 148(4), 711-722. (doi:10.1007/s00227-005-0114-2).

40. Rodriguez-Lanetty M., Krupp D.A., Weis V.M. 2004 Distinct ITS types of Symbiodinium in Clade C correlate with cnidarian/dinoflagellate specificity during onset of symbiosis. Mar Ecol Prog Ser 275, 97-102.

41. Rodriguez-Lanetty M., Wood-Charlson E.M., Hollingsworth L.L., Krupp D.A., Weis V.M. 2006 Temporal and spatial infection dynamics indicate recognition events in the early hours of a dinoflagellate/coral symbiosis. Mar Biol 149(4), 713-719.

42. Schoenberg D., Trench R. 1980 Genetic variation in Symbiodinium (=Gymnodinium) microadriaticum Freudenthal, and specificity in its symbiosis with marine Invertebrates. III. Specificity and infectivity of Symbiodinium microadriaticum. Proc R Soc Lond, Ser B: Biol Sci 207(1169), 445-460.

43. Jones R.J., Yellowlees D. 1997 Regulation and control of intracellular algae (equals zooxanthellae) in hard corals. Philos Trans R Soc Lond B Biol Sci 352(1352), 457-468.

44. Bourne D.G., Garren M., Work T.M., Rosenberg E., Smith G.W., Harvell C.D. 2009 Microbial disease and the coral holobiont. Trends Microbiol 17(12), 554-562. (doi:10.1016/j.tim.2009.09.004).

45. Warner M.E., Fitt W.K., Schmidt G.W. 1996 The effects of elevated temperature on the photosynthetic efficiency of zooxanthellae in hospite from four different species of reef coral: A novel approach. Plant, Cell Environ 19(3), 291-299.

46. Bennett A.F., Lenski R.E. 1997 Evolutionary adaptation to temperature. VI. Phenotypic acclimation and its evolution in Escherichia coli. Evolution 51(1), 36-44.

47. Salerno J.L., Reineman D.R., Gates R.D., Rappe' M.S. 2010 The effect of a sublethal temperature elevation on the structure of bacterial communities associated with the coral Porites compressa. J Mar Biol 2011, 9. (doi:10.1155/2011/969173).

48. Baird A., Maynard J.A. 2008 Coral adaptation in the face of climate change. Science 320(5874), 315. 
49. Barshis D.J., Stillman J.H., Gates R.D., Toonen R.J., Smith L.W., Birkeland C. 2010 Protein expression and genetic structure of the coral Porites lobata in an environmentally extreme Samoan back reef: does host genotype limit phenotypic plasticity? Mol Ecol 19(8), 1705-1720. (doi:10.1111/j.1365-294X.2010.04574.x).

50. Baird A.H., Bhagooli R., Ralph P.J., Takahashi S. 2009 Coral bleaching: the role of the host. Trends Ecol Evol 24(1), 16-20. (doi:10.1016/j.tree.2008.09.005).

51. Gates R.D., Edmunds P.J. 1999 The physiological mechanisms of acclimatization in tropical reef corals. Am Zool 39(1), 30-43.

52. Hawkins A. 1991 Protein turnover: a functional appraisal. Funct Ecol 5(2), 222233.

53. Hawkins A., Wilson I., Bayne B. 1987 Thermal responses reflect protein turnover in Mytilus edulis L. Funct Ecol 1, 339-351.

54. Rodriguez-Lanetty M., Harii S., Hoegh-Guldberg O. 2009 Early molecular responses of coral larvae to hyperthermal stress. Mol Ecol 18(24), 5101-5114. (doi:10.1111/j.1365-294X.2009.04419.x).

55. Fitt W.K., Gates R.D., Hoegh-Guldberg O., Bythell J.C., Jatkar A., Grottoli A.G., Gomez M., Fisher P., Lajuenesse T.C., Pantos O., et al. 2009 Response of two species of Indo-Pacific corals, Porites cylindrica and Stylophora pistillata, to short-term thermal stress: The host does matter in determining the tolerance of corals to bleaching. $J$ Exp Mar Biol Ecol 373(2), 102-110. (doi:10.1016/j.jembe.2009.03.011).

56. D'Croz L., Mate J.L. 2004 Experimental responses to elevated water temperature in genotypes of the reef coral Pocillopora damicornis from upwelling and non-upwelling environments in Panama. Coral Reefs 23(4), 473-483. (doi:10.1007/s00338-004-0397-7).

57. Brown B.E., Dunne R.P., Warner M.E., Ambarsari I., Fitt W.K., Gibb S.W., Cummings D.G. 2000 Damage and recovery of Photosystem II during a manipulative field experiment on solar bleaching in the coral Goniastrea aspera. Mar Ecol Prog Ser 195, $117-124$.

58. López-Maury L., Marguerat S., Bähler J. 2008 Tuning gene expression to changing environments: from rapid responses to evolutionary adaptation. Nat Rev Genet 9(8), 583-593.

59. Thompson D.M., van Woesik R. 2009 Corals escape bleaching in regions that recently and historically experienced frequent thermal stress. Proc R Soc Lond, Ser B: Biol Sci 276(1669), 2893-2901. (doi:10.1098/rspb.2009.0591).

60. Robison J.D., Warner M.E. 2006 Differential impacts of photoacclimation and thermal stress on the photobiology of four different phylotypes of Symbiodinium (Pyrrhophyta). J Phycol 42(3), 568-579. (doi:10.1111/j.1529-8817.2006.00232.x). 
61. Falkowski P.G., Raven J.A. 1997 Aquatic photosynthesis. Oxford, UK, Blackwell; 375 p.

62. Hill R., Larkum A.W.D., Frankart C., Kuhl M., Ralph P.J. 2004 Loss of functional Photosystem II reaction centres in zooxanthellae of corals exposed to bleaching conditions: using fluorescence rise kinetics. Photosynthesis Res 82(1), 59-72. 


\section{Chapter 3: Coral thermal tolerance: tuning gene expression to resist thermal stress}

\subsection{Abstract}

The acclimatization capacity of corals is a critical consideration in the persistence of coral reefs under stresses imposed by global climate change. The stress history of corals plays a role in subsequent response to heat stress, but the transcriptomic changes associated with these plastic changes have not been previously explored. In order to identify host transcriptomic changes associated with acquired thermal tolerance in the scleractinian coral Acropora millepora, corals preconditioned to a sub-lethal temperature of $3^{\circ} \mathrm{C}$ below bleaching threshold temperature were compared to both non-preconditioned corals and untreated controls using a cDNA microarray platform. After eight days of hyperthermal challenge, conditions under which non-preconditioned corals bleached and preconditioned corals (thermal-tolerant) maintained Symbiodinium density, a clear differentiation in the transcriptional profiles was revealed among the condition examined. Among these changes, nine differentially-expressed genes separated preconditioned corals from non-preconditioned corals, with 42 genes differentially expressed between control and preconditioned treatments, and 70 genes between non-preconditioned corals and controls. Differentially expressed genes included components of an apoptotic signaling cascade, which suggest the inhibition of apoptosis in preconditioned corals. Additionally, lectins and genes involved in response to oxidative stress were also detected. One dominant pattern was the apparent tuning of gene expression observed between preconditioned and non-preconditioned treatments; that is, differences in expression magnitude were more apparent than differences in the identity of genes differentially expressed. Our work revealed a transcriptomic signature underlying the 
tolerance associated with coral thermal history, and suggests that understanding the molecular mechanisms behind physiological acclimatization would be critical for the modeling of reefs in impending climate change scenarios.

\subsection{Introduction}

Coral reefs are of incredible value to human society, with a half billion people dependent on reefs which have been estimated to provide ecosystem services worth $\$ 375$ billion per year $[1,2,86]$. However, this vast resource may be rapidly diminished by coral bleaching, a loss of the mutualistic intracellular dinoflagellates, Symbiodinium, and/or loss of photosynthetic pigments [16], originally described by Glynn in 1984 [87]. First reported in the 1870s [88], massive coral die-off from bleaching is expected to intensify as a result of increases in the magnitude and frequency of warm-water anomalies $[12,15,89]$, the hyperthermal conditions responsible for bleaching. Therefore, the future of the reefs of the world is potentially in peril, with the potential for catastrophic coral bleaching and death resulting in the loss of half of the reefs worldwide in the next 20 to 40 years $[12,14,15,32]$. Corals need to markedly increase their thermal tolerance at a rate of 0.2 to $1.0{ }^{\circ} \mathrm{C}$ per decade by adaptive or acclimative processes [14]. The exploration of physiological limits of corals and underlying molecular signatures is therefore of great importance in predicting the fate of corals in decades to come.

Current models of coral bleaching initiate with thermal- and photo-inactivation of Symbiondinium photosystem II and destruction of photosynthetic pigments by reactive oxygen species (ROS), proceeding to ROS-mediated host cellular damage and initiation of apoptotic pathways $[12,17,20]$. Multiple modes of dinoflagellate symbiont loss have been characterized, including the apoptosis and necrosis of host and symbiont cells [17- 
19], failure of host cell adhesion leading to detachment cells housing symbionts [75], exocytosis [90], and host-mediated autophagy [91].

Prior work on acquired hyperthermal tolerance in reef-building corals has largely focused on the potential for changes in dinoflagellate symbionts [38-40, 42, 92, 93], but a critical consideration in forecasts of the future of reefs as we know them is the role of thermal history and acclimatization to heat stress. Multiple studies have demonstrated the effect of thermal preconditioning on later bleaching susceptibility during natural heat stress events [26, 28, 82, 94, 95] or from experimental mesocosms [24, 34, 96, 97]. Maynard et al. [28] compared the 1998 and 2002 bleaching events on the Great Barrier Reef and found that there was a lower incidence of bleaching in 2002 even though there was higher solar irradiance in the latter event. Moreover, colony mortality in 1998 was not high enough to explain the result via different selection [28]. The effect of thermal preconditioning on subsequent heat stress has previously been demonstrated experimentally on Acropora aspera by Middlebrook et al. [24] in which 48-hour prestress treatments resulted in later resistance to bleaching temperatures, with no loss of symbionts, decrease in photopigments, or drop in quantum yield. Plastic responses to heat following differential histories of stress have been documented to occur even within a colony, in the case of Goniastrea aspera [27]. West faces of colonies suffered prior solar bleaching, which appeared to confer tolerance to heat stress as the west faces resisted bleaching during natural heat stress [27]. Subsequent work by Brown et al. [25] found less photoinhibition in symbionts of the west faces of colonies, along with higher expression of host superoxide dismutase and heat-shock proteins upon thermal challenge. Significantly, though, the response to climate change may be heterogenous across species 
[98].

There is an existing body of literature characterizing the molecular and cellular responses of several coral species to heat stress and bleaching. Gates et al. [75] found an induction of HSP70 after six hours of heat stress in Montastraea franksi, with a subsequent return to control levels with continued stress, followed by a later increase. DeSalvo et al. [99] explored the transcriptome of heat-stressed and bleaching Montastraea faveolata, finding differentially expressed genes with functions involving response to oxidative stress and HSP activity, calcium homeostasis, cell death, cytoskeletal structure, and metabolism. They propose a model in which ROS lead to the generation of reactive nitrogen species, disrupting calcium homeostasis, and with resultant changes in the cytoskeleton and calcification, cell adhesion, and the induction of cell death [99]. DeSalvo et al. [100] also queried the transcriptomic response of Acropora palmata and found similar themes across taxa, noting parallels between differentially expressed genes in response to heat stress in M. faveolata and A. palmata. Genes detected included those with putative roles in molecular chaperones, growth arrest, nucleic acid stabilization, elimination of damaged macromolecules, nitric oxide signaling, and actin cytoskeleton restructuring [100].

In our previous work [96], it was shown that preconditioning Acropora millepora for ten days to temperatures $3^{\circ} \mathrm{C}$ below bleaching threshold conferred thermal tolerance to the corals. This acquired bleaching resistance occurred with no detectable changes in either the Symbiodinium or bacterial communities, as shown by denaturing gradient gel electrophoresis [96]. Altogether, these pieces of evidence suggest that thermal prestress has a role in preventing later bleaching, conferring maintenance of Symbiodinium density. 
These prior results suggest physiological plasticity of one or more members of the coral holobiont (composed of the cnidarian host, Symbiodinium, and prokaryotes [33]) as the mechanism for resistance to bleaching. Our overarching question is whether corals will be able to acclimatize to rising ocean temperatures. To address this question, we asked what are the molecular-level effects that are associated with thermal tolerance, and how this response differs from that of thermal injury. This necessitates the exploration of the molecular underpinnings of thermal tolerance plasticity, as well as thermal injury associated with bleaching. The molecular response of the coral host in thermal-tolerant preconditioned coral holobionts has not been previously characterized. Here we examined the host transcriptomes of both thermal-tolerant and heat-sensitive corals. We also identified thermal preconditioning treatments effective in the rapid acquisition of thermal tolerance for A. millepora. We present the first evidence of the transcriptional response of the host associated with acquired thermal tolerance in A. millepora, along with the profile of thermal injury observed in non-preconditioned corals. Furthering the understanding of the response of corals to heat stress will provide information critical for the conservation of reefs as we know them. For instance, such knowledge will help determine whether corals are acclimatizing, and which corals have the capacity to do so at a rate compatible with their survival in a changing global environment. Genes of interest in acclimatization may be followed-up as potential targets of rapid evolution or epigenetic modification in response to global climate change, potentially answering questions regarding adaptive responses of corals to looming threats. The application of this mechanistic knowledge will prove practical in management plans for conservation of reefs, holding the potential to identify tolerant and at-risk reefs. 


\subsection{Results}

A. millepora coral fragments were exposed to preconditioning treatments, with details regarding the treatment of coral fragments available in the Materials and Methods section. In brief, control treatments $(\mathrm{C})$ were treated only with ambient reef flat temperature water $\left(17^{\circ} \mathrm{C}\right.$ to $\left.25^{\circ} \mathrm{C}\right)$. Sustained-1 treatment (S1) tanks were subjected to ten days of $28^{\circ} \mathrm{C}$ thermal preconditioning prior to a $31^{\circ} \mathrm{C}$ thermal challenge, while sustained2 (S2) treatment was heated to $28^{\circ} \mathrm{C}$ for 17 days prior to exposure to $31^{\circ} \mathrm{C}$ thermal challenge. Pulse-1 (P1) and pulse-2 (P2) treatments were exposed to $28^{\circ} \mathrm{C}$ prestress for 48 hours one- and two weeks prior (respectively) to a $31^{\circ} \mathrm{C}$ thermal challenge. The nonpreconditioned (NPC) treatment was ramped up directly from ambient temperature to thermal challenge temperature. Temperature log data is displayed in Fig. 1.

\subsubsection{Symbiodinium density of corals with and without preconditioning}

The objective of this work is to elucidate differences between heat-sensitive corals and those with acquired thermal tolerance, and we are using bleaching as an indicator of thermal injury. As such, Symbiodinium cell counts were used to quantitatively assess bleaching. In control nubbins exposed to ambient temperatures, Symbiodinium density was relatively constant throughout the course of the experiment, in the range of 1.3-1.6 algal cells $10^{6} \mathrm{~cm}^{-2}$. By day 29 , after 8 days of exposure to water at $31^{\circ} \mathrm{C}$, both coral nubbins that had not been exposed to thermal pre-conditioning (NPC) and those exposed to pulse treatments (P1 and P2) had suffered significant bleaching, Symbiodinium densities having decreased $>70 \%(\mathrm{p}<0.001$, one-way ANOVA with Tukey HSD). By contrast, no significant declines in symbiont density were observed at that time in corals that had been subjected to sustained preconditioning treatments (S1 and S2) 
( $>0.20$, one-way ANOVA with Tukey HSD; Fig. 2).

\subsubsection{Comparison of gene expression levels}

Our intent in applying microarray analyses was to shed light on the transcriptional differences between thermal tolerance and thermal injury. To investigate changes in gene expression associated with thermal tolerance, microarrays were used in a three way comparison between preconditioned (S1), non-preconditioned (NPC) and control (ambient) coral nubbins. Secondly, we explored changes in gene expression associated with thermal injury by comparing NPC and control corals. Note in reference to gene expression results, the terms preconditioned, $P C$, and $S 1$ collectively refer to the 10-day preconditioning treatment. The data discussed in this publication have been deposited in NCBI's Gene Expression Omnibus [101] and are accessible through GEO Series accession number GSE41435

(http://www.ncbi.nlm.nih.gov/geo/query/acc.cgi?acc=GSE41435).

Our microarray analyses detected no differentially expressed genes (FDRadjusted $p<0.05$ ) between treatments on Day 4 (18 days prior to thermal challenge, before any thermal manipulations of S1 or NPC corals) or Day 20 (preconditioned corals had been exposed to $28^{\circ} \mathrm{C}$ prestress for 10 days; meanwhile, non-preconditioned corals were also at $28^{\circ} \mathrm{C}$ en route to $31^{\circ} \mathrm{C}$ thermal challenge). ANOVA and pairwise comparisons of the microarray data identified differentially expressed genes (FDRadjusted $\mathrm{p}<0.05$ ) after two, four, and eight days of thermal challenge. The microarrays contained numerous redundant features, with many ESTs forming single contigs. All redundancies in our dataset were congruent, with gene expression trends in agreement. 
At two days of $31^{\circ} \mathrm{C}$ thermal challenge, 23 genes were differentially expressed between non-preconditioned corals and control corals (10 and 13 up- and down-regulated, respectively), while six genes were differentially upregulated in S1 compared to controls (Fig. 3). At this sampling point, no differences between non-preconditioned and preconditioned treatments were detected by our analyses.

Still prior to visual signs of thermal bleaching and detectable symbiont loss, at four days of $31^{\circ} \mathrm{C}$ thermal challenge 27 genes were differentially expressed between nonpreconditioned corals and control corals (18 up-, nine downregulated), 32 genes showed differences in preconditioned compared to controls (18 up-, 14 downregulated), and one gene was downregulated between preconditioned and non-preconditioned treatments (Fig. $3)$.

With eight days of thermal challenge at $31^{\circ} \mathrm{C}$ the non-preconditioned corals are exhibiting substantial bleaching, with the loss of nearly $80 \%$ of Symbiodinium (Fig. 2). At this point, 70 genes were differentially expressed in comparisons of non-preconditioned to control corals (23 up-, 47 downregulated), 42 differentially expressed between preconditioned and control (19 up-, 23 downregulated), and nine genes identified in the comparison of preconditioned to non-preconditioned treatments (four up-, five downregulated) (Fig. 3).

\subsubsection{Spatial ordination of gene expression}

PCA plots illustrate the spatial relationships of gene expression patterns amongst and between treatments (Fig. 3). The first principal component (PC1) separates preconditioned and non-preconditioned treatments from controls after two, four, and eight days of thermal challenge. After eight days of thermal challenge, when non- 
preconditioned corals are undergoing bleaching, non-preconditioned and preconditioned corals are distinctly different not just in their Symbiodinium density, but also in the ordination of their differential gene expression pattern, as illustrated by their separation on PC2 (Fig. 3c).

\subsubsection{Differentially expressed genes shared across treatments}

Following two days of $31{ }^{\circ} \mathrm{C}$ thermal challenge, there is complete overlap in the identity of genes affected by non-preconditioned and preconditioned treatments during $31^{\circ} \mathrm{C}$ thermal challenge; all genes differentially expressed between S1 and Control are also differentially expressed between NPC and Control (Fig. 3, D-F). However, the overlap of genes involved does not illustrate the full picture, as though the same genes are affected, the magnitude of expression varies considerable (Fig. 3, G-I). There is a much more dramatic response from NPC/Control than from S1/Control both in the number of genes expressed, as well as the magnitude of expression.

After four days at $31^{\circ} \mathrm{C}, 74 \%$ ( 25 genes) of differentially expressed genes are shared between S1/Control and NPC/Control. The number of genes shared between NPC/C and PC/C continues to increases with time, with still more, 34 genes, shared after eight days of thermal challenge.

In all cases of shared, differentially expressed genes between NPC/Control and S1/control, the NPC/Control comparison has higher magnitude (in terms of absolute value) gene expression. The majority of shared genes differ by more than one-fold difference in expression (Fig. 3, G-I). The distinctions between treatments, initially shown by PCA of differentially expressed genes (Fig. 3), are borne out by differences in magnitude of expression, not by gene identity. 


\subsubsection{Gene ontology and enrichment tests}

Blast2GO was used for annotation of EST contigs and to test for enrichment of gene ontology (GO) terms between pairwise comparisons (www.Blast2GO.org; [102]). Tests for enrichment of gene ontology terms found no significantly enrichment GO terms. As previously discussed, much of the differentiation between comparisons was in gene expression magnitude, not the presence or absence of different genes in the MAANOVA result. A test of GO enrichment is unable to elucidate this difference. Additionally, tests for enrichment are hampered by the lack of BLAST hits for $45 \%$ of the differentially expressed genes, precluding their inclusion in enrichment tests.

\subsubsection{Genes involved in thermal injury}

After eight days of thermal challenge at $31^{\circ} \mathrm{C}$, the non-preconditioned corals bleached thoroughly. The differentially expressed genes between these nonpreconditioned and control coral fragments illustrate the transcriptomic response of corals undergoing thermal injury. Our gene ontology analysis was informative for this comparison, with the 45 differentially expressed genes falling into GO IDs including response to oxidative stress, cellular homeostasis, and oxidation/reduction.

Non-preconditioned corals are characterized by a more extreme modulation of many of the same genes differentially expressed in preconditioned corals (Fig. 3).

Notably, after eight days of thermal challenge these bleaching corals showed a marked increase in a heme-binding protein 2-like homolog, permease, glycine-rich RNA binding protein, chorion peroxidase, and a mannose-binding lectin. A decrease in transcripts was identified for homologs of a mannose-binding lectin, ricin b lectin, CD151, universal stress protein, $\mathrm{N} F-\kappa B$ inhibitor, calumenin, group II decarboxylase, and prefoldin 2 . It is 
important to distinguish that the up- and down-regulated mannose-binding lectins represent two distinct gene sequences.

\subsubsection{Gene expression co-occuring with thermal tolerance: Differential expression between preconditioned and non-preconditioned treatments}

The comparison of NPC to S1 transcriptome responses is important as it illustrates differences between bleaching, non-thermal tolerant corals and non-bleaching, thermal-tolerant individuals. At four days of thermal challenge at $31^{\circ} \mathrm{C}$, no corals in the experiment were bleaching, but a single differentially expressed gene between NPC and $\mathrm{S} 1$ preconditioned treatments was detected. This gene, a phosphate carrier protein ortholog, is presumably involved in supplying inorganic phosphate to ATP synthase. Differential expression of phosphate carrier protein has previously been implicated in response to stress, as in the freeze tolerance of the wood frog Rana sylvatica [103].

After eight days of thermal challenge, several genes with stress-relevant ontologies differentiated the NPC treatment from S1. The 2.38-fold increased expression of a mannose-binding lectin in the preconditioned S1 corals over NPC is of great interest. The importance of lectins in symbiosis has been highlighted in previous work, including in adult A. millepora [104] and Pocillopora damicornis [105], as well as in the larvae of Fungia scutaria [106] and A. millepora [78], and in octocorals [107].

A putative ferritin ortholog had more than two-fold higher expression in NPC than in S1 corals. Ferritin is involved in response to oxidative stress, sequestering iron to prevent destructive Fenton reactions [108, 109]. Transcription factor AP-1 exhibits higher expression in preconditioned corals. Among its diverse roles as a transcription 
factor acting in response to stimuli, AP-1 is involved in the gene regulatory response to stress [110].

\subsubsection{Gene expression co-occuring with thermal tolerance: Differential expression between preconditioned and control treatments}

A complementary part of the thermal tolerance story includes changes that separate preconditioned corals and untreated controls from non-preconditioned corals and controls. All differentially expressed genes at two days of thermal challenge in the S1/Control comparison were also differentially expressed between NPC and control corals, but with distinct differences in trend (Fig 3, G-1). While lectin, tyrosine kinase receptor, and follistatin homologs are upregulated in preconditioned corals in reference to controls, these genes are downregulated in non-preconditioned corals.

After fours days of thermal challenge, 32 genes are differentially expressed between S1 and control corals. This set of genes represents considerable overlap with the NPC/control comparison, but with much less change in magnitude, in all cases (Table 1). Two heme-binding protein 2-like orthologs are upregulated in preconditioned corals, as compared to controls. Thymosin beta 4 exhibits slightly increased expression. Two genes coding for ribosomal proteins, ribosomal protein 19 and $r b m 3$ protein, show slightly decreased expression, with the ribosome-associated nascent polypeptide-associated complex subunit alpha also showing decreased expression.

The nine genes detected as differentially expressed between S1/control and not between NPC and control after four days of thermal challenge potentially shed light on changes taking place prior to bleaching. One such gene is an electron transferring alpha polypeptide homolog, upregulated in the preconditioned treatment, with GO terms for 
this sequence including electron carrier activity, binding, and catalytic activity. A chorion peroxidase homolog is downregulated, with associated GO terms including response to stimulus, antioxidant activity, catalytic activity, and electron carrier activity.

After eight days of thermal challenge, 8 genes are unique to the S1/Control comparison. Among these, a rac serine threonine kinase homolog, with associated GO terms including signaling and response to stimulus, also showed increased expression. An upregulated sequence identified as an oxidase peroxidase by GO analysis has a potential role in antioxidant activity. Homologs of zinc finger protein 704 and tyrosine kinase are both downregulated, with potential roles in DNA binding and catalytic activity, respectively.

\subsubsection{Genes differentially expressed across multiple days}

Though the majority of differentially expressed genes vary across days, several are detected at two or more sampling times. An mRNA putatively coding for a glycinerich RNA binding protein was upregulated in NPC/C comparisons after two, four, and eight days of thermal stress. Thymosin beta- 4 shows decreased expression comparison of $\mathrm{NPC} / \mathrm{C}$ on two, four, and eight days of $31^{\circ} \mathrm{C}$ thermal challenge, with the $\mathrm{PC} / \mathrm{C}$ comparison showing a slight decrease after eight days of thermal challenge. Calumenin showed decreased expression in NPC/C comparisons over the course of thermal challenge, but displays an increase in preconditioned corals after eight days of thermal challenge. $N F-\kappa B$ inhibitor is downregulated after four and eight days in both NPC/C and $\mathrm{PC} / \mathrm{C}$ comparisons, but to a much smaller degree in preconditioned corals than in nonpreconditioned. 


\subsection{Discussion}

This is the first work to explore the transcriptional state associated with coral host thermal tolerance acquired by short-term preconditioning. A host molecular signature of bleaching resistance cements the role of the host as a critical factor in the persistence of the holobiont with impending threats of global climate change [111].

We have additionally shown that the duration of thermal preconditioning is critical for its efficacy. Middlebrook et al. [24] showed that $A$. aspera exposed to subbleaching preconditioning for 48 hours one- and two weeks prior to thermal challenge conferred resistance to bleaching and maintenance of thermal efficiency. However, our similarly-preconditioned pulse treatments (P1 and P2) were ineffective, bleaching alongside non-preconditioned corals, while sustained preconditioning (S1 and S2) led to thermal tolerance. These potential differences in effective preconditioning regimens between $A$. millepora and $A$. aspera bring attention to the consideration of physiological differences across species. Species-specific thermal physiologies are important considerations in the long-term management and modeling of coral reefs.

The effect of environmental stress on transcriptome states can be truly remarkable; for instance, in Saccharomyces cerevisiae more than half of the transcriptome is involved in response to environmental changes [112]. Intriguingly, the distantly-related S. cerevisiae and Schizosaccharomyces pombe exhibit a conserved stress response to most stress conditions, with upregulated genes involved in heat-shock, antioxidant roles, carbohydrate metabolism, and energy generation, and a downregulation in growth-related genes [112-114]. In Drosophila melanogaster, over 1200 genes were 
found to be differentially expressed in response to heat stress, and, while the specifics concerning stress responses in yeast and Drosophila differ, both involve common gene ontologies, including carbohydrate metabolism, cellular defense, protein folding, and energy production [115].

Prior investigation from our research group has been performed on the heatstressed larvae of A. millepora, with transcriptome analysis performed using cDNA microarrays [78]. This work showed initial rapid induction of heat shock proteins in heatstressed larvae, along with the decreased expression of a fluorescent protein and a mannose-binding C-type lectin. Curiously, these aposymbiotic larvae did not show detectable induction of genes involved in antioxidant stress response, suggesting that this stress may be associated with corals in symbio [78]. Vidal-Dupiol [105] identified the downregulation of a mannose-binding C-type lectin and a gene involved in calcium processes in Pocillopora damicornis. Using RNA-seq, Meyer et al. [116] also found increased expression of heat shock proteins with short-term heat stress, while observing decreased expression of ribosomal proteins and up-regulation of genes involved in ion transport and metabolism. Amongst these multiple studies, some common patterns fall out: initial upregulation of heat shock proteins in the first several hours of heat stress, then subsiding $[75,78,100]$, with later changes occurring in ribosomal protein expression and calcium transport/homeostasis [99, 105, 116]. Also notably, mannosebinding C-type lectins show decreased expression in response to heat stress across disparate coral taxa $[78,105]$.

We propose a model of thermal tolerance in which the preconditioned coral host exhibits an attenuated transcriptional response, in comparison to the more extreme 
response in gene expression magnitude observed in non-preconditioned corals. It appears that acclimatization prior to thermal challenge prevents an extreme response in transcriptional magnitude, as indicated by the preponderance of co-differentially expressed genes between non-preconditioned/control and preconditioned/control comparisons, differing largely by magnitude of expression (Fig. 3 G-I).

Such drastic differences between non-preconditioned and preconditioned treatments (both in comparison to control) may represent compensation and repair on the part of damaged non-preconditioned coral. We may be observing a transcriptome overwhelmed. Notably, in this experiment, we were unable to detect changes occurring at $28^{\circ} \mathrm{C}$. A dramatic stress, thermal challenge at $31^{\circ} \mathrm{C}$, was required to produce detectable differential gene expression between treatments. The explanation for this could be either biological or technical; it could be indicative of the role of post-transcriptional gene regulation at lower levels of stress, or could represent technical limits of the experiment.

Many of the gene expression changes observed were of small magnitude, particularly in the preconditioned, thermal-tolerant corals. Small changes in gene expression have previously been shown to be of physiological relevance, as in the case of precocious sexual maturation in the brains of salmon [117]. In the case of handling stress on trout, it has been found that the majority of stress-response genes exhibit small or moderate changes in expression [118]. Acquired thermal tolerance via preconditioning may be a case of physiological fine-tuning on the part of the host, not massive transcriptional changes of large magnitude.

\subsubsection{Lectins implicated in thermal tolerance}

We detected the differential expression of several lectins over the course of the 
experiment (Table 1). Most strikingly, a mannose-binding lectin (C_mge-C003-G2pre14_T3) was upregulated 2.83-fold in preconditioned corals after eight days of thermal challenge, compared to bleaching, non-preconditioned corals. Lectins have been shown to be critical in the recognition and onset of Cnidarian-algal symbioses, as in the work of Wood-Charlson et al. [106] on the coral Fungia scutaria and even earlier in Hydra viridis [119]. A mannose-binding lectin termed Millectin, isolated from A. millepora, has been show to bind to both Symbiodinium and pathogens [104]. Later on, Rodriguez-Lanetty et al. [78] showed that a homolog of Millectin in A. millepora larvae was down-regulated with thermal stress. Similarly, Vidal-Dupoil et al.[105] also identified a mannose-binding lectin in Pocillopora damicornis which is downregulated in association with thermal stress. Our results add to the body of work implicating lectins in the symbiosis, suggesting a role in thermal tolerance. The maintenance of a mannose-binding lectin may be important in the stability of coral-dinoflagellate symbiosis under duress.

\subsubsection{Heme-binding proteins, ferritin, and iron-induced oxidative injury}

Heme-binding proteins follow a pattern of expression in which they are upregulated in both non-preconditioned as well as preconditioned corals after four and eight days of thermal challenge. Though both experimental treatments show higher expression than controls, expression is generally higher in non-preconditioned treatments than in preconditioned treatments. After eight days of thermal challenge, ferritin expression was 2.50 -fold higher in non-preconditioned corals than in the preconditioned treatment. These events may be indicative of response to iron-induced oxidative injury.

Superoxide formed by the breakdown of Photosystem II under heat stress and 
resultant damage to host mitochondria [17] is converted to hydrogen peroxide. If the resultant hydrogen peroxide is not processed by antioxidant systems, hydrogen peroxide can undergo iron-catalyzed cleavage to the extremely reactive hydroxyl radical [120]. This process, the Fenton reaction, can be circumvented by the sequestration of iron [120]. Both heme-binding proteins and ferritin can fulfill this role of iron sequestration [121]. As such, heme-binding proteins may be an important part of the response of corals to heat stress, as indicated by upregulation in both preconditioned corals, as well as in nonpreconditioned corals prior to and during bleaching.

Ferritins are involved in response to oxidative stress and in iron homeostasis [122]. Ferritin expression upregulation, in the case of our experiment, is associated with bleaching and not thermal tolerance, possibly indicating a loss of stasis and dramatic response on the part of the host. Differential expression of ferritin has previously been reported in several other experiments of coral heat stress [78, 99, 123-125]. Additionally, the work of Schwarz et al. [126] indicates that ferritin appears to be undergoing adaptive evolution in A. millepora and A. palmata.

\subsubsection{Transcription Factor AP-1, NF-кB inhibitor, and their role in apoptosis}

The transcription factor AP-1 is a regulator of diverse cellular processes, including cell survival as well as death [127]. This gene, upregulated more than two-fold in preconditioned corals, may play a role in thermal tolerance.

Together, these two early response genes illustrate a hypothesis previously proposed using mammalian cells [128]. The early response genes comprising the AP-1 and NF- $\mathrm{NB}$ transcription factors are induced by environmental stress and thought to modulate responses to injury processes through the induction of target genes. Mattson et 
al. [128] showed that the DNA-binding of AP-1 and NF- $\kappa \mathrm{B}$ are associated with changes in the cellular redox environment.

In one model of cnidarian bleaching, heat and light stress lead to hydrogen peroxide from the host and symbiont, as well as superoxide from damaged host

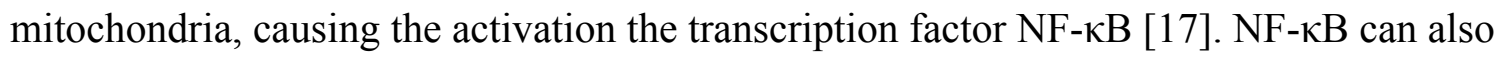
be activated by signals including p53 [129] and TNF-alpha [130]. NF- $\kappa \mathrm{B}$ can then directly activate apoptotic processes, or cause the upregulation of nitric oxide synthases, initiating a cascade also culminating in apoptosis [17]. The work of DeSalvo et al. [100] supports the involvement of $N F-\kappa B$ in coral bleaching, detecting the upregulation of two $N F-\kappa B$ pl05 homologs in thermal stress experiments in A. palmata.

In mammalian cells, heat stress can affect the function NF- $\kappa$ B by inhibiting the translocation of NF- $\mathrm{NB}$ to the nucleus. This sequestration of NF- $\kappa \mathrm{B}$ from the nucleus is believed to be facilitated by NF- $\kappa \mathrm{B}$ inhibitor $(\mathrm{I} \kappa \mathrm{B} \alpha)$, trapping NF- $\kappa \mathrm{B}$ in the cytoplasm. Heat stress can both prevent the degradation of functional $\mathrm{I} \kappa \mathrm{B} \alpha[131]$ and trigger an increase in mRNA expression of $I \kappa B \alpha[132,133]$.

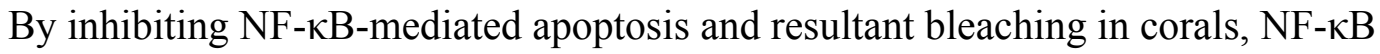
inhibitor has the potential to be a critical factor in host thermal tolerance and acclimatization. Our results suggest this, with $N F-\kappa B$ inhibitor expression lower in nonpreconditioned corals than in preconditioned corals both prior to bleaching in nonpreconditioned corals after four days of thermal stress, as well as while bleaching was underway, after eight days of thermal challenge.

From work on A. millepora, Pernice et al. [134] propose a model in which thermal stress activates caspase- 3 dependent apoptosis in cells destined for destruction, with a 
concurrent increase in expression of an anti-apoptotic $B c l-2$ ortholog in surviving cells. Similarly, Kvitt et al. [135] identify a putative anti-apoptotic gene in Stylophora pistillata, StyBcl-2, coexpressed with a caspase during thermal stress.

By experimentally blocking the apoptotic pathway with a caspase inhibitor, Tchernov et al. [136] demonstrated the apparent protection from bleaching of thermallychallenged corals. We propose that the initiation of an inhibitor of NF- $\mathrm{kB}$ may similarly act to arrest the apoptotic cascade, preventing bleaching, as observed in preconditioned corals in this experiment.

\subsubsection{Thymosin as an antioxidant and the role of tyrosine kinase receptor in response to oxidative stress}

Originally proposed to be a thymic hormone [137], thymosin beta-4 is the main actin sequestering protein in cells, preventing its polymerization [138]. It has other, diverse roles in cells, including cell proliferation and regeneration, and anti-inflammatory activities [137]. Recently, thymosin beta-4 has been experimentally shown to increase antioxidant and anti-apoptosis gene response in murine cells challenged with oxidative stress [139]. Thymosin beta-4 shows decreased expression in non-preconditioned corals throughout the thermal challenge, with a slight decrease in expression in preconditioned corals only occurring after eight days of thermal challenge. Its role in corals is as-yet unknown, but it could potentially be involved in cell survival.

After two days of $31^{\circ} \mathrm{C}$ thermal challenge, a putative tyrosine kinase receptor was downregulated in the NPC treatment and slightly upregulated in the PC treatment, in comparison to controls. The occurrence of this differential expression prior to the onset of bleaching is suggestive of a potential regulatory 
role in symbiosis. Importantly, work in other systems has show that tyrosine kinase receptors respond to oxidants [140-142].

\subsubsection{Calumenin and cnidarian/dinoflagellate symbiosis}

Though the precise role of calumenin in cnidarian/dinoflagellate symbiosis has not been elucidated, calumenin is the most upregulated gene of the symbiotic state in Anemonia viridis, with multiple paralogs and cnidarian-specific duplications [143]. Additionally, calumenin is preferentially expressed in the endoderm of $A$. viridis, the tissue layer harboring dinoflagellate symbionts [143]. It is downregulated in NPC, decreasing in expression throughout thermal challenge (Table 1). In contrast, calumenin shows no significant decrease in expression in preconditioned corals, but is instead upregulated after eight days of thermal challenge, in comparison to controls (Table 1). The role of calumenin in symbiosis is unclear. Ganot et al. [143] suggest that calumenin is involved in host/symbiont recognition, through its regulation of Sym32. Calumenin belongs to the CREC protein family, a group of $\mathrm{Ca}^{2+}$-binding proteins with diverse cellular functions [144]. Previous work suggests the breakdown of a cellular calcium exclusion system as component of coral bleaching $[37,145,146]$. The upset of calcium homeostasis is also well-established as an apoptotic trigger [147], an important consideration given that apoptosis of host cells is one proposed mechanism of cnidarian bleaching [17]. Overexpression of calumenin in thermal-tolerant corals and decreased expression during bleaching may therefore be involved in host/symbiont signaling, calcium homeostasis, or in apoptosis.

\subsubsection{Absence of differentially expressed $h s p s$}

This experiment did not detect differential expression of heat shock proteins in 
any treatments at any time point. Similarly, several studies examining thermal stress have not detected an upregulation of $h s p 70$ transcripts. Desalvo et al. [99] did not detect the upregulation $h s p 70$ after 24 hours of thermal stress in M. faveolata, while Mayfield et al. [148] also found no differential expression of hsp 70 in Seriatopera hystrix after 48 hours of heat stress. Voolstra et al. [125] identified no differentially expressed hsps after either 12 or 48 hours of heat stress in M. faveolata. It is possible that our sampling times following preconditioning and bleaching-threshold heat stress were not early enough to capture expression changes, as a heat shock protein transcriptional increase may have occurred but returned to normal levels in the 34.5 hour timespan between temperature increase and sampling. This interpretation is supported by Rodriguez-Lanetty et al. [78] in which transcriptional induction of $h s p 70$, hsp90, and gp96 in A. millepora larvae was detected after just three hours of exposure to heat. However, previous work on protein expression rather than mRNA has shown the rapid induction of heat shock proteins occurs in several corals species $[37,75,149,150]$.

Alternatively, biological variability leading to high variance between replicates may mask detection in this experiment. The differential expression of 488 unigenes between colonies in a common garden experiment with A. millepora calls attention to this potential explanation [151]. Notably, $H s p 70$ and catalase were among the differentially expressed genes [151]; clearly, intercolony variability in gene expression must be a consideration, and may affect the detection ability of a thermal stress experiment.

Prior work in M. faveloata by Desalvo et al. [152] found that host transcriptomic states are associated with the type of symbiont occupying the host. This is not the case in the present work, as our previous work detected no shift in symbiont type [96], and 
sampling for the experiment at hand occurred in tandem with the aforementioned work.

Microarray results from samples collected Day 4 and Day 20 of the experiment revealed no differentially expressed genes. This is not a surprising result for Day 4, as no thermal manipulations occurred at that time on treatments assayed by microarray analysis.

On Day 20, however, the S1 treatment had been preconditioned for 10 days and no changes in gene expression were detected. One potential explanation for this is that transcriptional changes during preconditioning were below the threshold of detection of the microarrays used for this experiment.

\subsubsection{The Importance of understanding acclimatization}

An understanding of the physiology surrounding coral thermal history and associated tolerance is critical for the modeling of reefs in impending climate change scenarios. These projections will be invaluable in management strategies for the preservation of reefs. Biomarkers of coral health and stress have previously been developed (e.g. [153-155]), but markers of coral health from studies considering thermal history and indicative of resultant physiological plasticity must be implemented. This will allow the identification of at-risk, non-preconditioned coral populations for the enactment of management plans.

While phenotypic plasticity is in and of itself a critical piece of the capacity corals to cope with increasing environmental stressors, the interplay of differential gene expression and adaptation provides additional potential for the future of reefs. For instance, a transgenerational memory of stress has been shown in Arabidopsis thaliana, with the supposition that the genomic interactions of epigenetic processes may increase the likelihood of adaptation [156]. There is evidence that, in Escherichia coli, stress itself 
begets mutation, providing variation for natural selection to act upon [157]. Stress response genes tend to be associated with TATA boxes, with important repercussions [158]. TATA-containing genes tend to have a higher evolutionary lability, being more susceptible to mutation and regulated by more transcription factors than TATA-less genes [158].The elucidation of the interplay of stress, acclimatization and plasticity, and adaptation will become important under global climate change.

\subsection{Methods}

\subsubsection{Coral collection, husbandry, and thermal stress treatments}

Collection of materials for downstream gene expression analysis was conducted in tandem with work reported in Bellantuono et al. [96], where temperature profile records are included. A. millepora branches $6-8 \mathrm{~cm}$ in length were cut from colonies on the reef flat in the vicinity of Heron Island (GBR), Queensland, Australia $\left(23^{\circ} 33^{\prime} \mathrm{S}\right.$, $151^{\circ} 54^{\prime} \mathrm{E}$ ) in June 2009 . Colonies used for collection were previously genotyped for the presence of a carbonic anhydrase intron, and were confirmed to be of one type [151]. Branches were embedded in marine epoxy in cut-off $15-\mathrm{ml}$ centrifuge tubes. Onehundred fifty coral fragments for use in gene expression analysis and 168 fragments for assessing Symbiondinium density were allowed to recover for 20 days prior to the beginning of temperature manipulations.

The experiment was carried out in independently-heated $15 \mathrm{~L}$ tanks operated as open systems, receiving unfiltered seawater from nearby reef flat via a flowing seawater system at a rate of 0.3 to 0.4 liters/minute, with additional flow provided by 250 liter/hour submersible pumps. Temperatures manipulations tanks were controlled with independent heaters. Fragments were randomly assigned to one of six treatments, with four replicate 
tanks for each treatment. Each tank contained 16 coral fragments, originating from multiple colonies. Colony was not considered a factor in our experimental design. Control treatments $(\mathrm{C})$ received ambient water $\left(17^{\circ} \mathrm{C}\right.$ to $\left.25^{\circ} \mathrm{C}\right)$ with no temperature manipulation. The sustained-1 treatment (S1) tanks were heated to $28^{\circ} \mathrm{C}$ for ten days prior to being ramped up to $31^{\circ} \mathrm{C}$. The sustained-2 (S2) treatment was heated to $28^{\circ} \mathrm{C}$ for 17 days prior to the increase to bleaching threshold. Pulse-1 (P1) and pulse-2 (P2) were heated to the prestress temperature for 48 hours one- and two weeks (respectively) prior to the ramp up to bleaching threshold temperature. The non-preconditioned (NPC) treatment was ramped up directly from ambient temperature to bleaching threshold temperature. Tank temperatures were ramped from $1-2^{\circ} \mathrm{C}$ per day, with temperature changes taking place at 06:30. Ambient water temperature was a mean of $21.4^{\circ} \mathrm{C}$ ( standard deviation $=1.6^{\circ} \mathrm{C}$ ). The total length of the experiment was 29 days; the thermal challenge portion of the experiment comprised the final eight days with the final 8 days at bleaching threshold (mean bleaching treatment $=31.0^{\circ} \mathrm{C}$, standard deviation $=0.6^{\circ} \mathrm{C}$ ). The experimental system was covered with transparent plastic sheets during heavy precipitation. Tanks were covered with shade cloth from 11:00-15:00 daily to simulate light attenuation due to high tide and maintain temperature stability.

\subsubsection{Symbiodinium density}

To assess bleaching, coral fragments were collected from each treatment at 17:00 on days $0,4,11,17,23,27$, and 29 . One fragment was sampled from each tank replicate $(n=4)$. For the determination of Symbiodinium densities per surface area, cell counts were performed using a Neubauer improved haemocytometer (Hirschmann Laborgeräte), with coral area assessed by a wax coating method [52]. 


\subsubsection{RNA extractions}

One coral nubbin was collected at 17:00 from each experimental and control tank for RNA extractions and immediately frozen in liquid nitrogen on Day 4 (18 days prior to thermal challenge), Day 20 (at which point preconditioned corals had been exposed to $28^{\circ} \mathrm{C}$ prestress for 10 days and non-preconditioned corals were also at $28^{\circ} \mathrm{C}$ en route to $31^{\circ} \mathrm{C}$ thermal challenge), and after two (Day 23), four (Day 25), and eight days (Day 29) of $31^{\circ} \mathrm{C}$ thermal challenge.

The topmost $0.5 \mathrm{~cm}$ of frozen coral nubbins were clipped and discarded using chilled bone cutters, and subsequently coral fragments $\sim 0.8 \mathrm{~cm}$ in length were cut. These fragments were crushed, and the frozen powder was transferred to Trizol Reagent (Invitrogen) and homogenized. Trizol RNA extraction protocol was followed as per manufacturer's protocol through phase separation, at which point the aqueous layer was recovered by pipetting, gently mixed with an equal volume of absolute ethanol, and further cleaned with an RNeasy Mini kit (QIAGEN). RNA was quantitated using a NanoDrop ND-1000 UV-Vis Spectrophotometer (Nano-Drop Technologies), and integrity was assessed by electrophoresis on 1.25\% MOPS-agarose gels (EmbiTec).

\subsubsection{Microarray hybridization}

Only RNA samples from control, NPC, and S1 were analyzed by microarray hybridization. These treatments were chosen as the S1 treatment (10 days of preconditioning at $28^{\circ} \mathrm{C}$ ) exhibited acquired thermal tolerance, with non-preconditioned treatments providing for valid comparisons to corals with thermal injury, and controls allowing for comparison with corals not subjected to stress treatments. Three biological replicates of each treatment/sampling time combination were assayed. The cDNA 
microarrays implemented in experiments are third generation arrays for A. millepora, produced jointly by the Australian National University and James Cook University. Each microarray possesses 18,124 features, representing as many cDNA clones $[159,160]$. Arrays for this experiment were manufactured in a single batch and randomly selected for each hybridization.

A reference design was chosen for this experiment due to its size and multiple treatments. RNA from all samples was mixed to make a reference sample. Complementary DNA was synthesized from $650 \mathrm{ng}$ total RNA as per Array 900 kit protocol (Genisphere) using SuperScript III reverse transcriptase (Invitrogen). Reference cDNA samples were synthesized using primers for downstream capture by Cy3; experimental samples were synthesized using primers for downstream capture by Cy5. Hybridizations were performed with formamide-based hybribization buffer (Genisphere) under mSeries LifterSlips (Thermo Scientific). Arrays were prehybridized with $1 \mu \mathrm{g}$ Human Cot-1 DNA for 90 minutes. Hybridization with cDNA was performed for 16 hours at $47^{\circ} \mathrm{C}$. Arrays were washed in $65^{\circ} \mathrm{C} 2 \mathrm{xSSC} / 0.2 \%$ SDS for 15 minutes, $2 \mathrm{x} \mathrm{SSC}$ at room temperature for 15 minutes, and $0.2 \mathrm{xSC}$ at room temperature for 15 minutes. Dye capture with Array 900 3DNA capture reagents (Genisphere) was performed at $50^{\circ} \mathrm{C}$ for 4 hours, using the aforementioned stringency washes. Following the final stringency washes, dried arrays were dipped in DyeSaver II (Genisphere). Immediately prior to scanning, each array was polished with a toluene / acetone solution (3:1, v/v) and drying by centrifugation. Arrays were scanned on a GenePix Personal 4100A (Axon Instruments) microarray scanner; initial quality control, gridding, and raw data export were performed using GenePix Pro 4.1. 


\subsubsection{Microarray Analysis}

Data were quality-filtered and reduced to 5000 features in order to eliminate spots below the noise window. Background-subtracted mean intensity values were log- and lowess-transformed using R/Maanova version 1.18 [161]. A fixed-effect ANOVA model was fit to the normalized data. Empirical-Bayes Fs statistic [162] was used to test for differentially expressed genes at each sampling time. P-values for each clone were calculated from 500 permutations of residual shuffling. John Storey's method for false discovery rate adjustment [163] was implemented, using an adjusted p-value threshold of less than 0.05 . For pairwise comparisons, T-tests were performed within MAANOVA for the identification of significant interactions within sampling points, using a jsFDRadjusted p-value cutoff of less than 0.05 . To explore patterns present in the multidimensional gene expression data, principal component analysis (PCA) was performed using R version 2.10.0 [61]. Blast2GO was used to annotate genes and to test for enrichment of particular functional groups between treatments (www.Blast2GO.org; [102]). 


\subsection{Acknowledgements}

We would like to thank Dr. Paulina Kaniewska, Alison Darling, Dr. Nela Rosic, Rachel Middlebrook, and the staff of the Heron Island Research Station for their aid in the field and laboratory work for this project. We also thank Tanya Brown and Scott Revell for their comments on early versions of this manuscript. This research was funded by an NSF-OCE grant (0851123) awarded to Mauricio Rodriguez-Lanetty. 


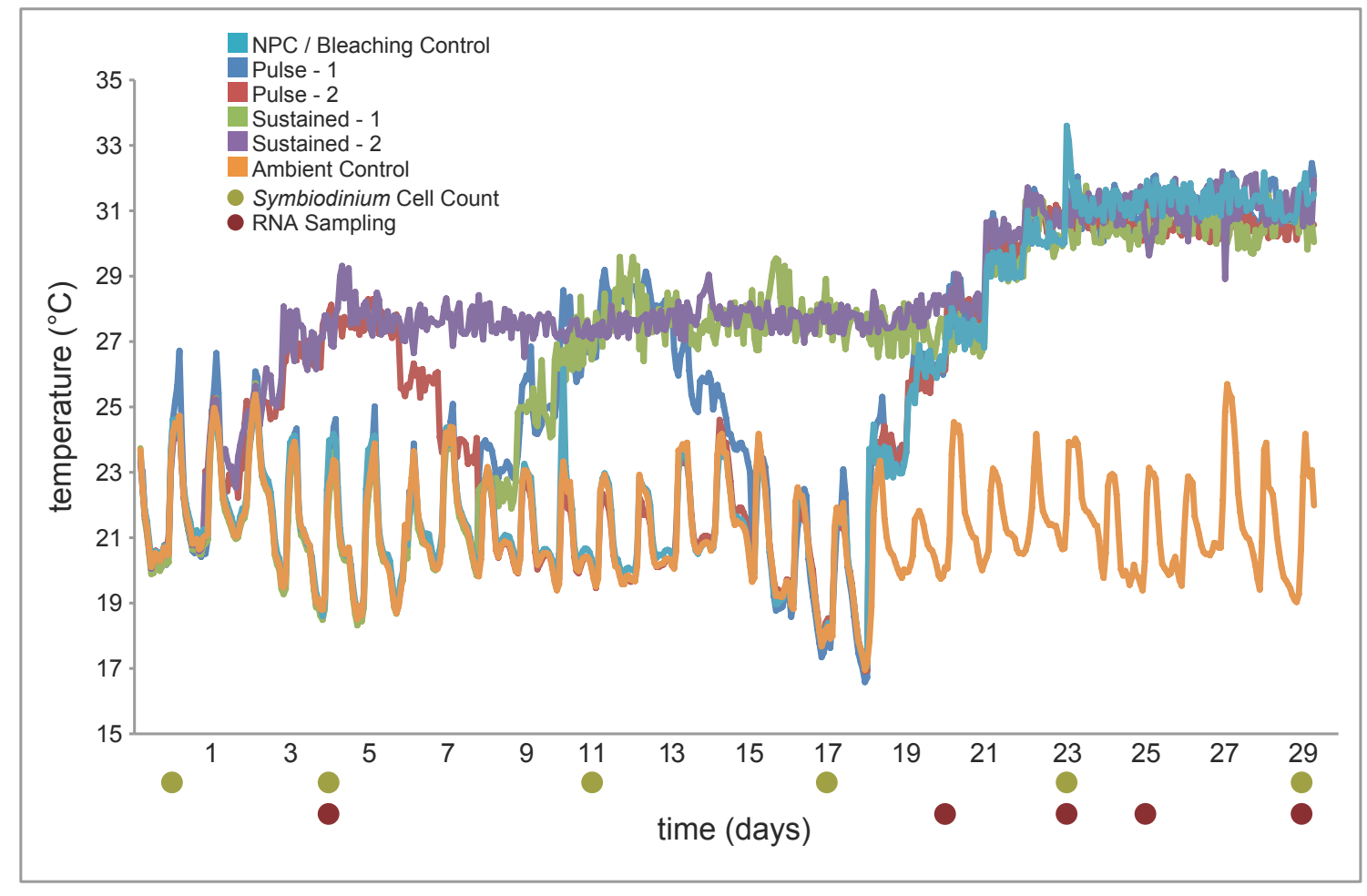

Figure 1. Temperature profiles of the thermal treatments to which Acropora millepora fragments were exposed. Non-preconditioned (NPC) treatment with no pre-stress period prior to exposure to $31^{\circ} \mathrm{C}$. Pulse $-1(\mathrm{P} 1)$ treament was exposed to a 2 -day $28^{\circ} \mathrm{C}$ prestress and returned to ambient temperature for 1 week prior to thermal challenge.

Sustained -1 (S1) treatment was exposed to 10 days of $28^{\circ} \mathrm{C}$ prestress. Sustained -2 treatment was exposed to 14 days of $28^{\circ} \mathrm{C}$ prestress. Pulse $-2(\mathrm{P} 2)$ treament was exposed to a 2 -day $28^{\circ} \mathrm{C}$ pre-stress and returned to ambient temperature for 2 weeks prior to thermal challenge. Sustained -2 treatment was exposed to 14 days of $28^{\circ} \mathrm{C}$ prestress. Ambient control (C) treatment was not challenged with any increase in temperature. This figure expands upon a smaller dataset originally published by Bellantuono et al. [96]. 


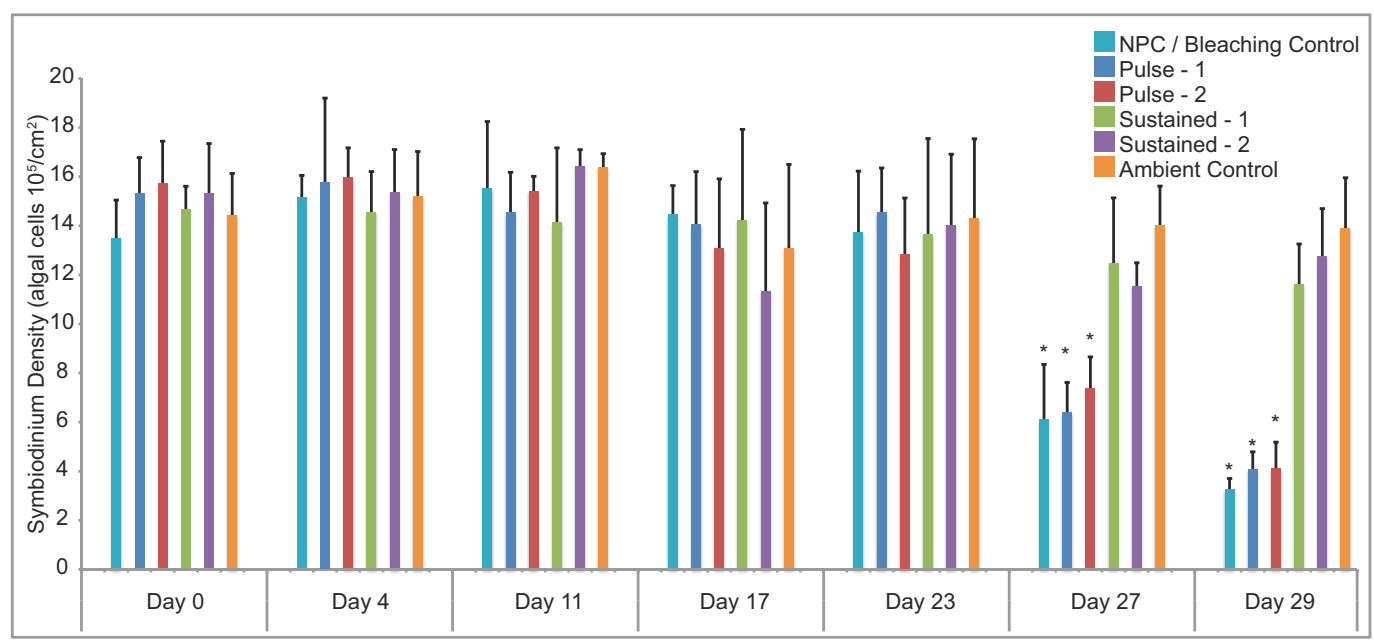

Figure 2. Symbiodinium density (algal cells per square centimeter). Resident Symbiodinium densities at 6 sampling times throughout the course of the experiment; days 23,27 , and 29 represent 2,6 , and 8 days of exposure to $31^{\circ} \mathrm{C}$. Asterisks indicate group is significantly different from controls $(\mathrm{p}<0.001$, one-way ANOVA with Tukey $\mathrm{HSD}, \mathrm{n}=4)$. A portion of the data presented in this figure was analyzed previously by Bellantuono et al. [96]. 


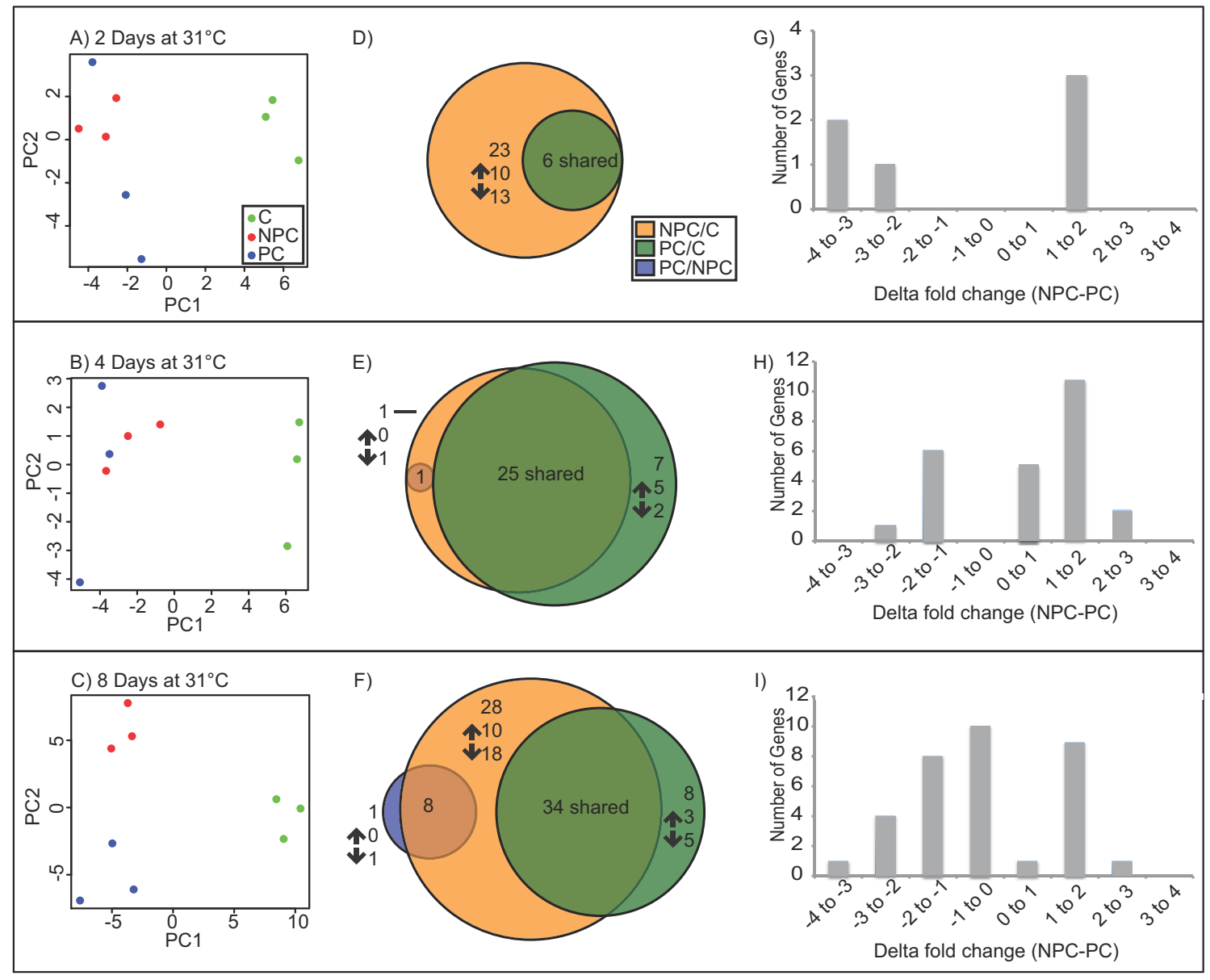

Figure 3. Microarray expression data. Rows A, B, and C represent gene expression from NPC, S1, and C treatments following 2,4 , and 8 days of $31^{\circ} \mathrm{C}$, respectively. Left column contains principal component analysis plots of differentially expressed genes. Center column pie chart illustrated the number and trend of differentially expressed genes, with overlaps indicating differentially expressed genes detected across treatments. Column right indicates fold change differences between shared differentially expressed genes NPC and S1 treatments, both in reference to control. 


\begin{tabular}{|c|c|c|c|c|}
\hline \multicolumn{5}{|l|}{2 days at $31^{\circ} \mathrm{C}$} \\
\hline Contig & Annotation (BLAST) & NPC-C & PC-C & PC-NPC \\
\hline S_D021-H11_88 & ---NA--- & 2.11 & 0.21 & \\
\hline $\begin{array}{l}\text { S_mge-C003-A11- } \\
\text { pre80_T3 }\end{array}$ & ---NA--- & 1.85 & 0.49 & \\
\hline C_G031-H09.b1.ab1 & $\begin{array}{l}\text {--NA--- } \\
\text { rac serine threonine }\end{array}$ & 1.68 & & \\
\hline $\begin{array}{l}\text { S_D034-C10_75 } \\
\text { S_MGE-A050-C7- }\end{array}$ & kinase & 1.29 & & \\
\hline post50-T3 & $\begin{array}{l}\text {---NA--- } \\
\text { glycine-rich rna binding }\end{array}$ & 1.22 & 0.15 & \\
\hline $\begin{array}{l}\text { C_D016-D12_92 } \\
\text { C_mge-A040-H12- }\end{array}$ & protein & 1.20 & & \\
\hline $\begin{array}{l}\text { post95- } \\
\text { C_MGE-B015-H7- }\end{array}$ & ---NA--- & 1.04 & & \\
\hline prawn55_ & ---NA--- & 0.91 & & \\
\hline $\begin{array}{l}\text { S_mge-B034-F3- } \\
\text { prawn21_T3 }\end{array}$ & $\begin{array}{l}\text { na }+k+\text { atpase alpha } \\
\text { subunit }\end{array}$ & 0.76 & & \\
\hline $\begin{array}{l}\text { C_mge-Ā047-G3-post22- } \\
\text { T }\end{array}$ & $\begin{array}{l}\text { collagen alpha-1 chain } \\
\text { lysosomal membrane }\end{array}$ & 0.69 & & \\
\hline C_D021-H3_24 & glycoprotein 2 & -0.52 & & \\
\hline $\begin{array}{l}\text { S_D047-G9_71 } \\
\text { C_mge-C011-F7- }\end{array}$ & ---NA--- & -0.84 & & \\
\hline $\begin{array}{l}\text { pre53_T3 } \\
\text { S D004-H4 }\end{array}$ & thymosin beta 4 & -1.05 & & \\
\hline $\begin{array}{l}\text { S_D004-H4 } \\
\text { C_mge-A044-E12- } \\
\text { post92- }\end{array}$ & $\begin{array}{l}\text {---NA--- } \\
\text { calumenin precursor }\end{array}$ & -1.18 & & \\
\hline S_D022-E7_53 & ---NA--- & -1.74 & & \\
\hline $\begin{array}{l}\text { S_D019-D4_28 } \\
\text { S_MGE-A034-H6- }\end{array}$ & ---NA--- & -1.74 & & \\
\hline $\begin{array}{l}\text { post47-T3 } \\
\text { C_MGE-C019-A5- }\end{array}$ & ---NA--- & -2.05 & & \\
\hline pre32_T3 & tyrosine kinase receptor & -2.25 & 0.13 & \\
\hline C_D004-A11 & lectin & -2.27 & 1.44 & \\
\hline S_D015-F4_30 & ---NA--- & -2.36 & & \\
\hline C_D016-C4_27 & follistatin & -2.52 & 1.01 & \\
\hline S_D033-B12_90 & ---NA--- & -2.84 & & \\
\hline \multicolumn{5}{|l|}{4 days at $31^{\circ} \mathrm{C}$} \\
\hline Contig & $\begin{array}{l}\text { Annotation (BLAST) } \\
\text { heme-binding protein 2- }\end{array}$ & NPC-C & PC-C & PC-NPC \\
\hline C_D035-H1_8 & like & 3.07 & 0.85 & \\
\hline S_GS01WG04.b1.ab1 & ---NA--- & 2.26 & 0.15 & \\
\hline C_X001-E7_53 & $\begin{array}{l}\text {---NA--- } \\
\text { heme-binding protein 2- }\end{array}$ & 2.1 & 0.52 & \\
\hline C_D037-C12_91 & $\begin{array}{l}\text { like } \\
\text { glycine-rich rna binding }\end{array}$ & 2.03 & 0.44 & \\
\hline C_D016-D12_92 & protein & 1.8 & -0.1 & \\
\hline S_D021-H11_88 & ---NA--- & 1.78 & 0.19 & \\
\hline C_D040-B2_10 & rbm3 protein & 1.74 & -0.14 & \\
\hline C_mge-A042-G6-post46- & sodium potassium & 1.54 & 0.58 & \\
\hline
\end{tabular}




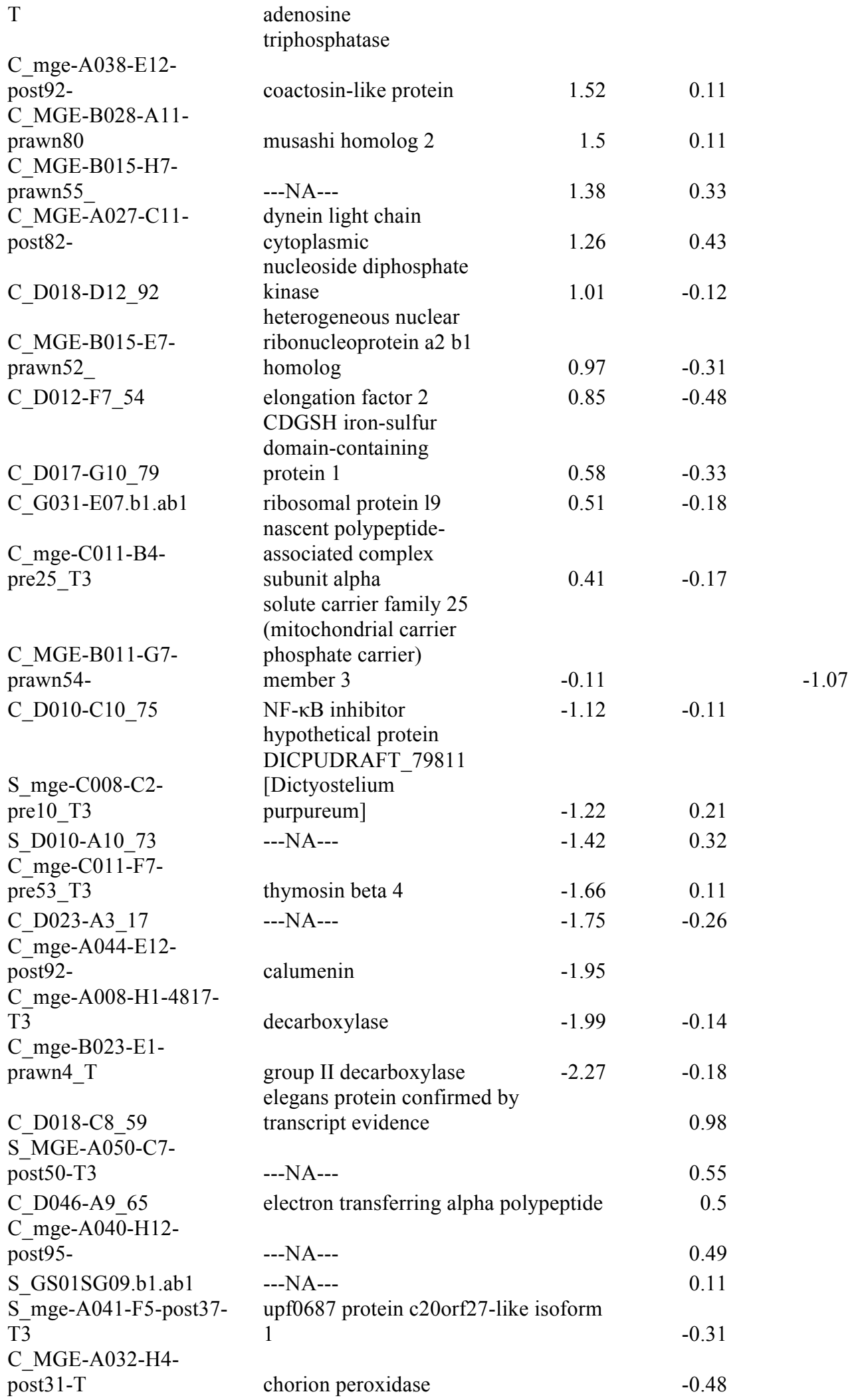




\section{8 days at $31^{\circ} \mathrm{C}$}

\section{Contig}

C_D035-H1_8

C_D018-C8_59

S_D021-H11 88

C MGE-B015-H7prawn55

C_X001-E7_53

C_G028-C04.b1.ab1

C_mge-C016-D4-

pre27_T3

C D016-D12 92

C_D003-E7

C_D012-A7_49

C_MGE-A032-H4post31-T

S_mge-C003-F9-

pre69_T3

C_mge-B017-G2-

prawn14

S_mge-A047-F6-post45-

T3

C_MGE-A050-D1-post3$\mathrm{T} 3$

C_MGE-A020-E4-

post28-T

C_MGE-A027-C11post82-

C mge-C012-G9-

pre70_T3

C_D049-C11_83

C_D028-B5_34

C D027-D7 52

C_mge-C003-A1pre0_T3

S D004-B9

C_mge-B035-C5prawn34

S_D008-A9

C D009-C9

C_MGE-C019-E2pre12_T3

S D030-E4 29

C mge-C001-G2-

pre14_T3

S_MGE-A018-E7-

post52-T3

C mge-C004-H9-

pre71_T3

C_D011-C4_27
Annotation (BLAST)

heme-binding protein 2-

like

permease

---NA---

---NA---

---NA---

mannose-binding lectin

---NA---

glycine-rich rna binding

protein

glutamine synthetase

succinate- gdp- alpha

subunit

chorion peroxidase or

animal haem peroxidase

---NA---

atp:adp antiporter

---NA---

potential c-type lectin

(XP 002087457)

fibrinogen-related

domains

dynein light chain

cytoplasmic

NPC-C

PC-C

PC-NPC

3.02

1.41

2.71

1.15

2.62

0.43

1.84

0.29

1.71

0.7

1.59

1.4

0.16

1.15

0.1

1.12

0.1

1.05

1.05

1.03

0.41

0.98

$-0.12$

0.94

0.93

$-0.24$

0.87

0.82

---NA---

0.78

---NA---

0.26

0.25

0.23

---NA---

0.23

UBX domain-containing protein 7

0.2

14-3-3 protein

$-0.13$

ltv1 homolog

$-0.13$

transcription factor ap-1

$-0.18$

---NA---

$-0.18$

---NA---

$-0.36$

ferritin

$-0.4$

---NA---

$-0.41$

ribosomal protein $137 \mathrm{a}$

$-0.43$
0.71

$-0.83$

2.38

0.71

$-0.46$
$-0.46$ 


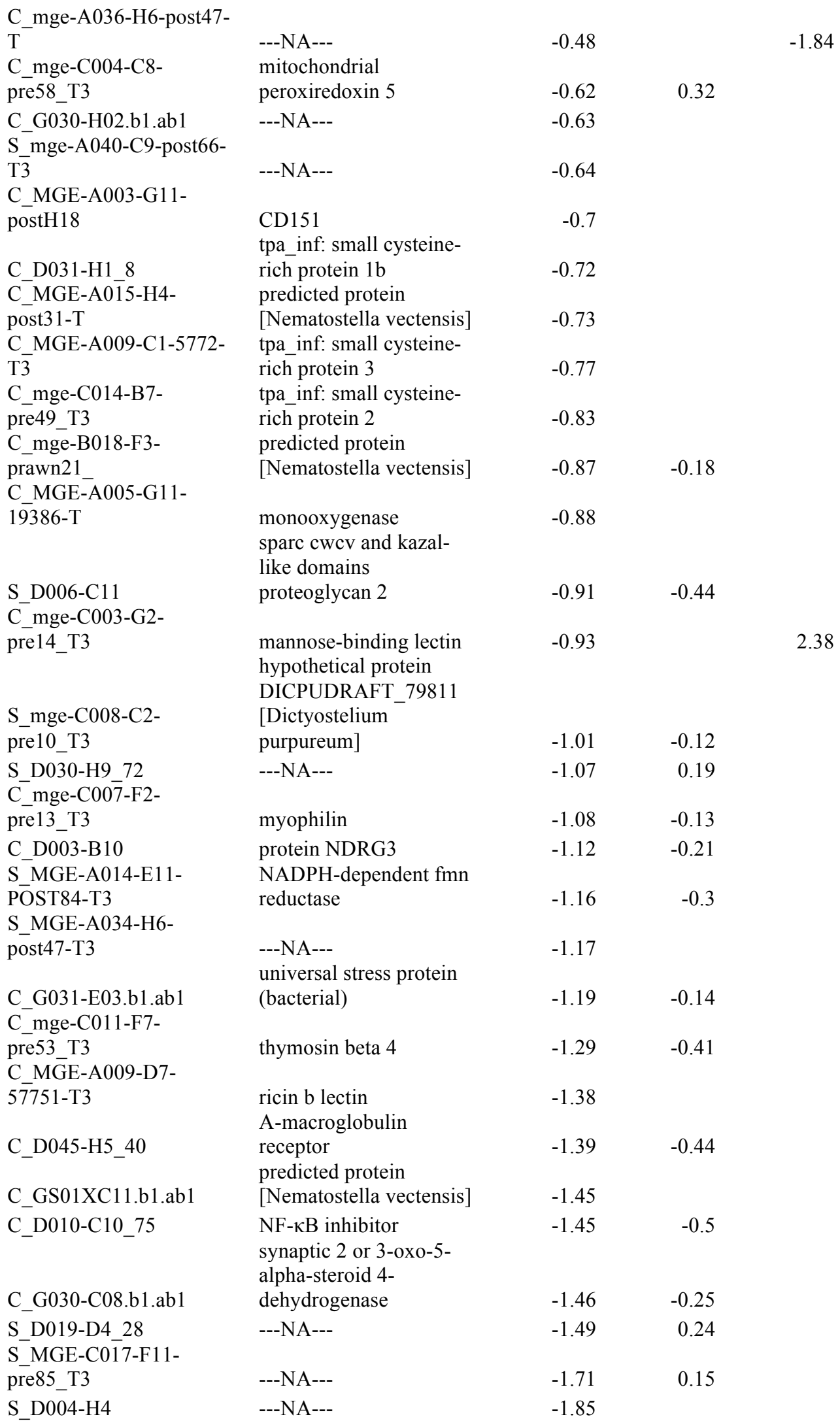




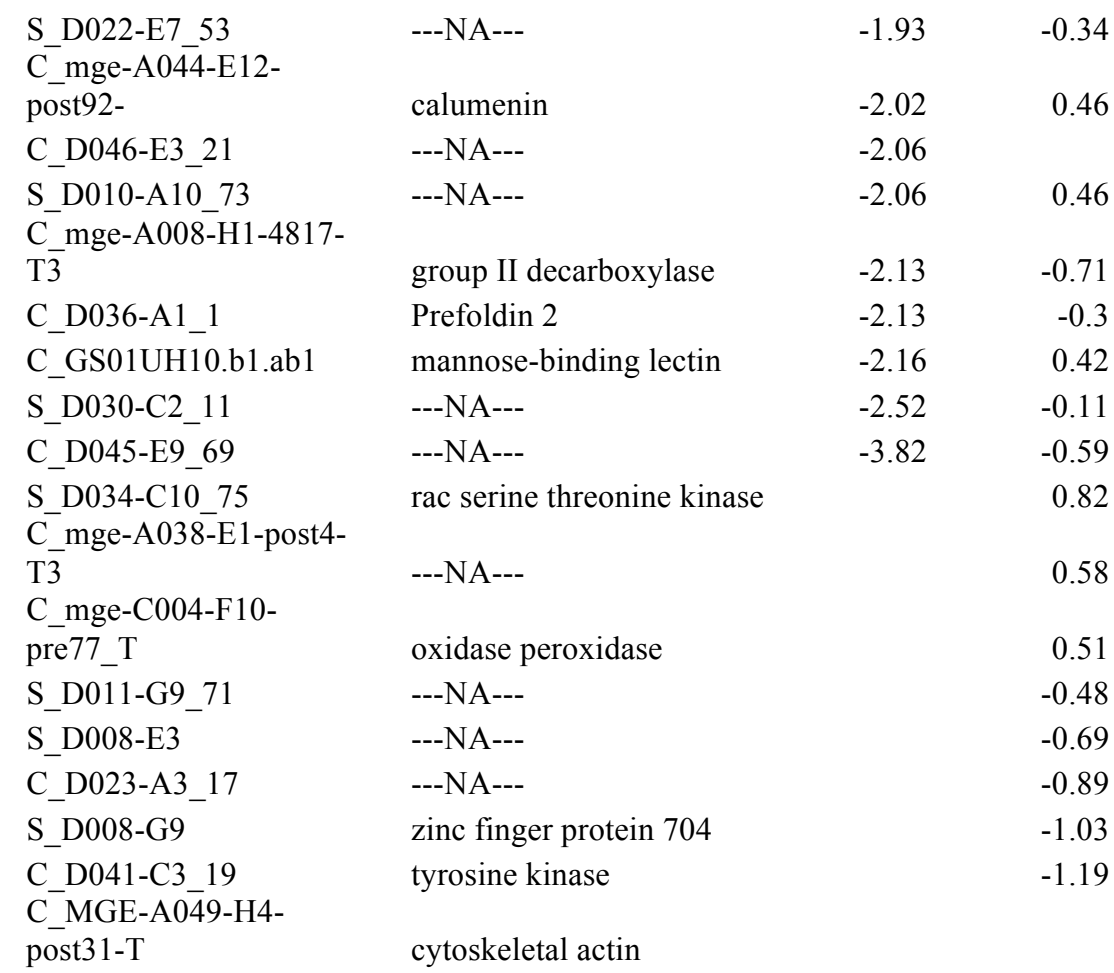

$-0.4$

Table 1. Differentially expressed genes at two, four, and eight days of thermal challenge. Differentially expressed genes detected via microarray analysis are represented by pairwise treatment comparison by day, indicating fold change difference for each treatment pair. Contigs from the microarray were identified using Blast2GO [102]; unknown genes are indicated by “---NA---." 


\subsection{References}

1. Brander L.M., Van Beukering P., Cesar H.S.J. 2007 The recreational value of coral reefs: a meta-analysis. Ecol Econ 63(1), 209-218.

2. Costanza R., dArge R., deGroot R., Farber S., Grasso M., Hannon B., Limburg K., Naeem S., Oneill R.V., Paruelo J., et al. 1997 The value of the world's ecosystem services and natural capital. Nature 387(6630), 253-260. (doi:10.1038/387253a).

3. Wilkinson C. 2004 Status of coral reefs of the World: 2004. Volume 2. Status of coral reefs of the world.

4. $\quad$ Fitt W.K., Brown B.E., Warner M.E., Dunne R.P. 2001 Coral bleaching: interpretation of thermal tolerance limits and thermal thresholds in tropical corals. Coral Reefs 20(1), 51-65. (doi:10.1007/s003380100146).

5. Glynn P.W. 1984 Widespread coral mortality and the 1982-83 El Niño warming event. Environ Conserv 11(02), 133-146.

6. Glynn P.W. 1993 Coral reef bleaching - ecological perspectives. Coral Reefs 12(1), 1-17. (doi:10.1007/bf00303779).

7. Eakin C.M., Lough J.M., Heron S.F. 2009 Climate variability and change: monitoring data and evidence for increased coral bleaching stress. Ecol Stud 205, 41-67.

8. Hoegh-Guldberg O. 1999 Climate change, coral bleaching and the future of the world's coral reefs. Mar Freshw Res 50(8), 839-866. (doi:10.1071/mf99078).

9. Hoegh-Guldberg O., Mumby P.J., Hooten A.J., Steneck R.S., Greenfield P., Gomez E., Harvell C.D., Sale P.F., Edwards A.J., Caldeira K., et al. 2007 Coral reefs under rapid climate change and ocean acidification. Science 318(5857), 1737-1742. (doi:10.1126/science.1152509).

10. Donner S.D., Skirving W.J., Little C.M., Oppenheimer M., Hoegh-Guldberg O. 2005 Global assessment of coral bleaching and required rates of adaptation under climate change. Global Change Biol 11(12), 2251-2265.

11. Hughes T.P., Baird A.H., Bellwood D.R., Card M., Connolly S.R., Folke C., Grosberg R., Hoegh-Guldberg O., Jackson J.B.C., Kleypas J., et al. 2003 Climate change, human impacts, and the resilience of coral reefs. Science 301(5635), 929-933.

12. Smith D.J., Suggett D.J., Baker N.R. 2005 Is photoinhibition of zooxanthellae photosynthesis the primary cause of thermal bleaching in corals? Global Change Biol 11(1), 1-11.

13. Weis V.M. 2008 Cellular mechanisms of Cnidarian bleaching: stress causes the collapse of symbiosis. J Exp Biol 211(19), 3059-3066. (doi:10.1242/jeb.009597). 
14. Dunn S.R., Schnitzler C.E., Weis V.M. 2007 Apoptosis and autophagy as mechanisms of dinoflagellate symbiont release during cnidarian bleaching: every which way you lose. Proc R Soc Lond, Ser B: Biol Sci 274(1629), 3079-3085.

(doi:10.1098/rspb.2007.0711).

15. Dunn S.R., Thomason J.C., Le Tissier M.D.A., Bythell J.C. 2004 Heat stress induces different forms of cell death in sea anemones and their endosymbiotic algae depending on temperature and duration. Cell Death Differ 11(11), 1213-1222. (doi:10.1038/sj.cdd.4401484).

16. Gates R.D., Edmunds P.J. 1999 The physiological mechanisms of acclimatization in tropical reef corals. Am Zool 39(1), 30-43.

17. Steen R.G., Muscatine L. 1987 Low-temperature evokes rapid exocytosis of symbiotic algae by a sea-anemone. Biol Bull 172(2), 246-263. (doi:10.2307/1541797).

18. Downs C.A., Kramarsky-Winter E., Martinez J., Kushmaro A., Woodley C.M., Loya Y., Ostrander G.K. 2009 Symbiophagy as a cellular mechanism for coral bleaching. Autophagy 5(2), 211-216.

19. Baker A.C. 2001 Reef corals bleach to survive change. Nature 411(6839), 765766.

20. Baker A.C. 2003 Flexibility and specificity in coral-algal symbiosis: Diversity, ecology, and biogeography of Symbiodinium. Annu Rev Ecol Evol Syst 34, 661-689. (doi:10.1146/annurev.ecolsys.34.011802.132417).

21. Baker A.C., Starger C.J., McClanahan T.R., Glynn P.W. 2004 Corals' adaptive response to climate change. Nature 430(7001), 741-741. (doi:10.1038/430741a).

22. Berkelmans R., van Oppen M.J.H. 2006 The role of zooxanthellae in the thermal tolerance of corals: a 'nugget of hope' for coral reefs in an era of climate change. Proc $R$ Soc Lond, Ser B: Biol Sci 273(1599), 2305-2312. (doi:10.1098/rspb.2006.3567).

23. Buddemeier R.W., Fautin D.G. 1993 Coral bleaching as an adaptive mechanism: A testable hypothesis. Bioscience 43(5), 320-326.

24. Rowan R. 2004 Coral bleaching - Thermal adaptation in reef coral symbionts. Nature 430(7001), 742-742. (doi:10.1038/430742a).

25. Brown B.E., Dunne R.P., Goodson M.S., Douglas A.E. 2002 Experience shapes the susceptibility of a reef coral to bleaching. Coral Reefs 21(2), 119-126. (doi:10.1007/s00338-002-0215-z).

26. Carilli J., Donner S.D., Hartmann A.C. 2012 Historical Temperature Variability Affects Coral Response to Heat Stress. PLoS ONE 7(3), e34418. 
27. Maynard J.A., Anthony K.R.N., Marshall P.A., Masiri I. 2008 Major bleaching events can lead to increased thermal tolerance in corals. Mar Biol 155(2), 173-182. (doi:10.1007/s00227-008-1015-y).

28. Thompson D.M., van Woesik R. 2009 Corals escape bleaching in regions that recently and historically experienced frequent thermal stress. Proc R Soc Lond, Ser B: Biol Sci 276(1669), 2893-2901. (doi:10.1098/rspb.2009.0591).

29. Williams G.J., Knapp I.S., Maragos J.E., Davy S.K. 2010 Modeling patterns of coral bleaching at a remote Central Pacific atoll. Mar Pollut Bull 60(9), 1467-1476. (doi:10.1016/j.marpolbul.2010.05.009).

30. Bellantuono A.J., Hoegh-Guldberg O., Rodriguez-Lanetty M. 2012 Resistance to thermal stress in corals without changes in symbiont composition. Proc $R$ Soc Lond, Ser B: Biol Sci 279(1731), 1100-1107. (doi:10.1098/rspb.2011.1780).

31. Castillo K.D., Helmuth B.S.T. 2005 Influence of thermal history on the response of Montastraea annularis to short-term temperature exposure. Mar Biol 148(2), 261-270. (doi:10.1007/s00227-005-0046-x).

32. Middlebrook R., Hoegh-Guldberg O., Leggat W. 2008 The effect of thermal history on the susceptibility of reef-building corals to thermal stress. $J$ Exp Biol 211(7), 1050-1056. (doi:10.1242/jeb.013284).

33. Oliver T.A., Palumbi S.R. 2011 Do fluctuating temperature environments elevate coral thermal tolerance? Coral Reefs 30(2), 429-440. (doi:10.1007/s00338-011-0721-y).

34. Brown B.E., Dunne R.P., Warner M.E., Ambarsari I., Fitt W.K., Gibb S.W., Cummings D.G. 2000 Damage and recovery of Photosystem II during a manipulative field experiment on solar bleaching in the coral Goniastrea aspera. Mar Ecol Prog Ser 195, 117-124.

35. Brown B.E., Downs C.A., Dunne R.P., Gibb S.W. 2002 Exploring the basis of thermotolerance in the reef coral Goniastrea aspera. Mar Ecol Prog Ser 242, 119-129. (doi:10.3354/meps242119).

36. Pandolfi J.M., Connolly S.R., Marshall D.J., Cohen A.L. 2011 Projecting coral reef futures under global warming and ocean acidification. Science 333(6041), 418-422. (doi:10.1126/science.1204794).

37. Desalvo M.K., Voolstra C.R., Sunagawa S., Schwarz J.A., Stillman J.H., Coffroth M.A., Szmant A.M., Medina M. 2008 Differential gene expression during thermal stress and bleaching in the Caribbean coral Montastraea faveolata. Mol Ecol 17(17), 3952-3971. (doi:10.1111/j.1365-294X.2008.03879.x). 
38. DeSalvo M.K., Sunagawa S., Voolstra C.R., Medina M. 2010 Transcriptomic responses to heat stress and bleaching in the elkhorn coral Acropora palmata. Mar Ecol Prog Ser 402, 97-113. (doi:10.3354/meps08372).

39. Rohwer F., Seguritan V., Azam F., Knowlton N. 2002 Diversity and distribution of coral-associated bacteria. Mar Ecol Prog Ser 243, 1-10. (doi:10.3354/meps243001).

40. Edgar R., Domrachev M., Lash A.E. 2002 Gene Expression Omnibus: NCBI gene expression and hybridization array data repository. Nucleic Acids Res 30(1), 207-210.

41. Conesa A., Gotz S., Garcia-Gomez J.M., Terol J., Talon M., Robles M. 2005 Blast2GO: a universal tool for annotation, visualization and analysis in functional genomics research. Bioinformatics 21(18), 3674-3676.

(doi:10.1093/bioinformatics/bti610).

42. De Croos J.N.A., McNally J.D., Palmieri F., Storey K.B. 2004 Upregulation of the mitochondrial phosphate carrier during freezing in the wood frog Rana sylvatica: Potential roles of transporters in freeze tolerance. J Bioenerg Biomembr 36(3), 229-239. (doi:10.1023/B:JOBB.0000031974.35812.c9).

43. Kvennefors E.C.E., Leggat W., Hoegh-Guldberg O., Degnan B.M., Barnes A.C. 2008 An ancient and variable mannose-binding lectin from the coral Acropora millepora binds both pathogens and symbionts. Dev Comp Immunol 32(12), 1582-1592.

(doi:10.1016/j.dci.2008.05.010).

44. Vidal-Dupiol J., Adjeroud M., Roger E., Foure L., Duval D., Mone Y., FerrierPages C., Tambutte E., Tambutte S., Zoccola D., et al. 2009 Coral bleaching under thermal stress: putative involvement of host/symbiont recognition mechanisms. $B M C$ Physiol 9(14), 1-16.

45. Wood-Charlson E.M., Hollingsworth L.L., Krupp D.A., Weis V.M. 2006 Lectin/glycan interactions play a role in recognition in a coral/dinoflagellate symbiosis. Cell Microbiol 8(12), 1985-1993. (doi:10.1111/j.1462-5822.2006.00765.x).

46. Rodriguez-Lanetty M., Harii S., Hoegh-Guldberg O. 2009 Early molecular responses of coral larvae to hyperthermal stress. Mol Ecol 18(24), 5101-5114. (doi:10.1111/j.1365-294X.2009.04419.x).

47. Koike K., Jimbo M., Sakai R., Kaeriyama M., Muramoto K., Ogata T., Maruyama T., Kamiya H. 2004 Octocoral chemical signaling selects and controls dinoflagellate symbionts. Biol Bull 207(2), 80-86. (doi:10.2307/1543582).

48. Arosio P., Levi S. 2002 Ferritin, iron homeostasis, and oxidative damage. Free Radic Biol Med 33(4), 457-463. (doi:Pii s0891-5849(02)00842-0

10.1016/s0891-5849(02)00842-0). 
49. Orino K., Lehman L., Tsuji Y., Ayaki H., Torti S.V., Torti F.M. 2001 Ferritin and the response to oxidative stress. Biochem J 357, 241-247. (doi:10.1042/02646021:3570241).

50. Hess J., Angel P., Schorpp-Kistner M. 2004 AP-1 subunits: quarrel and harmony among siblings. J Cell Sci 117(25), 5965-5973. (doi:10.1242/jcs.01589).

51. Baird A., Maynard J.A. 2008 Coral adaptation in the face of climate change. Science 320(5874), 315-315.

52. Causton H.C., Ren B., Koh S.S., Harbison C.T., Kanin E., Jennings E.G., Lee T.I., True H.L., Lander E.S., Young R.A. 2001 Remodeling of yeast genome expression in response to environmental changes. Mol Biol Cell 12(2), 323-337.

53. Chen D.R., Toone W.M., Mata J., Lyne R., Burns G., Kivinen K., Brazma A., Jones N., Bahler J. 2003 Global transcriptional responses of fission yeast to environmental stress. Mol Biol Cell 14(1), 214-229. (doi:10.1091/mbc.E02-08-0499).

54. Gasch A.P., Spellman P.T., Kao C.M., Carmel-Harel O., Eisen M.B., Storz G., Botstein D., Brown P.O. 2000 Genomic expression programs in the response of yeast cells to environmental changes. Mol Biol Cell 11(12), 4241-4257.

55. Sorensen J.G., Nielsen M., Loeschcke V. 2007 Gene expression profile analysis of Drosophila melanogaster selected for resistance to environmental stressors. $J$ Evol Biol 20(4), 1624-1636.

56. Meyer E., Aglyamova G.V., Matz M.V. 2011 Profiling gene expression responses of coral larvae (Acropora millepora) to elevated temperature and settlement inducers using a novel RNA-Seq procedure. Mol Ecol 20(17), 3599-3616. (doi:10.1111/j.1365294X.2011.05205.x).

57. Guiry A., Flynn D., Hubert S., O'Keeffe A.M., LeProvost O., White S.L., Forde P.F., Davoren P., Houeix B., Smith T.J., et al. 2010 Testes and brain gene expression in precocious male and adult maturing Atlantic salmon (Salmo salar). BMC Genomics 11. (doi:211

$10.1186 / 1471-2164-11-211)$.

58. Krasnov A., Koskinen H., Pehkonen P., Rexroad C.E., Afanasyev S., M $\sqrt{ } \partial \mathrm{ls} \sqrt{ } \S \mathrm{H}$. 2005 Gene expression in the brain and kidney of rainbow trout in response to handling stress. BMC Genomics 6(1), 3.

59. Meints R.H., Pardy R.L. 1980 Quantitative demonstration of cell surface involvement in a plant-animal symbiosis: Lectin inhibition of reassociation. J Cell Sci 43(JUN), 239-251. 
60. Berlett B.S., Stadtman E.R. 1997 Protein oxidation in aging, disease, and oxidative stress. J Biol Chem 272(33), 20313.

61. Torti F.M., Torti S.V. 2002 Regulation of ferritin genes and protein. Blood 99(10), 3505-3516.

62. Theil E.C. 2007 Coordinating responses to iron and oxygen stress with DNA and mRNA promoters: The ferritin story. Biometals 20(3), 513-521.

63. Polato N.R., Voolstra C.R., Schnetzer J., DeSalvo M.K., Randall C.J., Szmant A.M., Medina M., Baums I.B. 2010 Location-specific responses to thermal stress in larvae of the reef-building coral Montastraea faveolata. PLoS ONE 5(6), 1-11.

64. Richier S., Rodriguez-Lanetty M., Schnitzler C.E., Weis V.M. 2008 Response of the symbiotic cnidarian Anthopleura elegantissima transcriptome to temperature and UV increase. Comparative Biochemistry and Physiology Part D: Genomics and Proteomics 3(4), 283-289.

65. Voolstra C.R., Schnetzer J., Peshkin L., Randall C.J., Szmant A.M., Medina M. 2009 Effects of temperature on gene expression in embryos of the coral Montastraea faveolata. BMC Genomics 10(627), 1-9.

66. Schwarz J., Brokstein P., Voolstra C., Terry A., Miller D., Szmant A., Coffroth M., Medina M. 2008 Coral life history and symbiosis: functional genomic resources for two reef building Caribbean corals, Acropora palmata and Montastraea faveolata. BMC Genomics 9(1), 97.

67. Shaulian E., Karin M. 2002 AP-1 as a regulator of cell life and death. Nat Cell Biol 4(5), E131-E136.

68. Mattson D., Bradbury C.M., Bisht K.S., Curry H.A., Spitz D.R., Gius D. 2004 Heat shock and the activation of AP-1 and inhibition of NF- $\kappa$ B DNA-binding activity: possible role of intracellular redox status. Int J Hyperthermia 20(2), 224-233. (doi:10.1080/02656730310001619956).

69. Ryan K.M., Ernst M.K., Rice N.R., Vousden K.H. 2000 Role of NF-kB in p53mediated programmed cell death. Nature 404(6780), 892-896.

70. Ashkenazi A., Dixit V.M. 1998 Death receptors: signaling and modulation. Science 281(5381), 1305-1308.

71. Sonna L.A., Fujita J., Gaffin S.L., Lilly C.M. 2002 Invited review: Effects of heat and cold stress on mammalian gene expression. J Appl Physiol 92(4), 1725-1742.

72. Pritts T.A., Wang Q., Sun X., Moon M.R., Fischer D.R., Fischer J.E., Wong H.R., Hasselgren P.O. 2000 Induction of the stress response in vivo decreases nuclear factorkappa B activity in jejunal mucosa of endotoxemic mice. Arch Surg 135(7), 860. 
73. Wong H.R., Ryan M.A., Menendez I.Y., Wispé J.R. 1999 Heat shock activates the I- $\kappa \mathrm{B} \alpha$ promoter and increases I- $\mathrm{\kappa B} \alpha$ mRNA expression. Cell Stress Chaperones 4(1), 1.

74. Pernice M., Dunn S.R., Miard T., Dufour S., Dove S., Hoegh-Guldberg O. 2011 Regulation of apoptotic mediators reveals dynamic responses to thermal stress in the reef building coral Acropora millepora. PLoS ONE 6(1). (doi:e1609510.1371/journal.pone.0016095).

75. Kvitt H., Rosenfeld H., Zandbank K., Tchernov D. 2011 Regulation of apoptotic pathways by Stylophora pistillata (Anthozoa, Pocilloporidae) to survive thermal stress and bleaching. PLoS ONE 6(12). (doi:e28665

10.1371/journal.pone.0028665).

76. Tchernov D., Kvitt H., Haramaty L., Bibby T.S., Gorbunov M.Y., Rosenfeld H., Falkowski P.G. 2011 Apoptosis and the selective survival of host animals following thermal bleaching in zooxanthellate corals. Proc Natl Acad Sci U S A 108(24), 9905-9909. (doi:10.1073/pnas.1106924108).

77. Goldstein A.L., Badamchian M. 2004 Thymosins: chemistry and biological properties in health and disease. Expert opinion on biological therapy 4(4), 559-573.

78. Lodish H., Berk A., Zipursky S.L., Matsudaira P., Baltimore D., Darnell J. 1995 Molecular Cell Biology. New York.

79. Kumar S., Gupta S. 2011 Thymosin beta 4 prevents oxidative stress by targeting antioxidant and anti-apoptotic genes in cardiac fibroblasts. PLOS ONE 6(10). (doi:e2691210.1371/journal.pone.0026912).

80. Gamou S., Shimizu N. 1995 Hydrogen peroxide preferentially enhances the tyrosine phosphorylation of epidermal growth factor receptor. FEBS Lett 357(2), 161-164.

81. Heffetz D., Bushkin I., Dror R., Zick Y. 1990 The insulinomimetic agents H2O2 and vanadate stimulate protein tyrosine phosphorylation in intact cells. $J$ Biol Chem 265(5), 2896-2902.

82. Knebel A., Rahmsdorf H.J., Ullrich A., Herrlich P. 1996 Dephosphorylation of receptor tyrosine kinases as target of regulation by radiation, oxidants or alkylating agents. EMBO J 15(19), 5314-5325.

83. Ganot P., Moya A., Magnone V., Allemand D., Furla P., Sabourault C. 2011 Adaptations to endosymbiosis in a cnidarian-dinoflagellate association: differential gene expression and specific gene duplications. PLoS Genet 7(7), 1-17. 
84. Honore B. 2009 The rapidly expanding CREC protein family: members, localization, function, and role in disease. Bioessays 31(3), 262-277.

(doi:10.1002/bies.200800186).

85. Fang L.S., Huang S.P., Lin K.L. 1997 High temperature induces the synthesis of heat-shock proteins and the elevation of intracellular calcium in the coral Acropora grandis. Coral Reefs 16(2), 127-131.

86. Huang S.P., Lin K.L., Fang L.S. 1998 The involvement of calcium in heatinduced coral bleaching. Zool Stud 37(2), 89-94.

87. Sandeman I. 2006 Fragmentation of the gastrodermis and detachment of zooxanthellae in symbiotic cnidarians: a role for hydrogen peroxide and $\mathrm{Ca} 2+$ in coral bleaching and algal density control. Rev Biol Trop 54, 79-96.

88. Orrenius S., Zhivotovsky B., Nicotera P. 2003 Regulation of cell death: The calcium-apoptosis link. Nat Rev Mol Cell Bio 4(7), 552-565. (doi:10.1038/nrm1150).

89. Mayfield A.B., Wang L.-H., Tang P.-C.C., Fan T.-Y., Hsiao Y.-Y., Tsai C.-L., Chen C.-S. 2011 Assessing the impacts of experimentally elevated temperature on the biological composition and molecular chaperone gene expression of a reef coral. PLoS ONE 6(10), 1-13.

90. Black N.A., Voellmy R., Szmant A.M. 1995 Heat shock protein induction in Montastraea faveolata and Aiptasia pallida exposed to elevated temperatures. Biol Bull 188(3), 234-240. (doi:10.2307/1542301).

91. Sharp V.A., Brown B.E., Miller D. 1997 Heat shock protein (hsp 70) expression in the tropical reef coral Goniopora djiboutiensis. $J$ Therm Biol 22(1), 11-19. (doi:10.1016/s0306-4565(96)00029-0).

92. Granados-Cifuentes C., Bellantuono A.J., Ridgway T., Hoegh-Guldberg O., Rodriguez-Lanetty M. 2012 High natural gene expression variation in the reef-building coral Acropora millepora: Potential for acclimative and adaptive plasticity. BMC Genomics, Revised version in review.

93. DeSalvo M.K., Sunagawa S., Fisher P.L., Voolstra C.R., Iglesias-Prieto R., Medina M. 2010 Coral host transcriptomic states are correlated with Symbiodinium genotypes. Mol Ecol 19(6), 1174-1186. (doi:10.1111/j.1365-294X.2010.04534.x).

94. Downs C., Fauth J.E., Robinson C.E., Curry R., Lanzendorf B., Halas J.C., Halas J., Woodley C.M. 2005 Cellular diagnostics and coral health: declining coral health in the Florida Keys. Mar Pollut Bull 51(5), 558-569.

95. Downs C.A., Mueller E., Phillips S., Fauth J.E., Woodley C.M. 2000 A molecular biomarker system for assessing the health of coral (Montastraea faveolata) during heat stress. Mar Biotechnol 2(6), 533-544. 
96. Smith-Keune C., Dove S. 2008 Gene expression of a green fluorescent protein homolog as a host-specific biomarker of heat stress within a reef-building coral. Mar Biotechnol 10(2), 166-180.

97. Molinier J., Ries G., Zipfel C., Hohn B. 2006 Transgeneration memory of stress in plants. Nature 442(7106), 1046-1049.

98. Rosenberg S.M., Hastings P. 2003 Modulating mutation rates in the wild. Science 300(5624), 1382-1383.

99. Lopez-Maury L., Marguerat S., Baehler J. 2009 Tuning gene expression to changing environments: from rapid responses to evolutionary adaptation. Nat Rev Genet 10(1). (doi:10.1038/nrg2500).

100. Stimson J., Kinzie R.A. 1991 The temporal pattern and rate of release of zooxanthellae from the reef coral Pocillopora damicornis (Linnaeus) under nitrogenenrichment and control conditions. J Exp Mar Biol Ecol 153(1), 63-74.

101. Foret S., Kassahn K.S., Grasso L.C., Hayward D.C., Iguchi A., Ball E.E., Miller D.J. 2007 Genomic and microarray approaches to coral reef conservation biology. Coral Reefs 26(3), 475-486. (doi:10.1007/s00338-007-0206-1).

102. Grasso L.C., Maindonald J., Rudd S., Hayward D.C., Saint R., Miller D.J., Ball E.E. 2008 Microarray analysis identifies candidate genes for key roles in coral development. BMC Genomics 9. (doi:540

10.1186/1471-2164-9-540).

103. Wu H., Yang H., Churchill G. 2008 R/MAANOVA: An extensive R environment for the Analysis of Microarray Experiments.

104. Cui X., Hwang J.T.G., Qiu J., Blades N.J., Churchill G.A. 2005 Improved statistical tests for differential gene expression by shrinking variance components estimates. Biostatistics 6(1), 59-75.

105. Storey J.D. 2002 A direct approach to false discovery rates. J Roy Stat Soc B 64, 479-498. (doi:Unsp 1369-7412/02/64479 10.1111/1467-9868.00346).

106. R_Development_Core_Team. 2011 R: A language and environment for statistical computing. (Vienna, Austria, R Foundation for Statistical Computing. 


\section{Chapter 4: Upstream of Acropora millepora thermal tolerance: a preliminary study of putative regulatory sequences of thermal tolerance genes across the Great Barrier Reef}

\subsection{Abstract}

With the potential demise of reef-building corals on the horizon given ongoing climate change amid other anthropogenic environmental stressors, the understanding of coral adaptation and acclimatization is paramount for conservation of these organisms. We ask whether likely targets for cytosine methylation upstream of thermal tolerance genes in the coral Acropora millepora show signs of differential methylation in the northern versus southern extents of the Great Barrier Reef, two regions with differing patterns of historical thermal stress. Here, we utilized a targeted approach which employed bisulfite sequencing to characterize the methylation of DNA elements upstream of activator protein 1, inhibitor of $N F \kappa B$, and a mannose-binding lectin, three genes we have shown to be associated with acquired thermal tolerance in our prior work. The current study represents the first attempts at identification of cis-regulatory elements in corals. Though our assessment found no differential methylation across regions, we identified multiple mutations (i.e., Single Nucleotide Polymorphism, SNP) upstream of the genes-of-interest, with one SNP upstream of inhibitor of $N F \kappa B$ and five upstream of mannose-binding lectin varying significantly between the northern and southern Great Barrier Reef. The function of these putative promoter regions remains to be seen, but the variation in regulatory sequence across thermally-disparate geography serves to generate hypotheses regarding the role of regulatory element evolution in a coral adaptation context. 


\subsection{Introduction}

Coral bleaching is the loss of the mutualistic intracellular dinoflagellates, Symbiodinium, and/or loss of photosynthetic pigments [1], a fate caused by hyperthermal, light, and other sources of stress $[2,3]$. The breakdown of the essential symbiosis significantly compromises the health and survivorship of the coral $[4,5]$. Considering solely the carbon already emitted into the atmosphere, ignoring ongoing emissions in the interim, annual bleaching driven by climate change will occur by 2080 [6]. When considering ongoing emissions with optimistic reductions in carbon release (stabilizing at $550 \mathrm{ppm}$ carbon dioxide), reefs will undergo frequent mass bleaching events by 2030 [6]. The hope for coral lies in increased thermal tolerance; an additional $1.5^{\circ} \mathrm{C}$ would delay high frequency bleaching by fifty to eighty years [6]. Intriguingly, apparent bleaching tolerance as a result of prior stress has been observed in corals. For instance, less bleaching was observed in the 2002 warming event on the Great Barrier Reef than in a prior bleaching event in 1998, even though 2002 saw more stress than 1998, with higher ultraviolet irradiance in 2002 than in 1998 [7]. In the instance of reduced bleaching on the Great Barrier Reef in 2002 in comparison to 1998, attenuation in bleaching susceptibility was reportedly not the result of differential mortality of coral colonies and therefore it is suggested to be attributed to an acclimatization process [7]. Furthermore, the long-term effect of thermal tolerance has also been recently documented on Southeast Asian reefs, where coral populations that bleached during the last major warming event in 1998 showed decreased bleaching susceptibility to the thermal stress event that occurred in 2010 [8]. The apparent increase in thermal tolerance of corals from Southeast Asian reefs suggests that the thermal history of these sites may have played an important role in determining the bleaching severity in 2010 [8]. Another example 
is the case of one species, Goniastrea aspera, in which the faces of coral colonies that had acclimatized to high levels of light remained temperature tolerant even following shade conditions for four years, whereas colony faces which were not naturally preconditioned via photo stress were susceptible to heat stress [9].

Understanding the mechanisms behind the acquisition of thermal tolerant phenotypes is crucial if we are to improve the conservation plans for restoration and protection of reef corals in impending climate change scenarios. Several hypotheses have been postulated to explain the differential patterns of thermal tolerance phenotypes displayed in coral species populations from different geographical regions worldwide. These hypotheses include firstly the postulation that changes in both the Symbiodinium composition make-up [10-13] and associated bacterial community assemblages $[14,15]$ enhance thermal tolerance and survivorship. Secondly, adaptive processes that select for heat-resistant coral host genotypes need strong consideration given the hypothesized potential for massive underlying variation [16], but this hypothesis has not, as of yet, been tested. A third hypothesis holds that physiological acclimatization mechanisms reconfigure new physiological thresholds of tolerance in corals [17-19].

While some studies have shown evidence that some corals increase their thermal tolerance by switching/swapping less heat-resistant algal symbionts by more thermal-tolerant ones [11,20], other studies have documented that switches of new symbionts during warming events may not be stable in the long-term [21-23]. In the latter case, reversion back to the original algal genotypes of the coral host may occur after recovery from bleaching [24]. These findings are also in accordance with studies that have demonstrated that some opportunistic heat-tolerant symbionts are not physiologically optimal symbionts in many 
mutualistic consortia $[25,26]$. Regardless of the stability of the heat-resistant symbiont switches, it is also known that most coral species might not have the capacity or flexibility to switch their symbionts [21, 27]. Additionally, a model-based approach demonstrates that symbiont shifts or switches may be detrimental to reef resilience in the Caribbean [28]. The proposed deleterious effects of symbiont changes [28] imply that changes of the symbiont make-up might not be a feasible evolutionary strategy among the vast majority of coral species to adjust to rapid occurring environmental changes associated with global warming.

Physiological acclimatization provides an important mechanism to cope with changing environmental conditions, and coral and their intracellular symbionts might be able to respond and adjust in a timely and beneficial way to rapidly changing temperatures through this mechanism. Perhaps the most pertinent examples come from our recent studies where we have shown that coral can increase their thermal tolerance within a short-term acclimative process without changes of the Symbiodinium and bacterial symbionts [19]. We have further revealed that a host transcriptomic signature underlies the tolerance associated with coral thermal history, and postulated that similar process might also be underlying comparable acquisition of thermal tolerance observed in the wild that has not been correlated to selective mortality processes or to changes in the symbiotic makeup of the holobiont [18].

In a number of cases, corals exposed to anomalous heat events have displayed resistance and less susceptibility to subsequent stresses $[7,8,29,30]$. Because of the short time frame in which these reef coral populations have acquired thermal tolerance, it is assumed that it might be attributed to an acclimatization process [7, 18, 19]. A viable mechanism by which corals may potentially be increasing their thermal tolerance may reside in epigenetic modifications, where tolerance and/or resistance are based on the manipulation 
of the existing genetic information (reviewed by [31]). In any case, there exists evidence for the differential transcription across corals with different thermal histories [18, 32], but there has not yet been any investigation of the coral regulome, either of sequence or methylation.

Cis-regulatory elements provide multiple potential hypotheses for acclimatization, rapid evolution, and epigenetic memory of prior stress. The differential bleaching patterns previously observed in corals have not been demonstrated to be due to genotypes, but rather thermal history [7]. As such, epigenetic changes could explain these patterns. Additionally, mutation and evolution of cis-regulatory sequences also provides a potential mechanism by which coral could rapidly evolve to a changing climate regime. The importance of gene regulatory programs has been thoroughly investigated in the context of organismal diversity $[33,34]$. We hereby posit two distinct possibilities in coral adaptation and acclimatization that have not as of yet been investigated. Our first question is whether changes in the symbiotic reef corals are occurring above the level of DNA sequence evolution. The observed phenotypic plasticity, acquired thermal tolerance within one organism's lifetime, and stable memory effects through time support one hypothesis: epigenetics plays a role in coral stress tolerance. Our second question asks whether noncoding DNA sequences, putative cis-regulatory elements, vary across regions with disparate thermal history.

\subsubsection{Background on epigenetics and stress response}

Though we have elucidated a molecular response associated with acquired thermal tolerance of corals [18], transcription itself is not heritable to daughter cells (See review by Turner [35]), necessitating an epigenetic memory in the explanation of these events. Epigenetic mechanisms are numerous. Methylation of cytosine (generally at $\mathrm{CpG}$ sites) has been shown to be a modifier of transcriptional activity, with hypomethylation of active 
transcription factor binding sites and hypermethylation of silenced DNA. Nucleosome position and histone modifications affect chromatin structure and availability. Though a universal histone code has not been identified, generally trimethylation of $\mathrm{H} 3 \mathrm{~K} 4$ are suppressors of transcription, while the dimethylation of $\mathrm{H} 3 \mathrm{~K} 9$ and $\mathrm{H} 3 \mathrm{~K} 27$ are suppressors of transcription. Acetylation of lysine tails on histones $\mathrm{H} 3$ and $\mathrm{H} 4$ lysine are generally linked with transcriptional activation. Additionally, RNA-based mechanisms of epigenetic transcriptional modification exist. This study will only examine methylation in clustered CpGs upstream of genes-of-interest.

As long-lived organisms of indeterminate growth, epigenetic changes are a conceptually attractive mechanism of memory for previous stress in corals. Phenotypes resulting from epigenetic modification caused by the environment are well-documented in the literature. Consider the developmental environment of mice: enriching the diet of maternal mice with methyl donors increases the methylation of the IAP promoter in utero, shifting coat color (Reviewed by Jirtle and Skinner [36]). Additionally, in the Pacific oyster, Crassostrea gigas, DNA methylation was found to be involved in stress as well as environmental responses [37]. Yeast also demonstrate epigenetic phenomena; Saccharomyces cerevisiae previously called upon to induce GAL1 expression via culture on galactose media acquire the capacity to subsequently induce GAL1 more rapidly than yeast not previously exposed to galactose [38]. Of particular interest in the coral context is an example of another organism consisting of a host/microalgal symbiont: it has been demonstrated that in lichen, the fungal has more DNA methylation when engaged in symbiosis with its algal symbiont, as compared to the methylation found in the aposymbiotic fungal host [39]. 
Epigenetic processes have not only furthered our understanding of variation and regulation at the genomic and cellular levels, but they have also challenged our understanding of heritable phenotypic variation at the level of whole organisms and even the process of evolution by natural selection [40, 41]. Although many of the epigenetic mechanisms involved in differential gene expression are reset each generation, some epigenetic marks are faithfully transmitted across generations [42, 43] Several studies suggest that epigenetic variation alone can cause significant heritable variation in phenotypic traits (e.g. [44-46]).

Epigenetic effects via DNA methylation have been most thoroughly studied in plants, especially in regard to acclimative response to stress and the environment. For instance, in maize roots, a gene called ZmMI1 is induced by exposure to cold stress [47]. As a result of the treatment, the core region of the gene was found to have a reduction in methylation which persisted through periods free from cold stress [47]. An increase in DNA methylation in pea roots was associated with cold stress [48]. Under salinity stress, Mesembryanthemum crystallinum changes from C3 photosynthesis to CAM photosynthesis; the change in photosynthetic pathway is associated with the hypermethylation of a specific satellite DNA [49]. The presence of DNA methylation-based epigenetic responses in corals remains completely unexplored, but given the foundation of methylation-mediated alterations to plant epigenomes (Review by [50]), there is a sound basis for exploration in corals.

Although histone modifications may confer cytosine methylation (Reviewed by Chinnusamy and Zhu [50]), DNA methylation is the focus of the present study as this is seen as a more stable form of epigenetic modification than histone modifications. Additionally, 
DNA methylation has already been confirmed in an anthozoan cnidarian, the sea anemone Nematostella vectensis, as well as in the freshwater hydrozoan Hydra magnipapillata [51].

\subsubsection{Cis-regulatory elements and adaptation: evo-devo and eco-evo-devo}

The importance of gene regulatory programs has been thoroughly investigated in the context of organismal diversity (e.g., [33, 34]). More recently, the interaction of a larger trio, that of ecology, evolution, and development, has become recognized, termed eco-evo-devo. As a consequence of the generally highly pleiotropic nature of transcription factors, they tend to be conserved. However, downstream targets of transcription factors, that is, promoters and enhancers, are potentially expressed under context specific circumstances, and are thereby under more relaxed selection. While the protein-coding portion of a gene may be invariable across environments, the activity and function of promoters may be specific to the particular environment, as posited by Moczek et al. [52].

One of the foundational concepts behind evo-devo is that of ancestral genetic complexity; that is, that long-since diverged taxa share a basic collection of both patterning and structural genes [34]. For instance, of the $12 \mathrm{Wnt}$ gene families identified in vertebrates, 11 are found in the cnidarians [53]. Many of the genes identified in coral stress response, and in particular those which form the focus of this study, have vertebrate orthologs, thereby fulfilling this principle of evo-devo. If the evolution of cis-regulatory elements provides for the morphological diversity seen in metazoans via modification of developmental gene expression programs, the application of the same concepts to the advantageous adaptation of a stress response program is a natural extension. With cis-regulatory elements less hindered by the pleiotropic effects associated with protein-coding sequence evolution and the potential for the tinkering of already-present programs, taking a page from the evo-devo school of 
thought and considering the role of promoters and regulation in coral adaptation is necessary extension from current studies, which have tended to focus on transcriptomic effects and this far ignored upstream processes.

\subsubsection{Evidence for the heritability of stress response in coral}

The genetic basis of coral stress tolerance in the context of eco-response has seen notable investigation in recent times. The work of Csaszar et al. [54] attempts to estimate the amount of phenotypic variation with a genetic basis. Comparing two populations of $A$. millepora on a phenotypic basis, they identified heritabilities amongst photosynthetic traits and within the photoprotective profile of the symbionts. The group suggests low heritability with regard to host gene expression phenotypes, and as such express concern regarding host adaptation in the face of climate change [54]. However, it is worth mentioning that only the expression of four genes were assessed, and that manganese superoxide dismutate was found to be significantly heritable in one population, with a zinc metalloprotease heritable in the other [54]. Casting a wider net with the use of cDNA microarray interrogating 1,310 unigenes, Polato et al. [55] compared the heat stress response of Montastraea faveolata larvae from Mexico and Florida sites of origin. In spite of the presence of gene gene flow between the two sites assessed, the study revealed origin-specific gene expression patterns [55], giving evidence for a host response to differing environmental exposure. For further evidence for heritable parental influence, we look to the recent work of Polato et al. [56], in which parental crosses between Acropora palmata of known microsatellite genotypes we performed for the specific purpose of creating two pools of genotypically distinct larval offspring. Via transcriptome analysis of the developing larvae under heat stress, the differentially expressed genes were discovered between the two larval pools, indicating a 
heritable signature of thermal response in development [56]. Though these transcriptomebased studies are supportive of a heritable basis for thermal tolerance, they do not point to the actual locus responsible, or whether the effects are of genetic or transgenerational epigenetic influence.

In addition to the arguments for host and holobiont adaptation, there is evidence for the local adaptation of the symbiont [57]. Isolating Symbiodinium of the same type but from origins of disparate thermal history, Howells et al. [57] show that the thermal history of corals is affected by the provenance of the in hospite Symbiodinium. By performing a reciprocal transplant experiment with A. millepora between the warm central and cool southern Great Barrier Reef, Howells et al. [57] showed that the historical thermal limits to which corals were exposed were associated with physiological limits of the holobiont. Though the researchers speculate that genotype drives the difference in thermal response, bleaching tolerance, and growth under novel conditions, the experiment does not allow for the deterministic identification of the mechanism behind the phenotypes observed [57]; the mechanisms driving the observed differences in growth and thermal tolerance between transplant sites may be due to host and/or symbiont genotype, could conceivably be a persistent epigenetic state in one or more of the symbiotic partners. Clearly, an understanding the adaptive potential of all symbiotic partners is a critical piece of forecast reefs, and our current understanding of host adaptation is limited. Pinning down the mechanism behind observed patterns of heritable thermal response remains an open problem, yet an important one in the changing global climate. 


\subsubsection{Questions and aims}

Though prior work on corals has focused on differential genotypes across environmental gradients through the examination of neutral markers (e.g., [58]), epigenetics as a mechanism for acclimatization and the survey of putative functional DNA markers has only received cursory mention and no definitive empirical testing. There is an urgency to understand the epigenetic patterns and cis-regulatory elements that may be underlying physiological tolerance to thermal stress. This present study represents the first attempt at coral population epigenetics and the first assessment of potential regulatory elements across spatial and thermal regimes.

\subsection{Materials and methods}

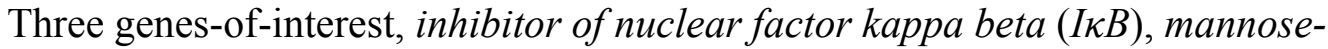
binding lectin $(M B L)$, activator protein $1(A P-1)$, were selected from the nine differentiallyexpressed genes with known association with acquired coral thermal tolerance [18]. In prior work [18], these genes were all upregulated in thermal-tolerant fragments of the reef-building coral A. millepora. Genes-of-interest for this study were chosen based upon knowledge of putative orthologs, the role of the genes in other studies, and the ability to uniquely map the genes to the A. millepora draft genome (www.coralbase.org; accessed December 10, 2012). The protein product of the gene $A P-1$ regulates a diverse range of cellular processes and is associated with both cell survival and cell death [59]. The protein produced by the gene $I \kappa B$ is hypothesized to halt NF- $\kappa \mathrm{B}$-mediated apoptosis of host gastrodermal cells containing in hospite Symbiodinium [18], thereby preventing apoptosis-based bleaching [60]. Mannosebinding lectins have recognized importance in the initiation and maintenance of cnidarian- 
algal symbioses $[61,62]$, with mannose-binding lectins also displaying decreased expression in response to heat stress in multiple coral taxa $[63,64]$.

The three selected genes, putative orthologs of inhibitor of nuclear factor kappa beta $(I \kappa B)$, mannose-binding lectin $(M B L)$, activator protein $1(A P-1)$, were mapped to the draft genome using a combination of local BLAST [65] and Exonerate [66].

Three kilobases (draft genome assembly quality permitting) of sequence upstream of the start codon of each gene-of-interest were examined for $\mathrm{CpG}$ enrichment using MethPrimer [67]. The following parameters were used to identify areas enriched for CpGs: Window $=100 ;$ Shift $=1 ;$ Observed $/$ Expected $>=0.6 ; \mathrm{CG} \%>=50 \%$. To identify candidate cis-regulatory elements within the 5'- flanking region of the genes of interest, the promoter identification tools PROSCAN version 1.7 [68] and Cister [69] were implemented on upstream sequences. Primers generated with the aid of MethPrimer were chosen for use on population samples based upon following criteria: 1) the primers flanked regions enriched for CpGs; 2) intended amplicons either contained putative cis-regulatory elements or resided in the direct proximity of such elements (see Figure 3.); and 3) amplified the intended target specifically and robustly from bisulfite-converted Acropora millepora genomic DNA.

Sample sites were selected on the basis of historical thermal differentials between sites; historical sea surface temperature data from 2000 to 2013 (available at http://coralreefwatch.noaa.gov/) indicates that the mean summer sea surface temperature is $2.3^{\circ} \mathrm{C}$ higher in Prince Charlotte Bay than Heron Island (Sites shown in Figure 1; historical SST synthesized in Figure 2). Tissue from live coral colonies had previously been collected and extracted in 2008 using the DNEasy Blood \& Tissue Kit (QIAGEN, Valencia, California, USA) from salt-saturated DMSO-preserved tissue samples collected, with DNA stored in 
Tris-EDTA at $-20^{\circ} \mathrm{C}$. The method of methylation detection we implemented depends upon the complete deamination of unmethylated cytosines to uracil by reaction with bisulfite, followed by downstream PCR of this template, to yield thymine at each position which was originally an unmethylated cytosine[70]. While unmethylated cytosines are converted, methylated cytosines are protected from bisulfite attack and do not undergo deamination; thereby, one can elucidate the presence or absence of cytosine methylation by the comparison of PCR-amplified, bisulfite-converted DNA with a reference sequence, either via Sanger sequencing or other SNP detection methods [70]. Eleven DNA samples from Prince Charles Bay, Queensland, Australia (collected in 2008) and 13 from Heron Island, Queensland, Australia, were used for downstream analysis. DNA samples were bisulfite-converted using 80 ng gDNA with the EpiTect Bisulfite kit (QIAGEN, Valencia, California, USA), following manufacturer's protocol for a $40 \mu$ l elution volume.

The initial intent was to use methylation-sensitive high resolution melting, a method which differentiated between methylated and unmethylated DNA based upon differential melt curves of differentially-methylated bisulfite-converted DNA [71, 72], providing rapid identification of methylation. As such, primers were designed to amplify fragments of less than 200 base pairs to enhance the sensitivity for methylation detection [72]. Fragments upstream of $I \kappa B, M B L$, and $A P-1$ were initially amplified using primer pairs IкB_BIS, AP1_BIS, and MBL_BIS, as listed in Table 1. Initial PCRs were carried out using on a BioRad CFX-96 real-time PCR machine. The reaction mix for each amplification consisted of 10 $\mu l$ of Precision Melt Supermix (Bio-Rad, Hercules, California, USA), $0.5 \mu$ l of each appropriate forward and reverse primer (Table 1), $1 \mu \mathrm{l}$ bisulfite-treated DNA (equivalent to 2 
ng gDNA), and $8 \mu \mathrm{l}$ water. No template controls employed water in place of bisulfite-treated DNA.

Thermal cycling was performed on a Bio-Rad CFX96 instrument, with SYBR as the selected fluorophore. The PCR program for $I \kappa B$ and $A P-1$-associated fragments included a 2 minute initial denaturation at $95^{\circ} \mathrm{C}$, followed by 40 cycles of $95^{\circ} \mathrm{C}$ denaturation for 10 seconds, $57^{\circ} \mathrm{C}$ annealing for 30 seconds, and $72^{\circ} \mathrm{C}$ extension for 30 seconds. Amplification was followed by a high-resolution melt analysis, beginning at $95^{\circ} \mathrm{C}$ for 30 seconds followed by $60^{\circ} \mathrm{C}$ for one minutes, and subsequently ramping from $65-95^{\circ} \mathrm{C}$ in $0.2^{\circ} \mathrm{C}$ increments at a rate of 10 seconds per step. The thermal program was identical for the $M B L$-associated fragment, with the exception of a $54^{\circ} \mathrm{C}$ annealing. PCR products were electrophoresed on $1 \%$ agarose/TBE gels to confirm amplification of a discrete product of the expected size (Table $1)$.

Preliminary direct Sanger sequencing of the products resulting from the bisulfite-PCR was initially performed to confirm the amplification of the intended loci. However, this sequencing effort additionally indicated the presence of SNPs between and within locations, and between the genome sequence and sample. The original intent was to use high resolution melting to identify differential methylation across samples [71, 72], as aforementioned, but the presence of polymorphisms across samples would confound the intended melt analysis. As such, we opted for the direct Sanger sequencing of the amplicons produced from all samples. However, direct sequencing using the aforementioned primers was inconsistent and tended to yield short, noisy reads. To circumvent this, universal sequencing primers were integrated into the 5' ends of the gene-specific bisulfite-PCR primers; M13REV (5'CAGGAAACAGCTATGACC-3') was added to each forward primer, and M13(-21) (5'- 
TGTAAAACGACGGCCAGT-3') was added to each reverse primer (Table 1.). PCR products from the primary bisulfite-PCR amplifications were electrophoresed on 1\% agarose/TBE gels. For each electrophoresed PCR sample, the product band was pierced with a $10 \mu l$ pipette tip. As such, the tips carried the template for a high fidelity/low cycle reamplification. The reamplification served to add M13 tails to the PCR products; the pipette tips were briefly immersed in the following reaction mix: $25 \mu$ OneTaq 2x Master Mix (New England Biolabs, Ipswich, Massachusetts, USA), $0.5 \mu$ each $(10 \mathrm{mM})$ of the appropriate M13-tailed forward and reverse primers (Table 1), and $24 \mu 1$ of water. The reamplification reaction mix was cycled with the following program on a Bio-Rad T100 instrument: a 2 minute initial denaturation at $95^{\circ} \mathrm{C}$, followed by 20 cycles of $95^{\circ} \mathrm{C}$ denaturation for 10 seconds, $57^{\circ} \mathrm{C}$ annealing for 30 seconds, and $72^{\circ} \mathrm{C}$ extension for 30 seconds, and a subsequent 7 minute final extension at $72^{\circ} \mathrm{C}$. The PCR products produced by reamplification were directly sequenced by the University of Florida ICBR Core Facility (Gainesville, Florida, USA) using the sequencing primer M13REV (5'-CAGGAAACAGCTATGACC-3').

Chromatograms were manually inspected for quality and misreads, and analyzed using Mutation Surveyor (SoftGenetics, State College, PA, USA), for both differential methylation as well as mutations, in reference to the A. millepora genome assembly. As the mutation data is preliminary and should be consider as such, SNPs were analyzed individually. For every SNP, a $2 \times 2$ contingency table was constructed by counting the number of times each new allele (in reference to the genome assembly) appears from each population samples (Heron Island vs. Prince Charles Bay); the analysis of the resultant contingency table with a Fischer's exact test was performed in R [73]. 


\subsection{Results}

\subsubsection{Identification of CpG islands and promoter-like elements}

The DNA sequences upstream of $A P-1, I \kappa B$, and $M B L$ were all associated with areas enriched for CpGs (Figure 3). Two CpG islands were found in association with $I \kappa B$, one 2,907 base pairs upstream of the start codon and extending 189 base pairs, and the other beginning 1358 base pairs from the start codon, with a total length of 100 base pairs (Figure 3 A). With $M B L$, six CpG islands of greater than 100 base pairs each were found between 977 to 2520 bases 5' of the start codon (Figure 3 B). Two CpG islands were found upstream of $A P-1$, one 1,626 base pairs upstream of the start codon and extending 189 base pairs, and the other beginning 90 base pairs from the start codon, with a total length of 100 base pairs (Figure 3 C). Promoter-like elements were identified in all three genes-of-interest; promoterlike elements indicated in Figure 3 represent a synthesis of both promoter identification tools implemented. Full data on promoter-like elements identified are given in Figure 4 and Table 7 for $I \kappa B$; Table 8 for $M B L$; and Figure 5, Table 9, and Table 10 for $A P-1$.

\subsubsection{Bisulfite sequencing}

Of the $24 \mathrm{CpGs}$ assayed in 24 samples (7 CpGs upstream of $A P-1 ; 9 \mathrm{CpGs}$ upstream of $I \kappa B$, CpGs in product: 9; 8 CpGs upstream of $M B L$ ), none show either complete or partial methylation. Inspection of non-CpG cytosine loci show complete conversion to thymine, indicating complete conversion via bisulfite treatment in the experiment. See Table 4, Table 5, and Table 6 for complete methylation and bisulfite conversion data for fragments upstream of .IKB, $M B L$, and $A P-1$. 


\subsubsection{Sequence variants between sites}

Mutation analysis of the targeted bisulfite-converted sequencing effort identified SNPs upstream of the three of the genes-of-interest surveyed. All sequence polymorphisms discovered are presented in reference to the A. millepora draft genome (www.coralbase.org; relevant sequence excerpts available in Table 3).

Thirty SNPs were identified in total, with 18 present in multiple individuals (12 singletons). Five of the polymorphisms exhibit frequency counts that differ significantly between Prince Charlotte Bay and Heron Island populations (Fischer's exact test, $\mathrm{P}>0.05$ ). With the limitations of the small dataset presented, meaningful calculation of linkage disequilibrium between SNPs is not viable, and note that no false discovery rate corrections are made for multiple tests.

\subsubsection{IKB}

Thirteen SNPs were identified upstream of $I \kappa B$, with two of the new alleles (position 1712 and 1750; see Table 2 A and Table 3) present in multiple samples. One of the new alleles, a guanine to adenine mutation at position 1750 , is present with significantly higher frequency in samples from Heron Island than in samples originating from Prince Charlotte Bay ( $p=0.00004$, Fischer's exact test, Table 2 A). The novel SNP is of particular interest as lies within a potential promoter region, as detected by Cister ([69]; see Figure 4 and Table 7), directly adjacent to a potential LSF-like binding site; the transcription factor itself, LSF, has numerous important roles in cell survival [74].

\subsection{5 $\mathrm{MBL}$}

Fifteen SNPs were identified upstream of $M B L$, with fourteen of the new alleles present in multiple samples (Table $2 \mathrm{~B}$ and Table 3). Four of the new alleles, a guanine to 
adenine mutation at position 1948, a guanine to adenine mutation at position 1954, an adenine to guanine mutation at position 1979 , and a guanine to thymine mutation at position 1994, are present with significantly higher frequency in samples from Heron Island $(\mathrm{p}<0.01$, Fischer's exact test, Table 2 B) than in samples originating from Prince Charlotte Bay. These polymorphic sites are in relative proximity to a promoter-like region, lying from position 2130 to 2380, which includes E2F-like and AABS_CS2-like promoter signals (Refer to Table 8) .

\subsubsection{AP-1}

Two SNPs were identified upstream of $A P-1$ : an adenine to guanine mutation at position 2120 , and a thymine to adenine mutation at position 2166 . Both of the novel alleles were present in two samples; the frequency of both of these novel alleles showed no significant difference between Heron Island and Prince Charlotte Bay $(\mathrm{P}=1$ at position 2120 and $\mathrm{P}=0.20$ at position 2166, Fischer's exact test, Table $2 \mathrm{C}$ ). These polymorphisms do, however, lie within the predicted promoter regions identified by both Proscan Version 1.7 [68] and Cister [69] (Refer to Table 9, Figure 5, and Table 10). Promoter-like elements were predicted in the direct vicinity, including an AP-1 binding site (position 2112) and CP1 (2027) detected with Proscan Version 1.7 [68], and CCAAT signals at positions 2064 to 2079 and 2024 to 2039, as indicated by Cister [69] (See Table 9, Figure 5, and Table 10).

\subsection{Discussion}

For more than a decade, the present and impending threats on reefs have been recognized, with an understanding that corals occupying reefs will either acclimatize, adapt, or perish $[4,6,75,76]$. Here, we have performed the first assessment of putative coral promoters across populations, spanning disparate thermal regimes. In the exploration of both 
acclimative and adaptive responses to thermal history, we have found that variation exists in regulatory sequence between populations with differing thermal histories. Underlying variation is a necessary precursor for adaptation, and this work provides key first-line of evidence of variation, which opens the door for the possibility of coral thermal adaptation and persistence in a changing climate.

\subsubsection{Polymorphic DNA upstream of thermal tolerance genes}

The multiple polymorphisms identified upstream of coding sequence for $I \kappa B, M B L$, and $A P-1$ should, with the evidence presented, be considered effects of population of origin, pending further studies. The work of van Oppen and collaborators [58] indicates significant population structure along the Great Barrier Reef. At present, we cannot rule out that the polymorphisms in the promoters of $I \kappa B$ and $M B L$ which differ significantly in frequency between a region with a history of higher thermal stress (Prince Charlotte Bay) than those from an area of a lower heat stress (Heron Island) are simply neutral mutations, with no effect on fitness. In spite of this, the polymorphisms in the 5' regions of $I \kappa B$ and $M B L$ appear in noteworthy locations, potentially in the promoter regions of these genes. In the human systems, there are many instances in which polymorphisms upstream of gene coding sequence display have significant effects on health and disease; for example, promoter polymorphisms have been identified as being significant factors in diverse conditions, such as the response to toxic shock syndrome [58], HIV progression [77], propensity for allergic asthma [78], and even stress response and depression [79]. With their broad-reaching impacts in the well-studied human system, the implications of promoter allelic diversity provides for corals is as-yet unknown, but holds the potential for involvement in response to stress and disease. 
With our evidence for variation within putative regulatory elements as well as significantly different frequencies of the SNPs between areas of variant historical stress, the potential implications of these polymorphisms in adaptation bears discussion.Evolution of the regulatory program of heat stress response is a conceivable mechanism for evolution of corals and the development of novel phenotypes, and the basis for this school of thought is far from novel. Evolutionary work with a cis-regulatory-element focus dates to that of Jacob and Monood in 1961 [80], though in bacterial operons. The core tenet of evo-devo, that phenotypes are dependent upon the timing and dosage of protein products, originally arose from the work of Zuckerkandl and Pauling [81]. King and Wilson [82] speculate on the surprising similarity of human and chimpanzee genes but disparities in form. The line of thought regarding morphological disparity despite gene similarity was clarified by Jacob in a landmark 1977 paper which brought focus to the importance of gene regulation in an adaptive context [83]. Carroll [34] suggests that cis-regulatory element remodeling is one mechanism by which the level of gene expression may be modified. Göttgens et al. [84] provide evidence for the remodeling of a promoter of critical gene in vertebrate development, $S C L$, with the fixation of several mutations associated with the mammalian radiation. The results presented here show that the underlying requirement for adaptation via cis-regulatory evolution elements is present: variation itself, upson which selective processes can act. While the frequencies of the $I \kappa B$ - and $M B L$-associated vary significantly between the northern and southern sites investigates, we cannot as yet rule out that the pattern observed is simply a mirroring of the population structure along the Great Barrier Reef [58], but we also cannot rule out the possibility that the observed differences have a functional basis. 
Prior work estimating the underlying variation in corals speculated that approximately 100 million somatic mutations could appear in a single medium-sized branching coral [16]. The experimental results presented here support that there may indeed be vast amounts of underlying variation between individuals, potentially allowing for selection and evolution of stress-tolerant genotypes. The rigorous extension of the results at hand, to elucidate physiological differences between the variant haplotypes of candidate promoters of $I \kappa B$ and $M B L$, will initially require identification of the transcription factor(s) binding these regions. Transcription factor identification could be accomplished via yeast-one-hybrid screening [85], and followed up with subsequent functional assessment of the variant promoter haplotypes in vitro (e.g., [86]).

\subsubsection{Absence of methylation at targeted loci}

It has long been held that cytosine methylation is not as pervasive in invertebrates as it is in mammals [86]. However, the regulation function of methylation in invertebrates has come to light in recent years, with increasingly more methylation identified in invertebrates, and a potential ancestral role of methylation posited as having importance in the control of genes subject to noisy or aberrant expression [87]. For instance, in both the pea aphid and honeybee, methylated genes tended to be universally expressed in alternate phenotypes of the organism [88]. Furthermore, in the honeybee, the DNA methylation has intrinsic and critical roles in the caste system; that is, the production of alternate phenotypes, and is influenced by nutrition [89]. One important consideration is that the genes explored here, $A P-1, M B L$, and $I \kappa B$, are not just at times of thermal stress but are also expressed under normal reef conditions, as shown by the expression of these three genes in the common garden experiment performed by Granados-Cifuentes et al. [90]. As such, the genes-of-interest in this study may like have 
important roles in the normal day-to-day physiology of the host, and may for that reason not be regulated by methylation. Despite our lack of evidence for methylation in the targeted survey performed, methylome analysis of corals, both for the basic understanding of gene regulation and as a potential mediator of acclimative responses to repeated stress, deserves deeper investigation.

Our presented lack of evidence of differential methylation across populations, or even the presence of any methylation at the loci-of-interest, should not be taken to indicate that methylation and other epigenetic mechanisms lack a role in coral acclimatization, thermal response, and stress memory; instead, we suggest that future works go beyond a genespecific target approach, and implement genome-wide assays to assess methylation patterns and identify differential methylation (or lack thereof) across corals with varying thermal tolerance and histories of stress exposure. An additional limitation of this study is that DNA samples were extracted from entire coral fragment homogenates, without respect for isolating nucleic acids from a particular tissue or cell type. The intrinsic mixture of cell types imposed by the extraction method attenuates any cell type-specific methylation signal. In recognition of the potential for signal attenuation due to DNA extraction from whole coral homogenates, future work should consider targeting specific cell and/or tissue types for methylation analysis depending upon the question at hand. For instance, the isolation of gastrodermal cells populated with dinoflagellates would be necessary to study the methylation state of cells engaged in symbiosis. 


\subsubsection{Conclusion}

The study presented here marks the first characterization of putative cis-regulatory elements in corals, alongside with the identification of polymorphism which vary significantly across a thermal gradient. As these DNA elements are associated with genes with a known role in coral thermal tolerance [18], are adaptive implications with these findings. With their intriguing location in putative cis-regulatory elements, the polymorphisms identified in this study open the door for future genome-wide scans of loci under selection in corals across thermal gradients, to identify potential selection and adaptation in progress. Additionally, the functional assessment of these promoters and others DNA elements-of-interest may serve to help unlock the mechanisms of thermal tolerance and understanding coral resilience in a world of changing oceans.

\subsection{Acknowledgments}

We thank Dr. Mehmet Dorak for his insights and expertise throughout the course of the investigation, Dr. Tyrone Ridgway for providing DNA samples from Prince Charlotte Bay, and Melissa Morlote-Triana for critical assistance in labwork. 


\section{Primer Name}

IKB_BIS_F

IKB BIS R

M13-IKB_BIS_F

M13-IKB_BIS_R

MBL_BIS_F

MBL_BIS

M13-MBL_BIS_F

M13-MBL BIS_R

TFAP1_BIS R

M13-TFAP1 BIS F

M13-TFAP1 BIS R transcription factor activator protein 1 (TFAP-1)

inhibitor of nuclear factor kappa beta (IKB) inhibitor of nuclear factor kappa beta (IKB)

inhibitor of nuclear factor kappa beta (IKB) inhibitor of nuclear factor kappa beta (IKB) mannose-binding lectin (MBL)

mannose-binding lectin (MBL)

mannose-binding lectin (MBL)

mannose-binding lectin $(M B L)$

transcription factor activator protein 1 (TFAP-1) transcription factor activator protein 1 (TFAP.1)
TFAP1_BIS_F

Amplicon Native Primer Sequence $\left(5^{\prime}-3^{\prime}\right)$

Length (bp)

Table 1. Novel primers pairs used for the amplification and reamplification of bisulfite-converted DNA and reamplification of PCR products for sequencing. Amplicon length indicates the size of the PCR fragment resulting from each pair of primers listed.
Annealing

Temperature $\left({ }^{\circ} \mathrm{C}\right)$
AATTAACATAAAAATATTACTAATAAACAAAAA

CAGGAAACAGCTATGACCTGTAGTTAATTATTATAGAGGAGGAGGT

TGTAAAACGACGGCCAGTAATTAACATAAAAATATTACTAATAAACAAAAA

TITAATTAGGATGTTGAAATATTAGAAAGA

TTCATATCATAAACCTACATAATAATCATT

CAGGAAACAGCTATGACCTTTAATTAGGATGTTGAAATATTAGAAAGA

TGTAAAACGACGGCCAGTTTCATATCATAAACCTACATAATAATCATT

AATAAAGTTTAAAGATATGATTAATTAGAG

TTATTTAAAATTAAACAAAAATCAACTAAC

TGTAAAACGACGGCCAGTTTATTTAAATTAAACAAAAATCAACTAAC
CAGGAAACAGCTATGACCAATAAAGTITAAAGATATGATTAATTAGAG
54

54

57

57

57

57
GTAGTTAATTATTATAGAGGAGGAGGT 


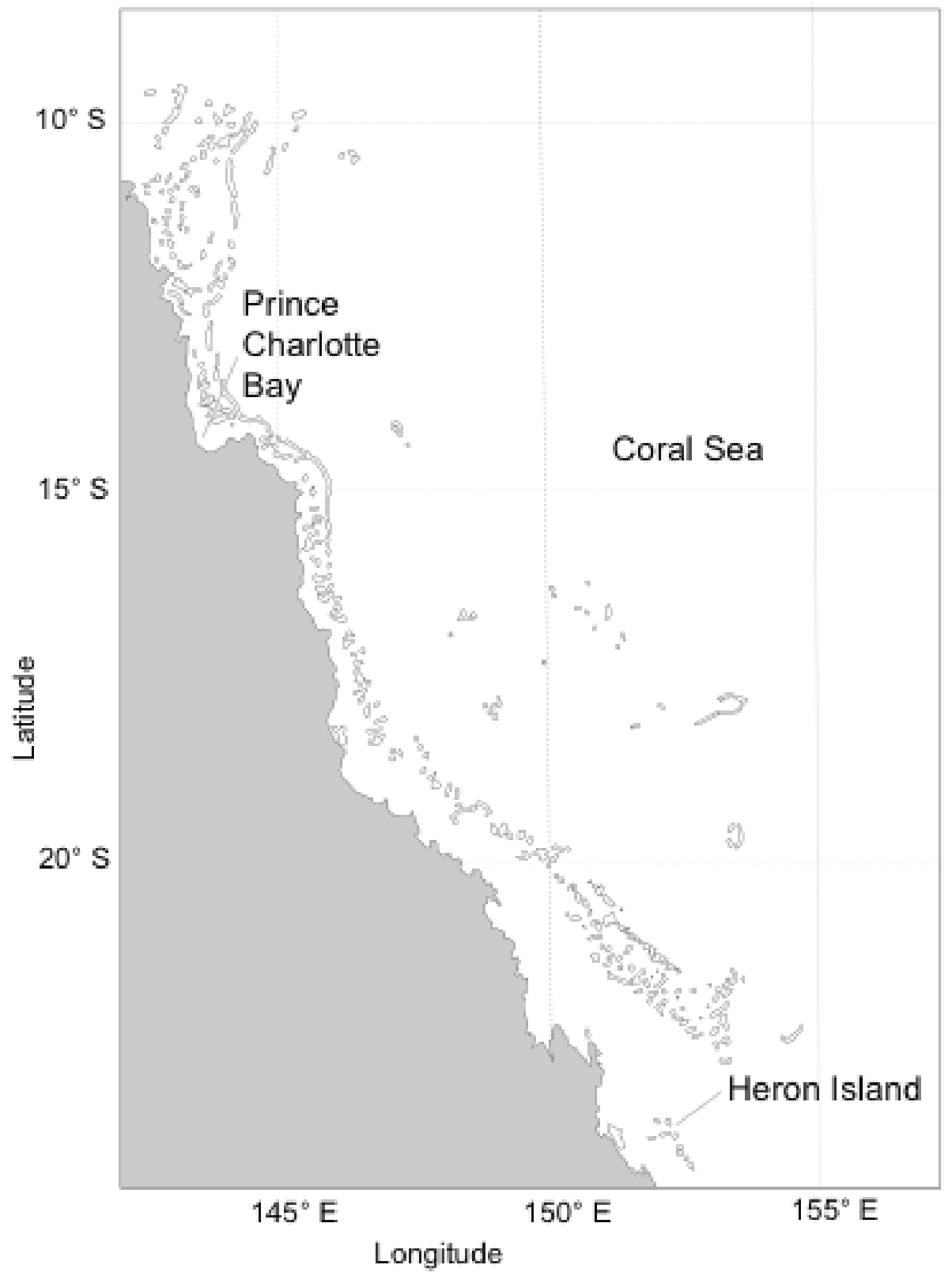

Figure 1. Map indicating the origin of A. millepora samples. Sample originate from the reef flat surrounding Heron Island (GBR), Queensland, Australia (23 26' 39" S, $151^{\circ} 54^{\prime}$ $47^{\prime \prime} \mathrm{E}$ ), and from Prince Charlotte Bay (GBR), Queensland, Australia (14 $25^{\prime} 0^{\prime \prime} \mathrm{S}, 144^{\circ}$ 0' 0" E). Map courtesy of Commonwealth of Australia (Geoscience Australia). 


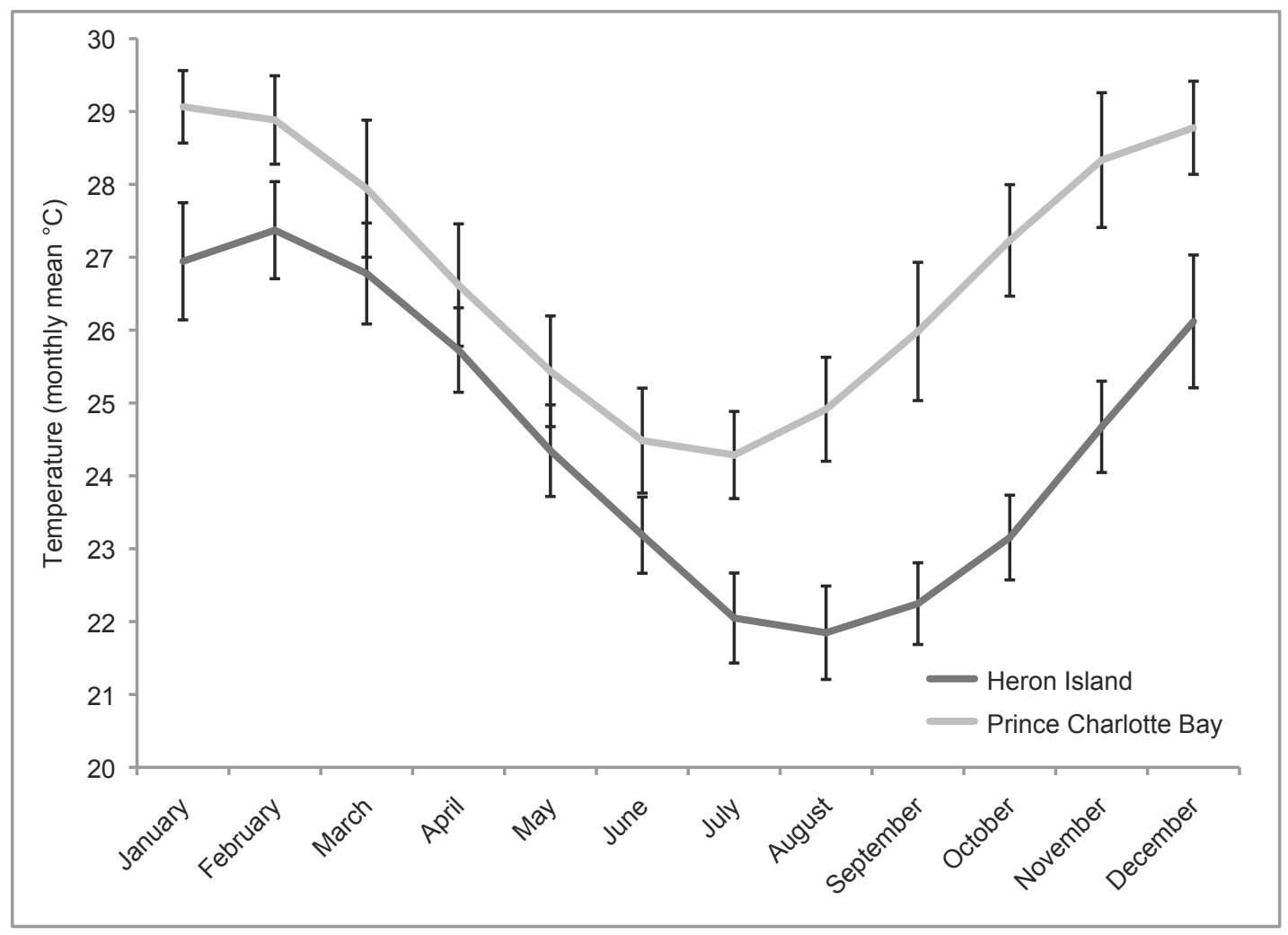

Figure 2. Mean sea surface temperature data from Prince Charlotte Bay and Heron Island. Historical SST data of the two regions from which samples originate from NOAA Coral Reef Watch, available at http://coralreefwatch.noaa.gov/. The figure summarizes sea surface temperature data from November 28, 2000, through July 11, 2013. Error bars indicate standard deviation. Mean Prince Charlotte Bay sea surface temperature is $26.9^{\circ}$ Cover the timespan analyzed; mean Heron Island temperature is $24.6^{\circ} \mathrm{C}$. 


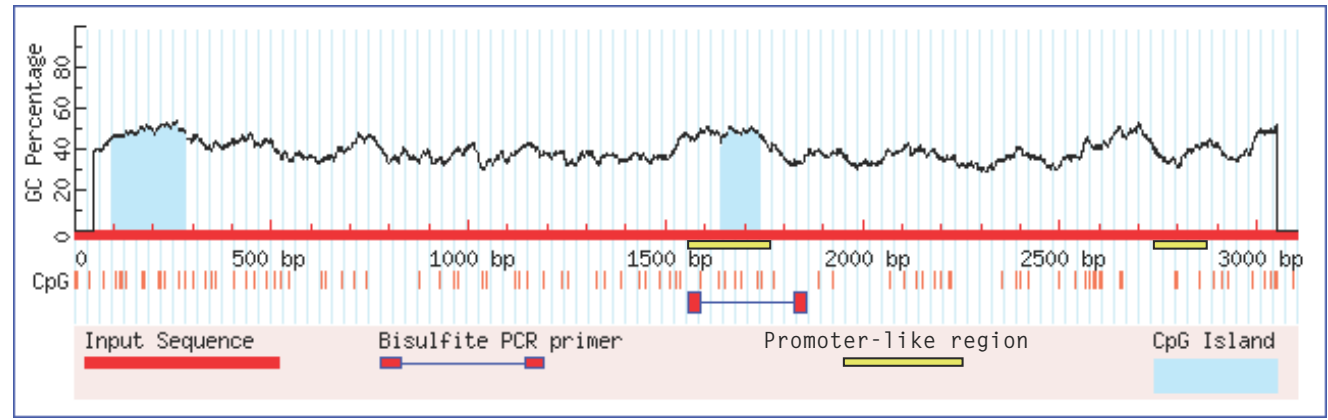

B. mannose-binding lectin $(M B L)$

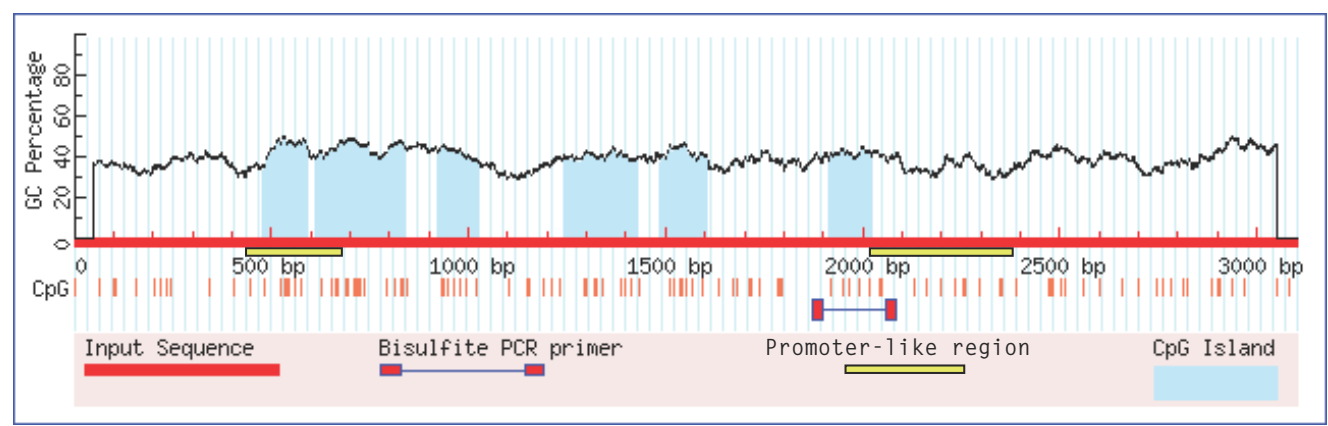

C. activator protein $1(A P-1)$

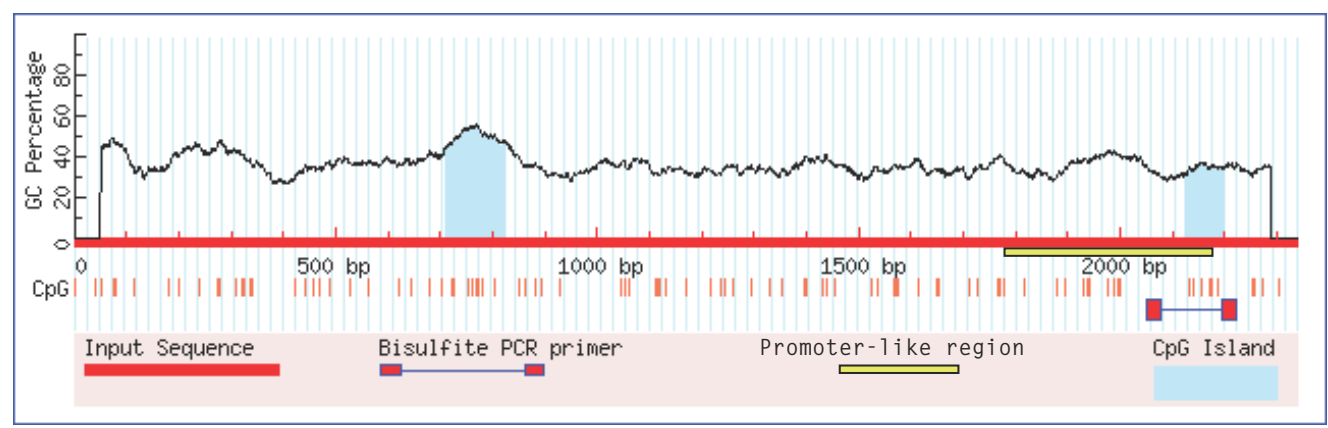

Figure 3. CpG locations and promoter-like elements identified upstream of inhibitor of nuclear factor kappa beta (A), mannose-binding lectin (B), and activator protein 1 (C). Sequences analysis three kilobases of sequence upstream of start codon as well as the first 100 base pairs of coding sequence is shown for inhibitor of nuclear factor kappa beta (A) and mannose-binding lectin (B); analysis of 2237 base pairs of activator protein 1 upstream sequence is shown, also with the first 100 base pairs of coding sequence. All sequences analyzed are shown in Table 3. 


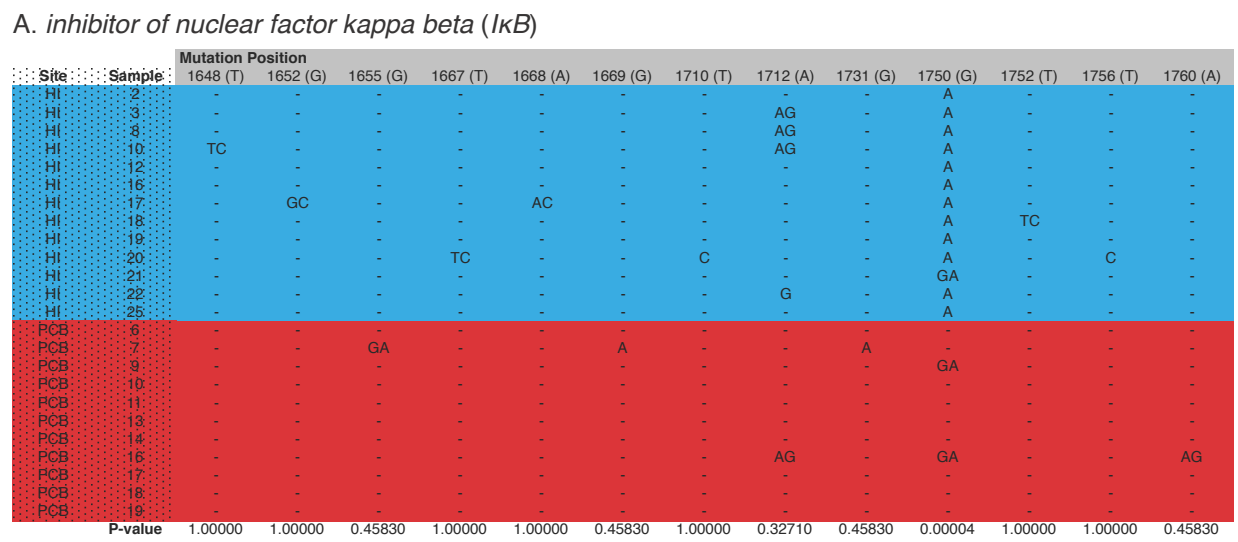

B. mannose-binding lectin (MBL)

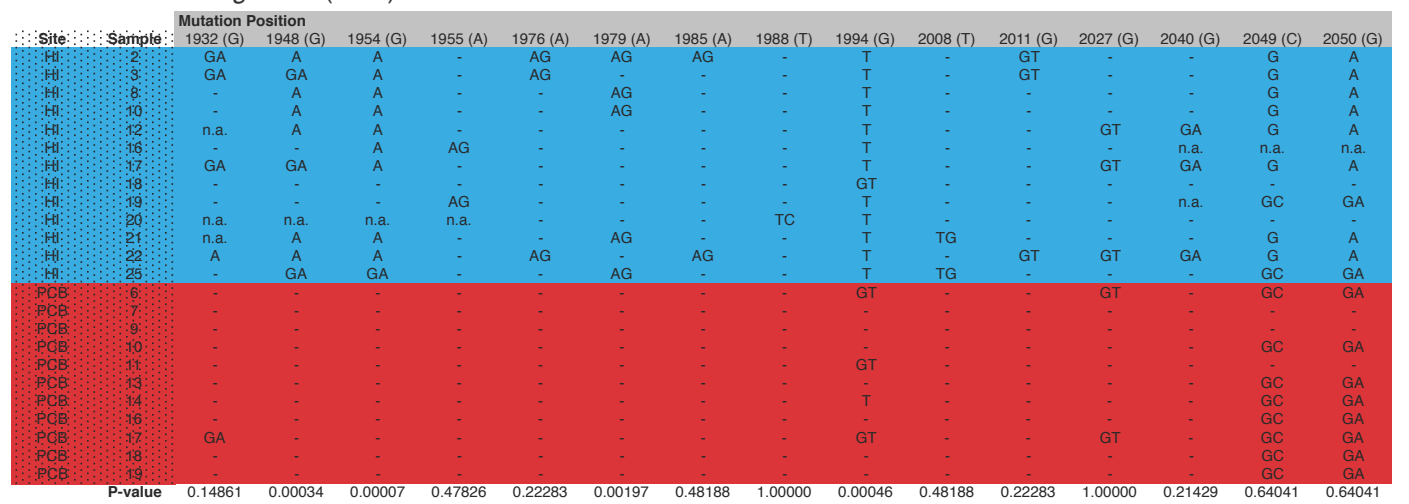

C. activator protein $1(A P-1)$

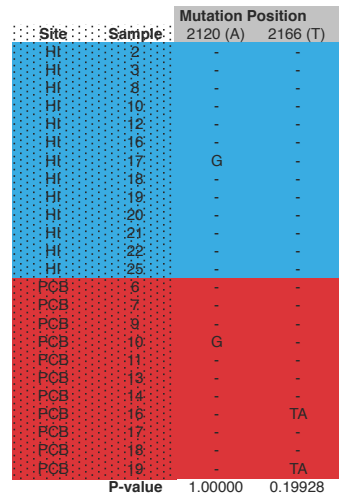

Table 2. DNA polymorphisms present between the reference genome (see Table 3 for relevant genomic sequences) and targeted bisulfite sequencing of fragments upstream of $\mathrm{I} \kappa \mathrm{B}, \mathrm{AP}-1$, and MBL. The top row of each matrix indicates the nucleotide position of each polymorphism, with the reference sequence at the given position in parentheses. Positions in the matrices containing a minus symbol (-) indicate that the particular sample does not vary from the reference genome at the corresponding locus. Variations from the reference genome are shown for each sample, with heterozygotes designated by the presence of two nucleotides at one locus. All positions are relative to sequences upstream of genes-of-interest available in Table 3, with the first position of each upstream sequence fragment corresponding with position one in this table. 


\section{inhibitor of nuclear factor kappa beta (IKB) upstream region (from NODE 187788)}

GAAAGTGGCGTATTGAACTGGTTATTTCCAACACTTTCGAAGAAAAGGCAGAGAACAGATGATCAAAGATTGCATCGAAACTGGTCTAGTTTCTTTGTCAGTGATGGCGGAATT AAACGTGCACGAGGTACACACGCTCACATCAGCCCCATGCAATGTGGTTATCATCTTACGTCTGCGCATAACTGTTGGGATAAATACCATGTTTGGGCCGTGCAGCTCGAGTT GACCGCGACCTTGACACAAGCTTTAGTGGGACTTTCCCGGACTAAGCTCAGTCGAGCAAAAAGTATGCTCTCAATTCGTCCAATATGCCACATGCCCTTCATAACTTTCGATCA CTCATAAGGCGCTCAAGCGTAGATCTTGGAAAAATCAGTAGTAAACAAAAGCTTTGTTGGGGCGCCATATTTGAACTTGATGCTGTAGCTTACAAGCTCGACCTTCCTTGGAGC CGAAGGAAAGGAGAGGAAGGAAAATAAATTCAGACCGACTCATTGACTTTTTTCGATATTCATAGAAGACGCGTCCAGGATTGCAAGCATCGAGCTATTTATTAGATGCATCTT GAAAATACTGACTACAAATGATAATGAAGTAGTTCCTCCCTTCAATTTTGGACAAAACTCGCCAGAAAACGTGAGGCACCAATTTAAAATAAAAACTAATGACTTTGTCTACGGG ATATATGGATTTATCCTTGCTTTACGCCTCCCCCTTCTCCAATGTTGCTTTGTGACGGCCCAACCAACATGGATATAAGGGAAGGGGAATAATACAGTTTCACTGTGACTTCTAG TGAAAGAAAGTGAGAGTCTTTTTCTCAATAATTTTTTCCAAGATTTAACCCCACTCCTCAAGTTGACAAAGACAGCGACCTGGCCAATCCTAAAAAAAATAACAAATGCTAACTC TAATCATAATTCGGTAGACTTGTTTGTGATGCTTATCAAAATAAATCTTGCGCAATCCTGGGCGTCTGTTCAAAACTGAAAGAAAATGAGGAGCCCAACTTGACATAGCTTTTGA TTATTTCCCCGCTGAAAGCGAATGTAATCAAAGTTTAAAAAGTTTATTTAAAAAAATAAGGACCTGGGTATCTGCCAGTTAAGGCTCCTGCGTATGTCCCGAAAAATTGAAACCT AAAGTGCGTGCTCAATACTTTCTTGATAACAATTTCTGTTTCTTAGCGTCCCCAGTCTGCTTTCTACAGCATGAAAGCCAATTAATCAATTATCGCACATTTTGTCTCCGATATAT TTGCCATGAATGGTAAAAGCATATCAATGATATTGTATTGGAGTCCTAGTCCTTAATCATGCTACGCACAAGGAGAGACTTAAGAGACGCTCAATATGCTATTTATTTTATTTTTT TCAAGAGCTGCGAAATTTGGACACAAGAGGTTGTCCAAGTTTATTCTGCTGATATTACGACCTCTAATGCATCCGATCATGTGAGATGTTTGATATATTTTTGATAAAAGCGGCA AGAAAATGAAAACAATCTTCGCCTGAGACAATGGTAACGAAACAAGTACGCTTTTCCCAATTGTT GGCTGCAGCCAATCACTACAGAGGAGGAGGCCGCGATAATGGAAGTAT ACATGAATGAGCCTCGACAGGCTAGTTCCGGATGGGTTGACTTTCCCCACTGATTAGTTTCGCATTTTTTGTCTATCAGCAATATTTTTATGTTAATCAGGGGCAAAACAAACAG GTTTGAAAACAGTGTCATCTTTGTATTTGGGTGTTTGGTTTAGGGTTATCTTTGATACGTTAAGGTGGGGAAAAAAGTGGGACAATGAGATCATCGAGAGGAGAATATTTCAAG ATTTTAACAAAGTATGGTGGTCCCTTCTGAGTAAAAGCCTTGTTTTCAGTAAAAGTTTCACTAAAAAGAATATTCTTCTGGAGTTTCTAGTCTGTTCTTTTTCAACATCAGATTTAA CTCACGGCGCTTACTTTTTCTGGGAAACTTTGTGCATGTACGCGAGGAAGAAAATAAATTTCAGCATGGATACCTCGAAGATTGATGAGCCGAATGAAAAGCTAATAATGCAAG TGTGAAGACAGAGAAAATGAAACTCTCAGACAAAGTTTTCCTTAAATAAAATCTTAAAACAGCGTTTTCAGACTGTTTGGGGAAAATACTGTCAAGCGTGTGAGTTATCACGTCA ATTCCTGCAAAGAACGTCATATTTGGGGGTGGTATAAAAAAGAAAATTATTTTCCTACTTGCATTTCCCTAAAATTGGACTCTGCTTAGCGATATTTCTCAATTAAAAACAGTTGT TTTGCCATCTGAATCGAATATCACACAACTGCACTAAGAGATCGAGCATTTAACACGAAAGTCGTATCGAAAGGTTTCACGCCCGGGGAATCCCCTAATTAATAATCTATTGTTT GCTGTTTATTGGCATTCCGGCACGTTTCACATGTTGCTGGGCTGACCCCAGGGTAACCCCCTAGGTTCTTTCCCTAAGTCCTGCATAAGACATTTITGCTGATTGGCCAGTCTA AGTTAATTCTTGTTCTAAAATCACCTCTGATTAGTCTATTCGTATCACGTGTTTAAATAGGGAAAATTCCCTTATGCATCAGAACTAGTTATATACAGCACAACCCGCCATCTTTG AAGTTGTCGGTAAAAGGATGGACTCACCCCAACAGCAACGAAAGCTAGTCCGACGAGGAGCCCCGTCGAAAGGAATTTCACAATACCATCTTTCTGCAGTTATTCAGCAC GGAGGAA

mannose-binding lectin (MBL) upstream region (from NODE_2455379) GATTCTTTTCTAAAAGGACACTCAAAGTGTAAGAAAGCAGAACGAAATTAAAGAGATAGGGTACAATAAAGAAACTAAATATTGAACCATTGCGACTCTTTTGTTCGTTCATGTT TTTGCGAGATAAAAGTTCCGCTCCCCAAAGTATCAATAATGTTGACAGATAGAAGTGTGGATTCAACTCTGCAGATGTGCTCATTTTGAACTTCATGCCTTTTCACCTTGGTCAT TCGATGCTAACAAAATGCTAGCATTGTTTCCTTCAGGCCTAAAGAAACCATAATGGAAGACGTTCAGAGAAGCTATGCAAAACAAATGAAAAGAAAATCAAACGGTTTTTTTTTTT
AAATATACCAGTTCCATGAGAATCGCAGGCCAATTGAGTCCATGCAGTGGTCCAAAAATGTTGTCGTTTATCACAGCGGCGACTTGCGCGCATTTTTTACTGACGACTTAACTT TGGGCGGCTCAAATGGACTGTGTTCAACTGAATCCACTCATGACCAAGATATCCAGTCGAATCAAATAGAAAACTGTTTTCGATAAAAGCTGACGAGCGTTGAAACTCCCAGTC TCGTTTGGCCCGAGACAAATATGCGCTCTCCGCGACTCTCGTTGATTGTCGAATGCTTTGATTCATCAAAGTTTAATCTGCTCCAATTTTCCAAGGCAGTAGTCCGAAGTTTTCT TTCTTTTAGCCCGAGTTCTCACTCACGCTTGTCGACTCTGGTGCGAGCTGAAAATGTGTTTCAACCCACCCTAATAACTCTTATAGTCATGGACTTGTGTTTTAGTTTGGCCCTG GCTCAAGTGACAACTCGCACGTAAACACATAGCGCTTACAACAGTACTCGAAAGCAGATACGCTCATCTTTAATGTTACGTTAGAGTAAAATCAAGGGCAACCGACGTGCAAAT TCAACTAAAAGCTGTAGAGAGACATTTCAAAGTTCCTTGGAATGTATAAAGACTGTTAAAGAGATGTTTTTATTCGCTAGAAGAATTTGATCTGTTAGGATTTCTTAGCTAAAAAT TCGTGTCCGAAAATTTTAGGGAATGAAATCTTCCTTTCAGAAATTGCGAGCTAAAATTTACTTCCCACGAAATTCCTAGGCAACGATTTGCTTCAAGAAAATGCTAGCTGACCTT TTGAGTGCCACAAATACCAAATATCACCCTTTCGAAAACGTTATAGACTATTTGTCCACGGTTTCGAACCTTTTAGGCGGTGCTTCAGTTACCAAGACTATAGGTTTTGGTAAAC TTAGAATCCGAAAATCTTAGGCGGTTTCACTTGCCCGAACAGATATTTAACCCAAACGTCTTGTTGGTTGCCTTTGTAAAATTTGCAAAGGTTTCTAGGTAGTGAAAGTCTACTG AGATTTCTACCACCACTCGGTTAGATTACTGGCGATTGAGTTTAATCGCGCGTAGAAATTGCCGGCCCTTAAAAGTGTCGTACTTTAGACCTTGCCTCATTCCGATAATAAAAG AGAAATTGTTCATCAATTTCATCTGAACGGCAGGCTGACAATAATCTCTTTATTAAGAAAATGACGCCTAGTATTTTCCGAGCAAAAAACAAGATACATTGTTTCCGCCTTTACC GTGAATCACAAACTTCGGCTTTAGGGGGCTAAAAATAAATGGGTAACAAAACACATGCAAATACGGACGCCACGTTTCTTGTCAAATATATCATTCATTCCTGTTGAAAAAAGG CTTGAGCTGAATTTTGTCTTTGGACAAGCCAATATCCTCAATTAGGATGCTGAAACATTAGAAAGAGCACAAGTGATCTTTGAGAGCGCAGGGTAAGATTTATGACTTAAAAGG CATTATGCAGGCTCATGACATACTTCATGACAAGAACACACAGCGTAATGATCAACTGAGGAATACGTCAATGTGAAGCTTTGTTCAGCACGCCACCGATCCTGATAGAT CCCAGTTAATCATATCACGAAATATTTACAATTATGGATTAAGGAGAGCAAATCGTGCGAGCTGTTTATCATGCTATCGCCCGTATTTTTGTGGGTTTTGATCAACTTAGTTTTAA CACCGAGCCATTCTCTTAAAGTACCATTAATCTATTAATTGAAGGTTTACATCACGTTCGAGTAAATATTCATGAAGTTTATTTCTTGACATTGCGCTTTCCATGAGTATGACTAT GTGAACACAGCTGTTTCTATGGACTTTAACTGCACATCAATTAGGCTTCCAATGTGCTATCTCGCCACGTATAACGACCTCAGTATTTTACGAAACTTATCATTCGCACTGAGCA GGCTGCTAGAGCAGATAACAAGAGAACAAGGTAAACGTGAAGTTTCTTGTGGTGTTTTTTTCTTTTTCTTTTCCTTGTCGATGAATTATCCTTAGGGCCAAAATGAAGAGGGCTA CCTCTGGGAGGAATGTGCGGCTTCAATGTAACATATTTGGTAATAATAATCCTAAAGCGAGATGAGACAATTTAAACTAAGCAGAAAATGGCAGGAAATTAAGGTCGTTTCATT TAAAGGCGTAATTCTTCTTATTCAACGGTCATTTAGATCCTTCATGTATACCTTGTCCGTACATCTCGACAATCTCAATGCACAAAAAGCCATTTTAGGCCAAAACCAAAATGTTA AGTAGGTTTAAAATAACGCAGATAGTAGCCGCCGCGATAAGCTGTTGTCTTGATCCAATTGCAGAACCGACCCTGATCCTTGCAGATAACTGACTTGTCGCCTAGTGGAAAGT CAA

activator protein 1 (AP-1) upstream region (from NODE 1789852) TTCGCCAAAAAAAGAAAAAAAAAAGGGAAGAGCAATTTAAATTATTGTATTAGAGAAGGTATCTTAAACGAGTGGGGGCAAGGTTTTCCGTACTTCTATCCACTTCAAGTACCAA AGTGCCCCTCCGGTACTTAGATGATTTGTGTTCATACTGTTGAACGTTACGTGATACCCTGAAGTATTTTCCTCTACAACGCGTGACCAATGCGCGGCGTATTACACGTATTAC GAAGATGTCTTCTATTGTTTTCAAAAACAATAAAAGAAGAAGTAAAAACAAGGATGTCTTATTCAACCTAAAATAGAGCGATAAAAAACATCACACTTCGTCAATTTTCCATAAAT CGATCAACAACTCGTGATTGCACTTAATCGGGAAAAACCCATTCAAACATTTGATTATCACCAATCCTTCGACTTCCTAATTTTCCTCACCAGCTCTAATATCACCGAAACAAAG TTTTACTGTGTAATGGGAACAATCCCAGAAATTCTAGAATTAGTTTCGTTTCAGTTGGTTGCAGACAAGGCGTGTTCTGTTAAGTATCATTTGACAAAACAATTCCGCGTTTCATA AAAGGGTGTACTTCCGTTTGAAAACAAAGTGCGTGTCGCCTTTTCAACCTGCAAAGAGGGTGTGCCGTCTCGTGACAAACGTACGAGGCACCGTGGATGCAGGTAGCTGGAA GCACCGAACTTTTCATCCATTGTTAAACAGTCTTATCAATCAGGCTTCCGGTCAAGTTTACGACATGAACCTTCAGCTTACGAATAATTTCACGCAATTTATATTGGATTCTATGA TCCTATATTTCGCAATTTTTAAGAATTGGTTTTCTGTTGCTTACTGCTTGCTTCATTCTAGAGTCAAAAACTCTTAAAATAAAGCCCTTTGATCCTTGAAAGCAAGTTTCCTTTTGTT CTAAGATTGAGTCGACCACGAAGGTTCGAGGAAAGAATAATAGAACATAAATTCAGGAACACAATATAATTATGGCCACGGCGACGATTGTAATTTGTCGAAATTTCTCTTATAA TTACAATCACTCCTGTTTTCGGAGAAAAAAAGGGATATGTATTCCAATGTATATTTGTCTGCTTTGCGGGAAATAAAGAAAGTTTATCGATAAACGTTTGCACTTTTATCGCCTTT TATGGTAAATTTAGAGCTACACCAGGTGACGATTAAAACACAAGACTAGTTAAAATTCAACACACGATTTCAGAACTCATTAAATCACGCATCAAGGTTATTTTTTCTCTTTCAGT TTTTTGACCTAAGCTCGTCGATGAAATTAATGTCAACTGACAGCCCAATACGTGACTTCGGCAGCTAAATAAGTCGAGAAAGTTGAAGAAATAATTCAAGACCCAATATTTCAT GCAAACAAATTCAAATCTCAATCTGTCGAAAATGCAATAATCGTGGTTTTATCCTACTTATAAGACAATCGCAACCGAACGTGACAGTAAAAAATTTCACAACAAATTGTCACTTC ACTACTTCCAAGCCAAACAGATAATAAACTAAACTTCCACGTTCGTTTTCTCGGTATAAATTTCTGCCCTGAAGAAAGGAGGCTTTCCGGTAAATAAAAAAAAACTTTGTGAATC ATAAAATAAAAAGACTCAATTCTACTTGTATCAAACGTTCCAGAGCTTTCGATTGAGTTCTAGTTCTTGAAGCAATTCAAATCAACGGAAAATTCGCGCTTTACTGTCACTTAGGA ATTATGCCTTTTGTTTTCGGCATGTTTTCCGGTTGACGTCACGTTTCTAAGCCTTCTGTCAAGAACAACCAATCATCAGAAGCATTAGAACAAAGTTCAAAGATATGACCAATCA GAGTTTAGATGACATATTTTTGCCAAAAATAGTAACTGACTCAAACTTTATTTGAATTCGATTTCGACGGAAATAAAAGTTGCGTTTTGCTGTAATCACGAGCGGTGTAAAACGTT ACAAAGGCAATTTGAAGCTTGATTTTACATCAA

Table 3. Sequences upstream of inhibitor of nuclear factor kappa beta, mannose-binding lectin, and activator protein 1, mined from A. millepora draft genome

(www.coralbase.org). Assembly node indicates the assembly contig of origin. Annealing sites of primers are indicated with bold type. The first 100 base pairs of coding sequence are designated with bold type, with the sense strand shown. 


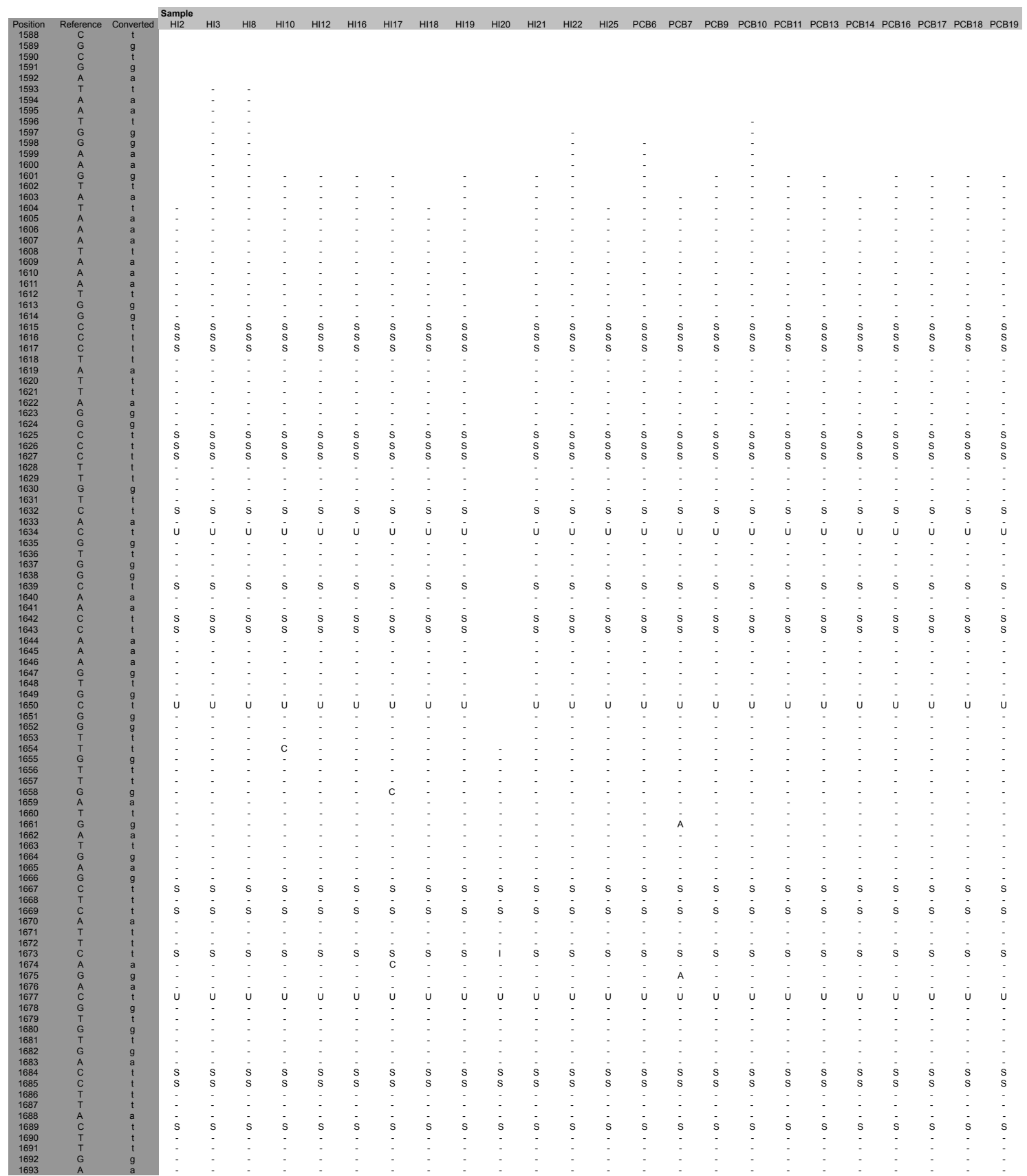

Table 4. Bisulfite sequencing results from $I \kappa B$ upstream region. Successful conversion of non-CpG cytosines is indicated by "S." Unmethylated cytosines within CpG sites are noted with "U." Methylated cytosines within $\mathrm{CpG}$ islands would be indicated with "M" (none are present). (Table continues on following page.) 


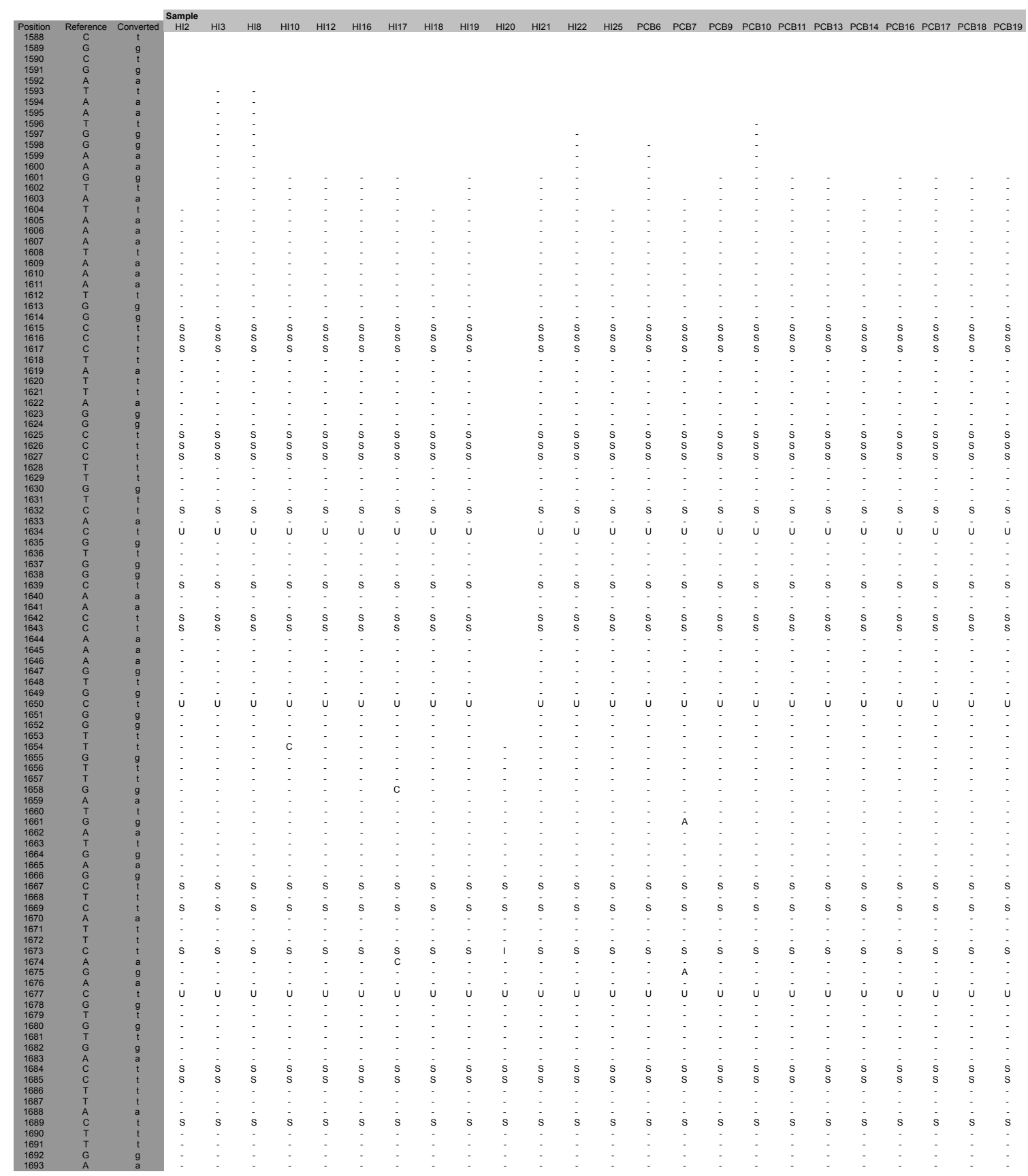

Table 4. Bisulfite sequencing results from $I \kappa B$ upstream region (continued from previous page). 


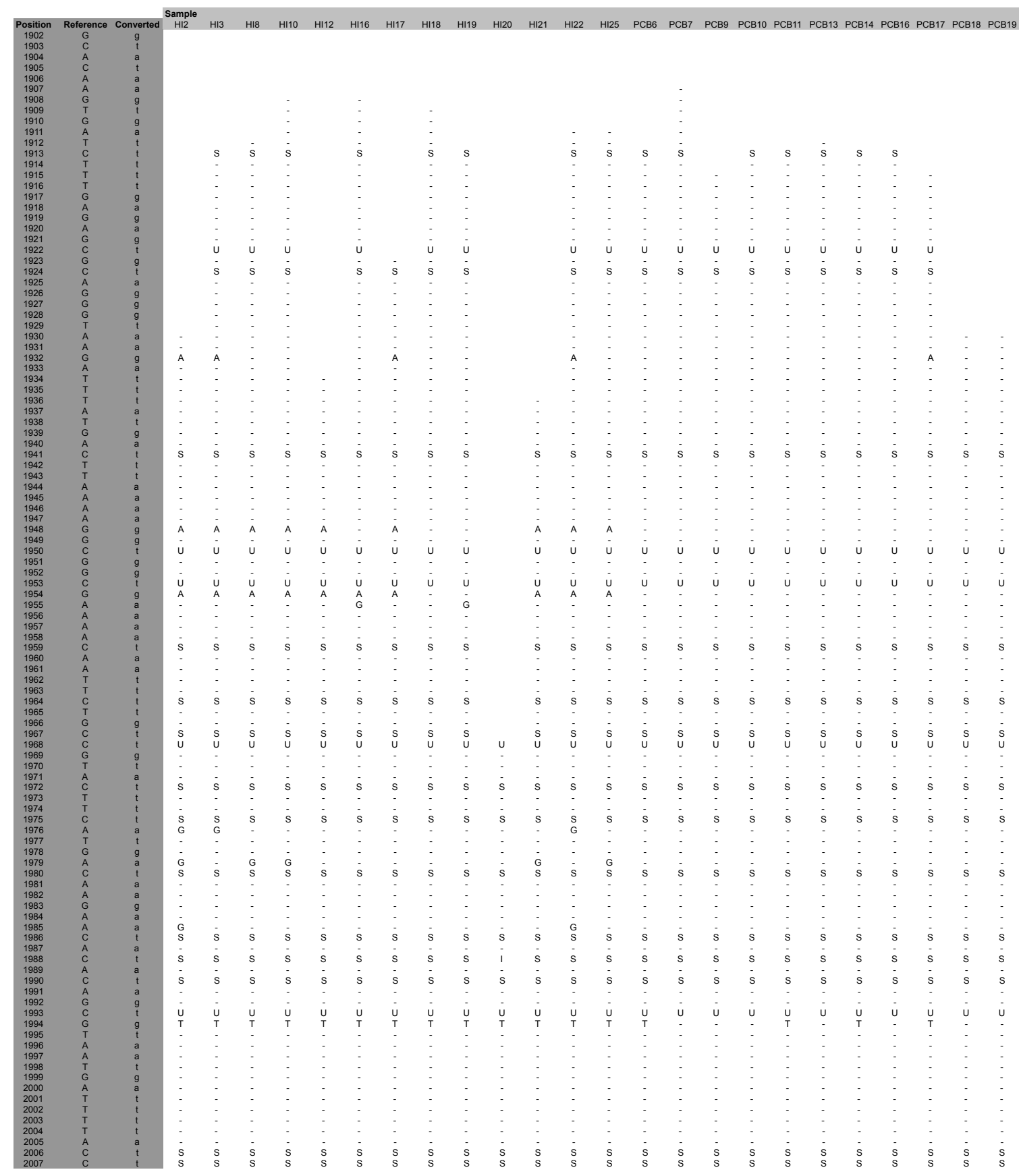

Table 5. Bisulfite sequencing results from $M B L$ upstream region. Successful conversion of non-CpG cytosines is indicated by "S." Unmethylated cytosines within CpG sites are noted with "U." Methylated cytosines within $\mathrm{CpG}$ islands would be indicated with "M" (none are present). (Table continues on following page.) 


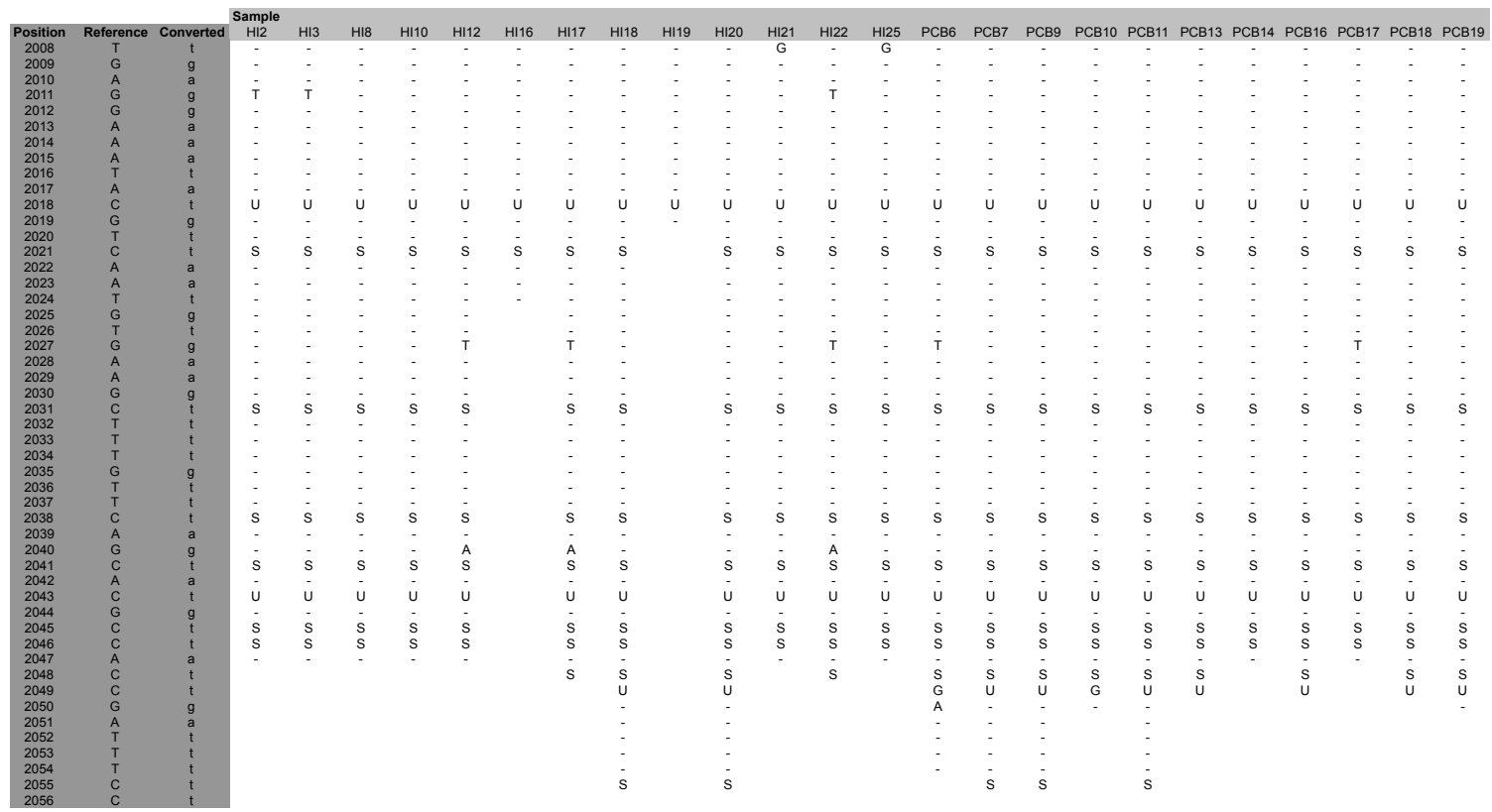

Table 5. Bisulfite sequencing results from MBL upstream region (continued from previous page). 


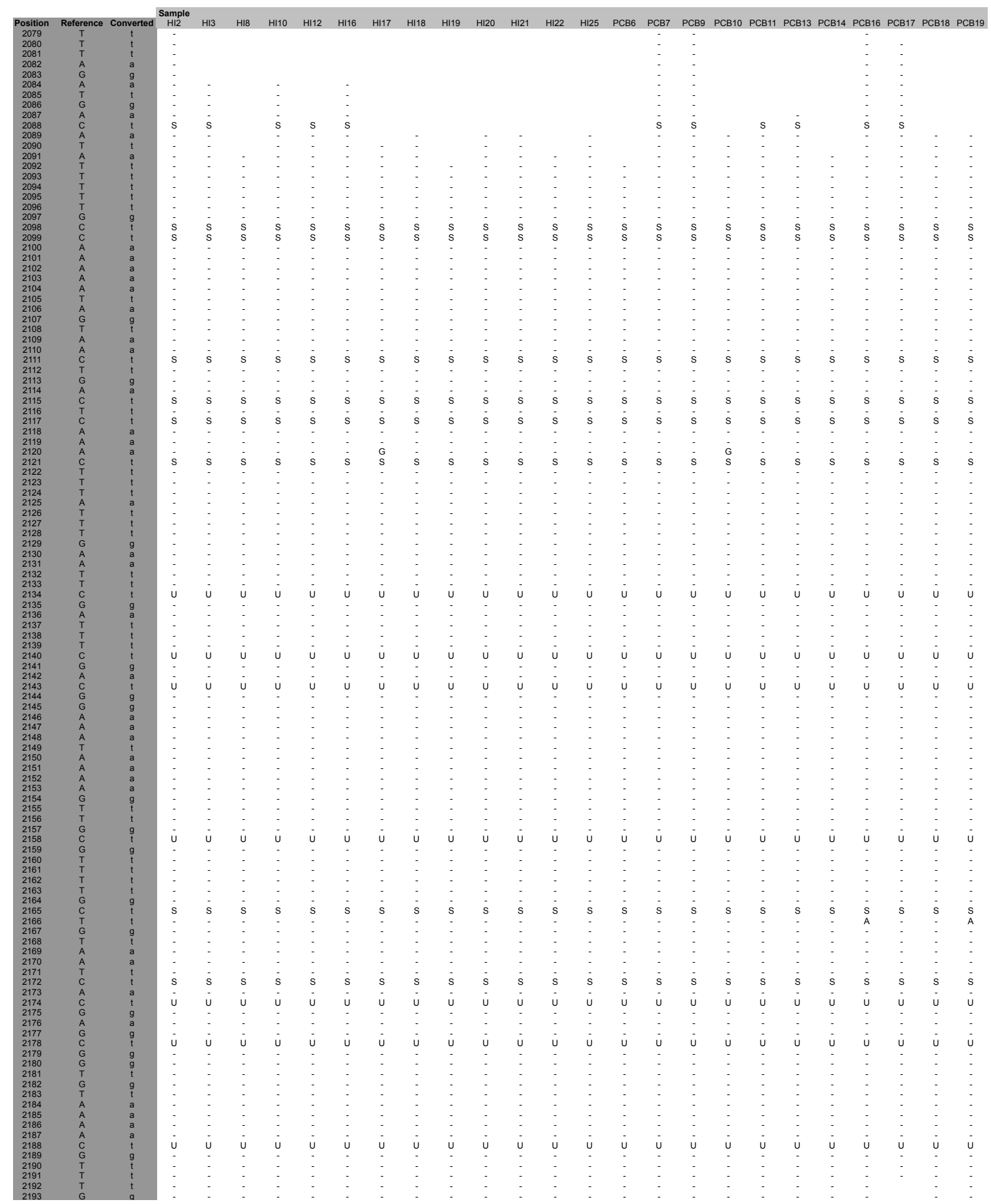

Table 6. Bisulfite sequencing results from $A P-1$ upstream region. Successful conversion of non-CpG cytosines is indicated by "S." Unmethylated cytosines within CpG sites are noted with "U." Methylated cytosines within $\mathrm{CpG}$ islands would be indicated with "M" (none are present). 


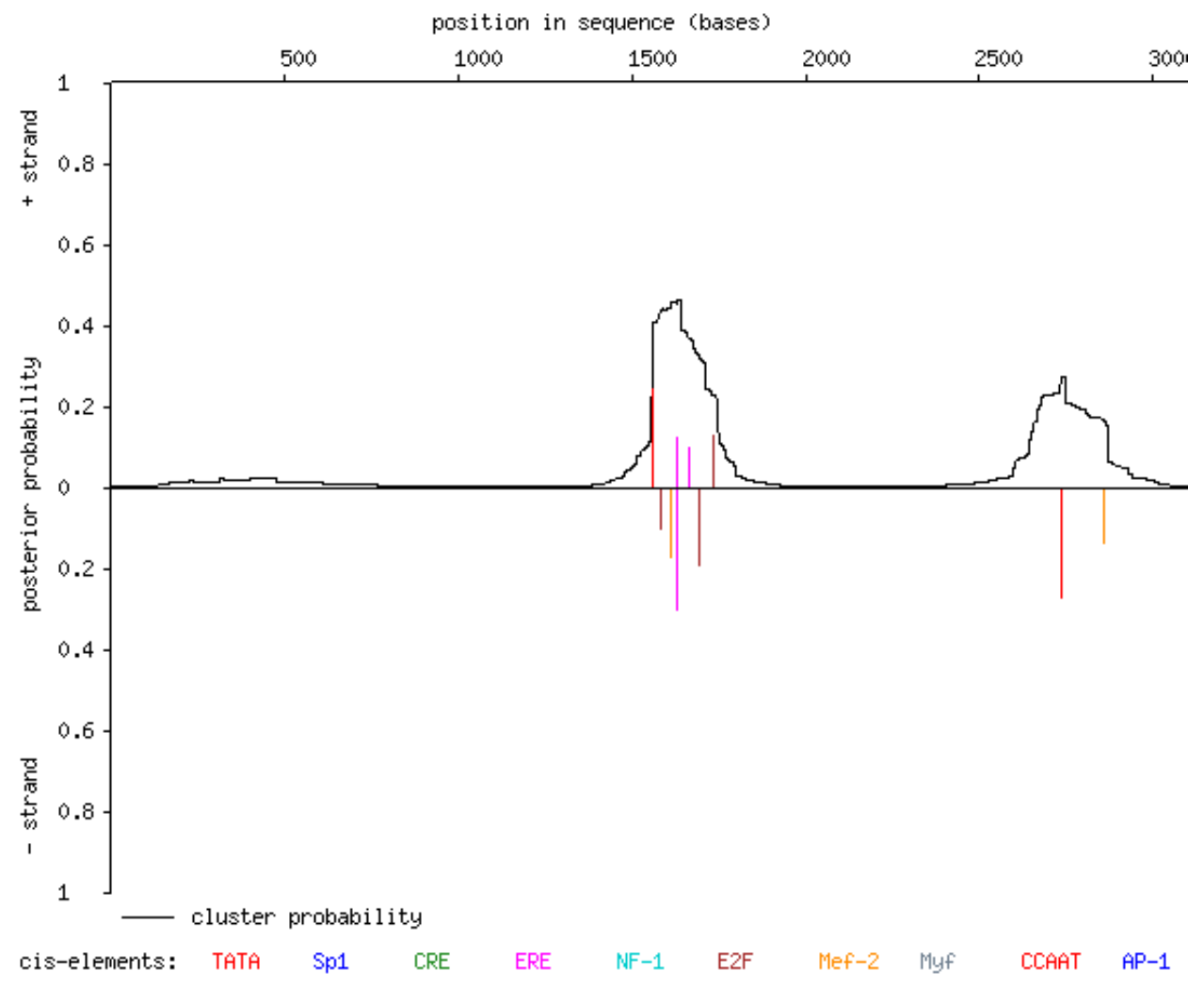

Figure 4. Plot of promoter posterior probabilities of inhibitor of nuclear factor kappa beta $(I \kappa B)$ upstream region (sequence analyzed shown in Table 3) with Cister [69]. 


\begin{tabular}{|l|l|l|l|}
\hline Type & Strand & Position & Sequence \\
\hline CCAAT & + & 1560 to 1575 & tgcagccaatcactac \\
\hline Myc & + & 1630 to 1639 & gtcacgtggc \\
\hline ERE & + & 1665 to 1678 & agctcattcagacg \\
\hline LSF & + & 1734 to 1748 & acaggctagttccgg \\
\hline E2F & - & 1583 to 1594 & gaggccgcgata \\
\hline SRF & - & 1614 to 1626 & gcctattaggcc \\
\hline Myc & - & 1630 to 1639 & gtcacgtggc \\
\hline LSF & - & 1695 to 1709 & cgagctttaacctgc \\
\hline CCAAT & - & 2734 to 2749 & ttgctgattggccagt \\
\hline SRF & - & 2859 to 2871 & gccatcttggtc \\
\hline
\end{tabular}

Table 7. Promoter-like elements and positions identified in inhibitor of nuclear factor kappa beta $(I \kappa B)$ upstream region using Cister [69]. 


\begin{tabular}{|l|l|l|}
\hline Name & Strand & Location \\
\hline junB-US2 & + & 487 \\
\hline Sp1 & + & 575 \\
\hline myosin-specific & - & 542 \\
\hline MBF-I & - & 551 \\
\hline CREB & - & 566 \\
\hline Sp1 & - & 580 \\
\hline CREB & - & 668 \\
\hline E2F & - & 2134 \\
\hline AABS_CS2 & - & 2350 \\
\hline
\end{tabular}

Table 8. Promoter-like elements and positions identified in $M B L$ upstream region using Proscan Version 1.7 [68]. One promoter region is predicted on the forward strand at positions 427 to 677, with a second located on the reverse strand at position 2380 to 2130 . 


\begin{tabular}{|l|l|l|}
\hline Name & Strand & Location \\
\hline TFIID & + & 1784 \\
\hline beta-pol_CS & + & 1993 \\
\hline CREB & + & 1994 \\
\hline ATF & + & 1994 \\
\hline CREB & + & 1995 \\
\hline E4F1 & + & 1996 \\
\hline ATF/CREB & + & 1996 \\
\hline CREB & + & 1997 \\
\hline CP1 & + & 2027 \\
\hline AP-1 & + & 2112 \\
\hline INF.1 & - & 1956 \\
\hline CREB & - & 1998 \\
\hline ATF/CREB & - & 1999 \\
\hline CREB & - & 2000 \\
\hline CREB & - & 2001 \\
\hline ATF & - & 2001 \\
\hline CREB & - & 2001 \\
\hline ATF & - & 2001 \\
\hline ATF & - & 2002 \\
\hline beta-pol_CS & - & 2002 \\
\hline C-fos_US5 & - & 2002 \\
\hline EivF & - & 2002 \\
\hline c-fos_US5 & - & 2002 \\
\hline E4TF1 & - & 2002 \\
\hline EivF & - & 2002 \\
\hline EivF/CREB & - & 2002 \\
\hline MLTF & - & 2003 \\
\hline CTF & - & 2034 \\
\hline HNF1 & - & 2042 \\
\hline CTF & - & 2074 \\
\hline Y & - & 2076 \\
\hline AP-1 & - & 2118 \\
\hline PEA1 & - & 2118 \\
\hline & & \\
\hline
\end{tabular}

Table 9. Promoter-like elements and positions identified in $A P-1$ upstream region using Proscan Version 1.7 [68]. One promoter region is predicted on the forward strand at positions 1784 to 2034, with a second located on the reverse strand at position 3175 to 1925. 


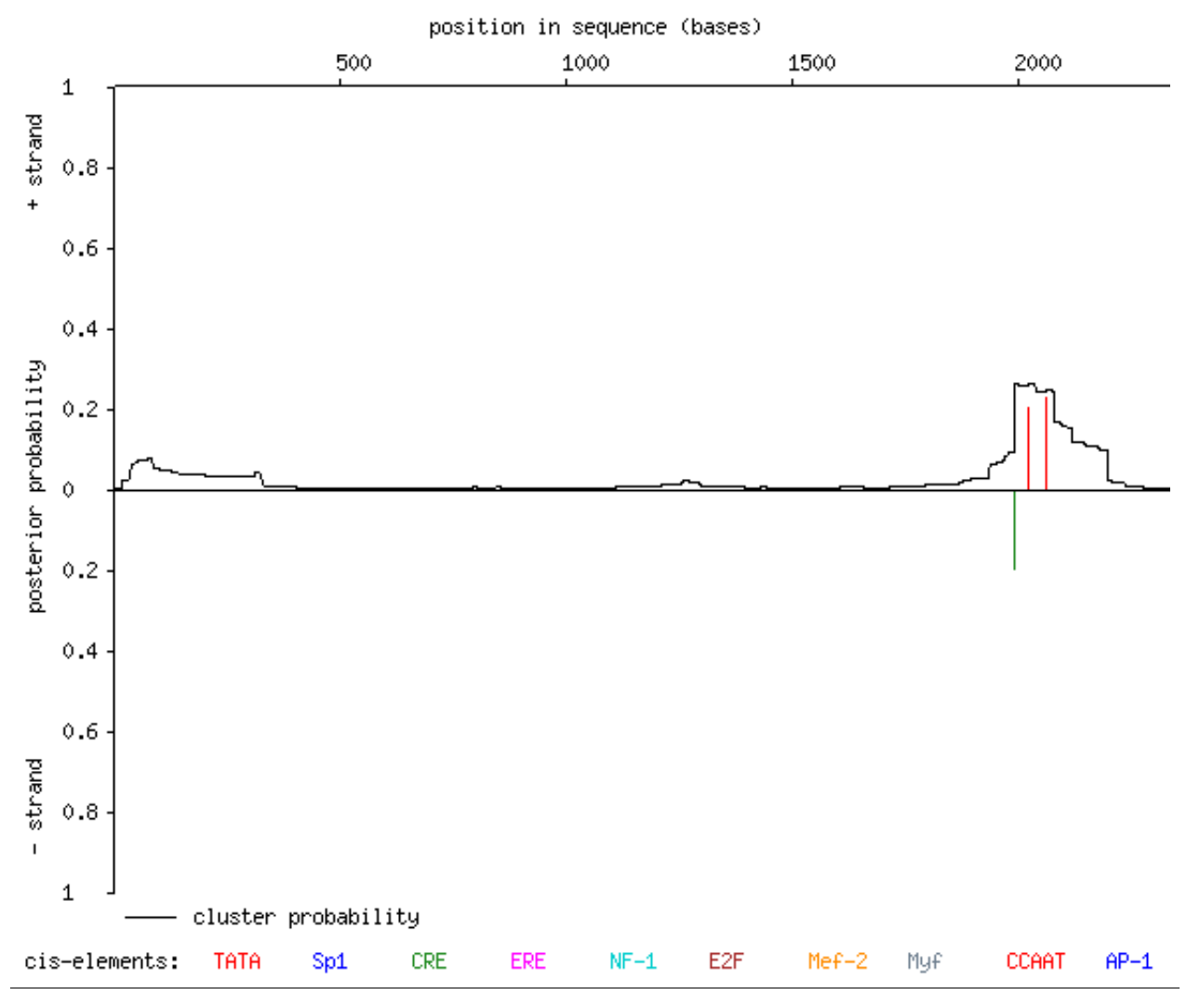

Figure 5. Plot of promoter posterior probabilities of activator protein 1 (AP-1) upstream region (sequence analyzed shown in Table 3) with Cister [69]. 


\begin{tabular}{|l|l|l|l|}
\hline Type & Strand & Position & Sequence \\
\hline CCAAT & + & 2024 to 2039 & aacaaccaatcatcag \\
\hline CCAAT & + & 2064 to 2079 & tatgaccaatcagagt \\
\hline CRE & - & 1992 to 2003 & gttgacgtcacg \\
\hline
\end{tabular}

Table 10. Promoter-like elements and positions identified in activator protein $1(A P-1)$ upstream region using Cister [69]. 


\subsection{References}

1. $\quad$ Fitt W.K., Brown B.E., Warner M.E., Dunne R.P. 2001 Coral bleaching: interpretation of thermal tolerance limits and thermal thresholds in tropical corals. Coral Reefs 20(1), 51-65. (doi:10.1007/s003380100146).

2. Gates R.D., Edmunds P.J. 1999 The physiological mechanisms of acclimatization in tropical reef corals. Am Zool 39(1), 30-43.

3. Glynn P.W. 1993 Coral reef bleaching - ecological perspectives. Coral Reefs 12(1), 1-17. (doi:10.1007/bf00303779).

4. Hoegh-Guldberg O., Mumby P.J., Hooten A.J., Steneck R.S., Greenfield P., Gomez E., Harvell C.D., Sale P.F., Edwards A.J., Caldeira K., et al. 2007 Coral reefs under rapid climate change and ocean acidification. Science 318(5857), 1737-1742. (doi:10.1126/science.1152509).

5. Hughes T.P., Baird A.H., Bellwood D.R., Card M., Connolly S.R., Folke C., Grosberg R., Hoegh-Guldberg O., Jackson J.B.C., Kleypas J., et al. 2003 Climate change, human impacts, and the resilience of coral reefs. Science 301(5635), 929-933.

6. Donner S.D. 2009 Coping with commitment: projected thermal stress on coral reefs under different future scenarios. PLoS ONE 4(6).

(doi:e571210.1371/journal.pone.0005712).

7. Maynard J.A., Anthony K.R.N., Marshall P.A., Masiri I. 2008 Major bleaching events can lead to increased thermal tolerance in corals. Mar Biol 155(2), 173-182. (doi:10.1007/s00227-008-1015-y).

8. Guest J.R., Baird A.H., Maynard J.A., Muttaqin E., Edwards A.J., Campbell S.J., Yewdall K., Affendi Y.A., Chou L.M. 2012 Contrasting Patterns of Coral Bleaching Susceptibility in 2010 Suggest an Adaptive Response to Thermal Stress. PLoS ONE 7(3). (doi:e3335310.1371/journal.pone.0033353).

9. Brown B.E., Cossins A.R. The potential for temperature acclimatisation of reef corals in the face of climate change. In Coral Reefs: An Ecosystem in Transition (pp. 421-433, Springer.

10. Baker A.C. 2001 Reef corals bleach to survive change. Nature 411(6839), 765766.

11. Baker A.C., Starger C.J., McClanahan T.R., Glynn P.W. 2004 Corals' adaptive response to climate change. Nature 430(7001), 741-741. (doi:10.1038/430741a).

12. Berkelmans R., van Oppen M.J.H. 2006 The role of zooxanthellae in the thermal tolerance of corals: a 'nugget of hope' for coral reefs in an era of climate change. Proc $R$ Soc Lond, Ser B: Biol Sci 273(1599), 2305-2312. (doi:10.1098/rspb.2006.3567). 
13. Rowan R. 2004 Coral bleaching - Thermal adaptation in reef coral symbionts. Nature 430(7001), 742-742. (doi:10.1038/430742a).

14. Reshef L., Koren O., Loya Y., Zilber-Rosenberg I., Rosenberg E. 2006 The coral probiotic hypothesis. Environ Microbiol 8(12), 2068-2073. (doi:10.1111/j.14622920.2006.01148.x).

15. Rosenberg E., Koren O., Reshef L., Efrony R., Zilber-Rosenberg I. 2007 The role of microorganisms in coral health, disease and evolution. Nature Reviews Microbiology 5(5), 355-362. (doi:10.1038/nrmicro1635).

16. van Oppen M.J.H., Souter P., Howells E.J., Heyward A., Berkelmans R. 2011 Novel genetic diversity through somatic mutations: fuel for adaptation of reef corals? Diversity 3(3), 405-423.

17. Baird A.H., Bhagooli R., Ralph P.J., Takahashi S. 2009 Coral bleaching: the role of the host. Trends Ecol Evol 24(1), 16-20. (doi:10.1016/j.tree.2008.09.005).

18. Bellantuono A.J., Granados-Cifuentes C., Miller D.J., Hoegh-Guldberg O., Rodriguez-Lanetty M. 2012 Coral thermal tolerance: tuning gene expression to resist thermal stress. PLoS ONE 7(11). (doi:e50685

10.1371/journal.pone.0050685).

19. Bellantuono A.J., Hoegh-Guldberg O., Rodriguez-Lanetty M. 2012 Resistance to thermal stress in corals without changes in symbiont composition. Proc R Soc Lond, Ser B: Biol Sci 279(1731), 1100-1107. (doi:10.1098/rspb.2011.1780).

20. Berkelmans R., De,Äôath G., Kininmonth S., Skirving W.J. 2004 A comparison of the 1998 and 2002 coral bleaching events on the Great Barrier Reef: spatial correlation, patterns, and predictions. Coral Reefs 23(1), 74-83.

21. Goulet T.L. 2006 Most corals may not change their symbionts. Mar Ecol Prog Ser 321, 1-7.

22. Goulet T.L., Coffroth M.A. 2003 Stability of an octocoral-algal symbiosis over time and space. Mar Ecol Prog Ser 250, 117-124. (doi:10.3354/meps250117).

23. Thornhill D.J., LaJeunesse T.C., Kemp D.W., Fitt W.K., Schmidt G.W. 2006 Multi-year, seasonal genotypic surveys of coral-algal symbioses reveal prevalent stability or post-bleaching reversion. Mar Biol 148(4), 711-722. (doi:10.1007/s00227-005-0114-2).

24. Sampayo E., Ridgway T., Bongaerts P., Hoegh-Guldberg O. 2008 Bleaching susceptibility and mortality of corals are determined by fine-scale differences in symbiont type. Proc Natl Acad Sci U S A 105(30), 10444. 
25. Coffroth M.A., Poland D.M., Petrou E.L., Brazeau D.A., Holmberg J.C. 2010 Environmental symbiont acquisition may not be the solution to warming seas for reefbuilding corals. PLOS ONE 5(10), e13258.

26. Little A.F., van Oppen M.J.H., Willis B.L. 2004 Flexibility in algal endosymbioses shapes growth in reef corals. Science 304(5676), 1492-1494. (doi:10.1126/science.1095733).

27. Rodriguez-Lanetty M., Krupp D.A., Weis V.M. 2004 Distinct ITS types of Symbiodinium in Clade C correlate with cnidarian/dinoflagellate specificity during onset of symbiosis. Mar Ecol Prog Ser 275, 97-102.

28. Ortiz J.C., Gonzalez-Rivero M., Mumby P.J. Can a thermally tolerant symbiont improve the future of Caribbean coral reefs? Global Change Biol 19(1), 273-281. (doi:10.1111/gcb.12027).

29. Brown B.E., Dunne R.P., Warner M.E., Ambarsari I., Fitt W.K., Gibb S.W., Cummings D.G. 2000 Damage and recovery of Photosystem II during a manipulative field experiment on solar bleaching in the coral Goniastrea aspera. Mar Ecol Prog Ser 195, $117-124$.

30. Thompson D.M., van Woesik R. 2009 Corals escape bleaching in regions that recently and historically experienced frequent thermal stress. Proc R Soc Lond, Ser B: Biol Sci 276(1669), 2893-2901. (doi:10.1098/rspb.2009.0591).

31. Boyko A., Kovalchuk I. 2008 Epigenetic control of plant stress response. Environ Mol Mutagen 49(1), 61-72.

32. Barshis D.J., Ladner J.T., Oliver T.A., Seneca F.O., Traylor-Knowles N., Palumbi S.R. 2012 Genomic basis for coral resilience to climate change. Proc Natl Acad Sci U S A 110(4), 1387-1392. (doi:10.1073/pnas.1210224110).

33. Carroll S.B. 2000 Endless forms: the evolution of gene regulation and morphological diversity. Cell 101(6), 577-580. (doi:10.1016/s0092-8674(00)80868-5).

34. Carroll S.B. 2008 Evo-devo and an expanding evolutionary synthesis: A genetic theory of morphological evolution. Cell 134(1), 25-36. (doi:10.1016/j.cell.2008.06.030).

35. Turner B.M. 2009 Epigenetic responses to environmental change and their evolutionary implications. Philosophical Transactions of the Royal Society B-Biological Sciences 364(1534), 3403-3418. (doi:10.1098/rstb.2009.0125).

36. Jirtle R.L., Skinner M.K. 2007 Environmental epigenomics and disease susceptibility. Nat Rev Genet 8(4), 253-262. (doi:10.1038/nrg2045). 
37. Gavery M.R., Roberts S.B. DNA methylation patterns provide insight into epigenetic regulation in the Pacific oyster (Crassostrea gigas). BMC Genomics 11. (doi:48310.1186/1471-2164-11-483).

38. Kundu S., Horn P.J., Peterson C.L. 2007 SWI/SNF is required for transcriptional memory at the yeast GAL gene cluster. Genes Dev 21(8), 997-1004. (doi:10.1101/gad.1506607).

39. Armaleo D., Miao V. 1999 Symbiosis and DNA methylation in the Cladonia lichen fungus. Symbiosis 26(2), 143-163.

40. Danchin â., Charmantier A., Champagne F.A., Mesoudi A., Pujol B., Blanchet S. Beyond DNA: integrating inclusive inheritance into an extended theory of evolution. Nat Rev Genet 12(7), 475-486.

41. Jablonka E., Lamb M.J. 1989 The inheritance of acquired epigenetic variations. $J$ Theor Biol 139(1), 69-83.

42. Jablonka E., Raz G. 2009 Transgenerational epigenetic inheritance: prevalence, mechanisms, and implications for the study of heredity and evolution. The Quarterly review of biology $\mathbf{8 4}(2), 131-176$.

43. Verhoeven K.J., van Gurp T.P. 2012 Transgenerational effects of stress exposure on offspring phenotypes in apomictic dandelion. PLOS ONE 7(6), e38605.

44. Cubas P., Vincent C., Coen E. 1999 An epigenetic mutation responsible for natural variation in floral symmetry. Nature 401(6749), 157-161.

45. Johannes F., Porcher E., Teixeira F.K., Saliba-Colombani V., Simon M., Agier N., Bulski A., Albuisson J., Heredia F., Audigier P., et al. 2009 Assessing the impact of transgenerational epigenetic variation on complex traits. PLoS Genet 5(6). (doi:e100053010.1371/journal.pgen.1000530).

46. Scoville A.G., Barnett L.L., Bodbyl-Roels S., Kelly J.K., Hileman L.C. 2011 Differential regulation of a MYB transcription factor is correlated with transgenerational epigenetic inheritance of trichome density in Mimulus guttatus. New Phytol 191(1), 251263. (doi:10.1111/j.1469-8137.2011.03656.x).

47. Steward N., Ito M., Yamaguchi Y., Koizumi N., Sano H. 2002 Periodic DNA methylation in maize nucleosomes and demethylation by environmental stress. $J$ Biol Chem 277(40), 37741-37746. (doi:10.1074/jbc.M204050200).

48. Labra M., Vannini C., Sala E., Bracale M. 2002 Methylation changes in specific sequences in response to water deficit. Plant Biosyst 136(3), 269-275. (doi:10.1080/11263500212331351179). 
49. Dyachenko O.V., Zakharchenko N.S., Shevchuk T.V., Bohnert H.J., Cushman J.C., Buryanov Y.I. 2006 Effect of hypermethylation of CCWGG sequences in DNA of Mesembryanthemum crystallinum plants on their adaptation to salt stress. BiochemistryMoscow 71(4), 461-465. (doi:10.1134/s000629790604016x).

50. Chinnusamy V., Zhu J.K. 2009 Epigenetic regulation of stress responses in plants. Curr Opin Plant Biol 12(2), 133-139.

51. Steele R.E., David C.N., Technau U. 2011 A genomic view of 500 million years of cnidarian evolution. Trends Genet 27(1), 7-13. (doi:10.1016/j.tig.2010.10.002).

52. Moczek A.P., Sultan S., Foster S., Ledon-Rettig C., Dworkin I., Nijhout H.F., Abouheif E., Pfennig D.W. 2011 The role of developmental plasticity in evolutionary innovation. Proceedings of the Royal Society B-Biological Sciences 278(1719), 27052713. (doi:10.1098/rspb.2011.0971).

53. Kusserow A., Pang K., Sturm C., Hrouda M., Lentfer J., Schmidt H.A., Technau U., von Haeseler A., Hobmayer B., Martindale M.Q., et al. 2005 Unexpected complexity of the Wnt gene family in a sea anemone. Nature 433(7022), 156-160. (doi:10.1038/nature03158).

54. Csaszar N.B.M., Ralph P.J., Frankham R., Berkelmans R., van Oppen M.J.H. 2010 Estimating the potential for adaptation of corals to climate warming. PLoS ONE 5(3). (doi:e9751 10.1371/journal.pone.0009751).

55. Polato N.R., Voolstra C.R., Schnetzer J., DeSalvo M.K., Randall C.J., Szmant A.M., Medina M., Baums I.B. 2010 Location-specific responses to thermal stress in larvae of the reef-building coral Montastraea faveolata. PLoS ONE 5(6). (doi:e1122110.1371/journal.pone.0011221).

56. Polato N.R., Altman N.S., Baums I.B. 2013 Variation in the transcriptional response of threatened coral larvae to elevated temperatures. Mol Ecol 22(5), 1366-1382. (doi:10.1111/mec.12163).

57. Howells E.J., Beltran V.H., Larsen N.W., Bay L.K., Willis B.L., van Oppen M.J.H. 2012 Coral thermal tolerance shaped by local adaptation of photosymbionts. Nature Climate Change 2(2), 116-120. (doi:10.1038/nclimate1330).

58. van Oppen M.J.H., Peplow L.M., Kininmonth S., Berkelmans R. 2011 Historical and contemporary factors shape the population genetic structure of the broadcast spawning coral, Acropora millepora, on the Great Barrier Reef. Mol Ecol.

59. Shaulian E., Karin M. 2002 AP-1 as a regulator of cell life and death. Nat Cell Biol 4(5), E131-E136.

60. Weis V.M. 2008 Cellular mechanisms of cnidarian bleaching: stress causes the collapse of symbiosis. J Exp Biol 211(19), 3059-3066. (doi:10.1242/jeb.009597). 
61. Meints R.H., Pardy R.L. 1980 Quantitative demonstration of cell surface involvement in a plant-animal symbiosis: lectin inhibition of reassociation. J Cell Sci 43(JUN), 239-251.

62. Wood-Charlson E.M., Hollingsworth L.L., Krupp D.A., Weis V.M. 2006 Lectin/glycan interactions play a role in recognition in a coral/dinoflagellate symbiosis. Cell Microbiol 8(12), 1985-1993. (doi:10.1111/j.1462-5822.2006.00765.x).

63. Rodriguez-Lanetty M., Harii S., Hoegh-Guldberg O. 2009 Early molecular responses of coral larvae to hyperthermal stress. Mol Ecol 18(24), 5101-5114. (doi:10.1111/j.1365-294X.2009.04419.x).

64. Vidal-Dupiol J., Adjeroud M., Roger E., Foure L., Duval D., Mone Y., FerrierPages C., Tambutte E., Tambutte S., Zoccola D., et al. 2009 Coral bleaching under thermal stress: putative involvement of host/symbiont recognition mechanisms. $B M C$ Physiol 9(14), 1-16.

65. Altschul S.F., Madden T.L., Schaffer A.A., Zhang J.H., Zhang Z., Miller W., Lipman D.J. 1997 Gapped BLAST and PSI-BLAST: a new generation of protein database search programs. Nucleic Acids Res 25(17), 3389-3402. (doi:10.1093/nar/25.17.3389).

66. Slater G.S., Birney E. 2005 Automated generation of heuristics for biological sequence comparison. BMC Bioinformatics 6. (doi:3110.1186/1471-2105-6-31).

67. Li L.C., Dahiya R. 2002 MethPrimer: designing primers for methylation PCRs. Bioinformatics 18(11), 1427-1431. (doi:10.1093/bioinformatics/18.11.1427).

68. Prestridge D.S. 2000 Computer software of eukaryotic promoter analysis. In Transcription factor protocols (pp. 265-295, Springer.

69. Frith M.C., Hansen U., Weng Z.P. 2001 Detection of cis-element clusters in higher eukaryotic DNA. Bioinformatics 17(10), 878-889.

(doi:10.1093/bioinformatics/17.10.878).

70. Frommer M., McDonald L.E., Millar D.S., Collis C.M., Watt F., Grigg G.W., Molloy P.L., Paul C.L. 1992 A genomic sequencing protocol that yields a positive display of 5-methylcytosine residues in individual dna strands. Proc Natl Acad Sci US A 89(5), 1827-1831. (doi:10.1073/pnas.89.5.1827).

71. Wojdacz T.K., Dobrovic A. 2007 Methylation-sensitive high resolution melting (MS-HRM): a new approach for sensitive and high-throughput assessment of methylation. Nucleic Acids Res 35(6). (doi:10.1093/nar/gkm013).

72. Wojdacz T.K., Moller T.H., Thestrup B.B., Kristensen L.S., Hansen L.L. 2010 Limitations and advantages of MS-HRM and bisulfite sequencing for single locus 
methylation studies. Expert Review of Molecular Diagnostics 10(5), 575-580. (doi:10.1586/erm.10.46).

73. R_Development_Core_Team. $2011 \mathrm{R}$ : A language and environment for statistical computing. (Vienna, Austria, R Foundation for Statistical Computing.

74. Yoo B.K., Gredler R., Vozhilla N., Su Z.Z., Chen D., Forcier T., Shah K., Saxena U., Hansen U., Fisher P.B., et al. 2009 Identification of genes conferring resistance to 5fluorouracil. Proc Natl Acad Sci U S A 106(31), 12938-12943. (doi:10.1073/pnas.0901451106).

75. Donner S.D., Skirving W.J., Little C.M., Oppenheimer M., Hoegh-Guldberg O. 2005 Global assessment of coral bleaching and required rates of adaptation under climate change. Global Change Biol 11(12), 2251-2265.

76. Hoegh-Guldberg O. 1999 Climate change, coral bleaching and the future of the world's coral reefs. Mar Freshw Res 50(8), 839-866. (doi:10.1071/mf99078).

77. McDermott D.H., Zimmerman P.A., Guignard F., Kleeberger C.A., Leitman S.F., Murphy P.M., Multicenter A.C.S.M. 1998 CCR5 promoter polymorphism and HIV-1 disease progression. Lancet 352(9131), 866-870. (doi:10.1016/s0140-6736(98)04158-0).

78. Kraan T., van Veen A., Boeije L.C.M., van Tuyl S.A.P., de Groot E.R., Stapel S.O., Bakker A., Verweij C.L., Aarden L.A., van der Zee J.S. 1999 An IL-13 promoter polymorphism associated with increased risk of allergic asthma. Genes Immun 1(1), 6165.

79. Caspi A., Sugden K., Moffitt T.E., Taylor A., Craig I.W., Harrington H., McClay J., Mill J., Martin J., Braithwaite A., et al. 2003 Influence of life stress on depression: moderation by a polymorphism in the 5-HTT gene. Science 301(5631), 386-389. (doi:10.1126/science.1083968).

80. Jacob F., Monod J. 1961 Genetic regulatory mechanisms in the synthesis of proteins. J Mol Biol 3(3), 318-356.

81. Zuckerkandl E., Pauling L.B. 1965 Evolutionary divergence and convergence in proteins. In Evolving Genes and Proteins (eds. Bryson V., Vogel H.), pp. 97-166. New York, NY, Academic Press.

82. King M.-C., Wilson A.C. 1975 Evolution at two levels in humans and chimpanzees. Science 188(4184), 107-116.

83. Jacob F.o. 1977 Evolution and tinkering. Science 196(4295), 1161-1166.

84. Gottgens B., Ferreira R., Sanchez M.J., Ishibashi S., Li J.A., Spensberger D., Lefevre P., Ottersbach K., Chapman M., Kinston S., et al. 2010 Cis-regulatory 
remodeling of the SCL locus during vertebrate evolution. Mol Cell Biol 30(24), 57415751. (doi:10.1128/mcb.00870-10).

85. Luo Y., Vijaychander S., Stile J., Zhu L. 1996 Cloning and analysis of DNABinding proteins by yeast one-hybrid and one-two-hybrid systems. Biotechniques 20(4), 564-568.

86. Fan F., Wood K.V. 2007 Bioluminescent assays for high-throughput screening. Assay Drug Dev Technol 5(1), 127-136. (doi:10.1089/adt.2006.053).

87. Mandrioli M. 2007 A new synthesis in epigenetics: towards a unified function of DNA methylation from invertebrates to vertebrates. Cell Mol Life Sci 64(19-20), 25222524. (doi:10.1007/s00018-007-7231-7).

88. Hunt B.G., Brisson J.A., Yi S.V., Goodisman M.A.D. 2010 Functional conservation of dna methylation in the pea aphid and the honeybee. Genome Biology and Evolution 2, 719-728. (doi:10.1093/gbe/evq057).

89. $\quad$ Foret S., Kucharski R., Pellegrini M., Feng S.H., Jacobsen S.E., Robinson G.E., Maleszka R. 2012 DNA methylation dynamics, metabolic fluxes, gene splicing, and alternative phenotypes in honey bees. Proc Natl Acad Sci U S A 109(13), 4968-4973. (doi:10.1073/pnas.1202392109).

90. Granados-Cifuentes C., Bellantuono A.J., Ridgway T., Hoegh-Guldberg O., Rodriguez-Lanetty M. 2013 High natural gene expression variation in the reef-building coral Acropora millepora: potential for acclimative and adaptive plasticity. BMC Genomics 14. (doi:10.1186/1471-2164-14-228). 


\section{Chapter 5: Conclusions and future investigations}

\subsection{Conclusions}

This dissertation was built upon questions of coral acclimatization, resilience, and adaptation in a changing climate. The primary aims of this dissertation focused on ascertaining the capacity for a reef building coral to acquire thermal tolerance in a controlled experimental setting, determining whether changes were a consequence of alterations of symbiotic partnerships between the host and the dinoflagellate and prokaryotic community, and then identifying the molecular underpinnings of coral thermal tolerance, from a host transcriptomic perspective as well as a survey of cisregulatory elements.

Chapter 2 asked whether coral can acclimatize to thermal stress via preconditioning, and whether any increases in thermal tolerance as a result of prestress were associated with changes in the symbiotic community of the host. By experimentally preconditioning $A$. millepora to sublethal heat stress and subsequently challenging with thermal stress in comparison to non-preconditioned corals, Chapter 2 showed that $A$. millepora can rapidly acquire thermal tolerance, resisting bleaching. Principal findings for Chapter 2 also include that there was no shift or switch in the dominant type of Symbiodinium in hospite. Further, acquired thermal tolerance was not associated with a change in coral-associated prokaryotes, though the signature of a heat-related shift in both thermal tolerant and non-preconditioned corals was observed. Taken together, this demonstrates that thermal tolerance can occur entirely through acclimatization, through the modulation of physiology of one or more of the members of the coral holobiont. 
The question addressed in Chapter Three follows up on the principal findings of Chapter Two; having revealed that thermal preconditioning and the imparted bleaching tolerance has a basis in acclimatization, the primary question driving the investigation was: What is the host transcriptomic state associated with coral thermal tolerance, in comparison to thermal sensitivity? The findings identified a host molecular response associated with coral thermal tolerance. Some patterns observed include that the differentially expressed genes of preconditioned and nonpreconditioned corals differ largely in magnitude of expression, rather than the identity of the differentially expressed genes. That is, generally, the preconditioned (heat-tolerant) host appears to display an attenuated transcriptomic response to stress, in comparison with changes marked by higher levels of expression in nonpreconditioned (heat-sensitive) corals. Further, the study of the transcriptome identified several key genes upregulated in thermal tolerant corals under heat challenge. These thermal tolerance genes include a mannose binding lectin, hemebinding protein, ferritin, transctiption factor $A P-1, N F-\kappa B$ inhibitor, calumenin, and a tyrosine kinase receptor.

Chapter Four investigated regions upstream of three host thermal tolerance

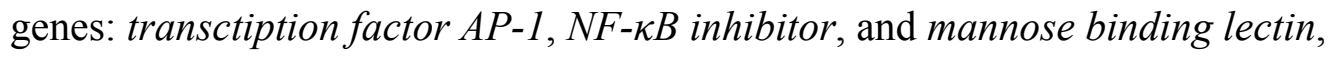
exploring both methylation state and DNA polymorphisms. One compelling yet uninvestigated hole in the literature is just how corals maintain a long-term memory of prior stress events. To examine this, in Chapter Four, the primary question was whether $\mathrm{CpG}$ islands upstream of three genes associated with thermal tolerance exhibited differences in methylation from A. millepora samples collected from a 
region of historically high heat stress in comparison to samples from a site with lower long-term average sea surface temperatures. The study did not identify any methylation whatsoever in the targeted survey, but shed light on polymorphic DNA sequences in the promoters of all genes surveyed. Two of the genes, inhibitor of $N F \kappa B$ and mannose-binding lectin, possessed polymorphisms which differ significantly in frequency between the historically warmer and cooler regions. Though our study cannot differentiate whether the differences between populations are adaptive or simply the effect of drift and isolation, the presence of underlying genetic diversity in a putative gene control region is of distinct interest for reasons of adaptive potential.

Overally, my dissertation work has shown that, even sans a shift in symbiotic partners, the coral host can exhibit a phenotypically plastic, acclimative molecular response to thermal stress in relation to recent stress events. Further, we have identified putative promoter-like elements upstream of three thermal tolerance genes. Taken together, this novel body of research provides direct evidence of coral acclimization and potential for adaption, providing critical insights in this time of global change.

\subsection{Future investigations}

This dissertation lays the groundwork for several future lines of research. Future work should be focused around three important aims:

1) Metatranscriptomics of long-term coral acclimization

2) Identifying the epigenetic basis of coral acclimatization

3) Adaptation of corals to warmer climate 


\section{4) Characterization of promoter polymorphisms}

In my dissertation, evidence for rapid host-based acclimatization has been shown. However, further work should undertake the experimental determination of tolerance longevity. Future studies should make use of modern metatranscriptomics, to capture not just the host transcriptome, but also the gene expression patterns of the resident Symbiodinium and potentially prokaryotic consortia, as transcriptomics of acclimatization of these micrbial symbiotic partners remains unknown. Such studies will identify how long tolerance from acclimation persists, as well as the contributions of the entire holobiont to the heat-tolerant phenotype.

Despite previous literature suggesting an acquired thermal tolerance as well as support for genotype-independent acclimatization in Chapter Two, the epigenetic basis of acquired thermal tolerance of corals remains to be identified. Full-genome coverage methylomics investigations of preconditioned corals exhibiting acquired thermal tolerance could be employed to compare methylation patterns with thermally sensitive corals. Further, patterns of methylation between the products of manipulative experiments and natural pools of sensitive and tolerant corals would make for potentially enlightening comparisons. Methylation should not be considered the end of the road in coral epigenetic studies; other mechanisms of epigenetic marking should be investigated as well, including histone variants and modifications.

Despite much conjecture, there has been little effort to determine whether the coral host is, in fact, undergoing genetic adaptation to warming seas. The technology now exists to undertake this initiative with reasonable economy. For instance, genotyping $A$. millepora across its latitudinal range using restriction site associated 
DNA sequencing (RADseq) and mapping reads to the genome would allow for the identification of loci under selection.

Additionally, the identification of polymorphisms in putative promoters of inhibitor of $N F \kappa B$ and mannose binding lectin with significantly different frequencies between the historically warmer northern region of the Great Barrier Reef and cooler southern region deems further investigation. Firstly, it needs to be determined whether the apparent structure in the distribution of these polymorphisms in the candidate control regions of these thermal tolerance genes is the result of selection, or due to drift and a simple artifact of the populations of origin. Additionally, functional investigation of the promoter's interaction with as-yet unknown transcription factors will be necessary to determine the effects of the detected mutations.

Ultimately, we are critically lacking in our understanding of the coral stress response and mechanisms of acquired thermal tolerance and the adaptive potential of the holobiont. More complete information is imperative for the forecast and management of coral reefs in coming decades. 


\section{VITA}

\section{ANTHONY JOHN BELLANTUONO}

August 25, 1983

2006

$2007-2008$

2008-2012

2012-2013
Born, Bristol, Connecticut

B.S., Marine Biology University of New England Biddeford, Maine

Research Assistant

Supervisor: Daniel Martinez

Pomona College

Claremont, California

Doctoral Candidate

University of Louisiana Lafayette

Lafayette, Louisiana

Board of Regents Fellow

University of Louisiana Lafayette

Lafayette, Louisiana

Doctoral Candidate

Florida International University

Miami, Florida

Teaching Assistant

Florida International University

Miami, Florida

\section{PAPERS AND PUBLICATIONS}

Bellantuono AJ, Hoegh-Guldberg O, Rodriguez-Lanetty M. 2012. Resistance to thermal stress in corals without changes in symbiont composition. Proc R Soc Lond, Ser B: Biol Sci 279: 1100-1107.

Bellantuono AJ, Granados-Cifuentes C, Miller DJ, Hoegh-Guldberg O, RodriguezLanetty M .2012. Coral Thermal Tolerance: Tuning Gene Expression to Resist Thermal Stress. PLoS ONE 7(11): e50685. doi:10.1371/journal.pone.0050685.

Granados-Cifuentes C, Bellantuono AJ, Ridgway T, Hoegh-Guldberg O, RodriguezLanetty M. 2013. High natural gene expression variation in the reef-building coral 
Acropora millepora: Potential for acclimative and adaptive plasticity. BMC Genomics 2013, 14:228 doi:10.1186/1471-2164-14-228.

Rodriguez-Lanetty M, Granados-Cifuentes C, Barberan A, Bellantuono AJ, Bastidas C. 2013. Ecological inferences from a deep screening of the complex bacterial consortia associated with the coral, Porites astreoides." Molecular Ecology: published online: 19 Jul 2013. DOI: 10.1111/mec.12392.

Rodriguez-Lanetty, M. Granados-Cifuentes, C., Bellantuono, A., Bastidas, C. 2012. Beneficial Bacteria Meeting. Toward understanding the role of bacterial consortia in coral's health: Ecological inferences from genomic-based community analysis. $4^{\text {th }}$ ASM Conference on Beneficial Microbes. San Antonio, Texas, USA. October 22-26, 2012.

Bellantuono A., Rodriguez-Lanetty, M. 2012. - Symbiotic Coral thermal tolerance: tuning gene expression to resist thermal stress. $7^{\text {th }}$ International Symbiosis Society Congress. Kraków, Poland. July 22-28, 2012.

Bellantuono, A., Granados-Cifuentes, C., Hoegh-Guldberg, O., Miller D., RodriguezLanetty, M. 2012. Molecular response associated with thermal tolerance in the reefbuilding coral Acropora millepora. International Coral Reef Symposium. Cairns, Australia. July 9-13, 2012.

Bellantuono, A., Rodriguez-Lanetty, M. 2011. Potential Mechanisms of Coral Acclimatization to Heat Stress. University of Louisiana Department of Biology Seminar Series. Lafayette, LA, USA. Sep. 2011.

Bellantuono, A., Rodriguez-Lanetty, M. 2011. Short-term thermal preconditioning in Acropora millepora: bleaching resistance without shifts in dinoflagellate or prokaryote symbiont composition. Benthic Ecology Meeting. Mobile, Alabama, USA. Mar. 2011.

Bellantuono, A., Rodriguez-Lanetty, M. 2010. Acclimatization of the tropical reef coral Acropora millepora to hyperthermal stress. University of Louisiana Department of Biology Seminar Series. Lafayette, LA USA. Apr. 2010.

Bellantuono, A., Rodriguez-Lanetty, M. 2009. Acclimatization of tropical reef corals to global climate change. University of Louisiana Department of Biology Seminar Series. Lafayette, LA, USA. Apr. 2010.

Bellantuono, A., R.A. Wahle, K.A. Hovel. 2006. Shelter fidelity of the juvenile American lobster, Homarus americanus, in two regions. Benthic Ecology Meeting. Quebec City, Quebec, Canada. Mar. 2006. 